\title{
Rapid Estimate of Solid Volume in Large Tuff Cores Using a Gas Pycnometer
}

\author{
RECEIVED \\ OCT 151996 \\ OSTI
}

Prepared by

A. M. Geddis, A. G. -Guzman, R. L. Bassett

Edited by

C. Thies

The University of Arizona

Prepared for

U.S. Nuclear Regulatory Commission 


\section{AVAILABILITY NOTICE}

Availability of Reference Materials Cited in NRC Publications

Most documents cited in NRC publications will be available from one of the following sources:

1. The NRC Public Document Room, 2120 L Street, NW., Lower Level, Washington, DC 20555-0001

2. The Superintendent of Documents, U.S. Government Printing Office, P. O. Box 37082 , Washington, DC 20402-9328

3. The National Technical Information Service, Springfield, VA 22161-0002

Although the listing that follows represents the majority of documents cited in NRC publications, it is not intended to be exhaustive.

Referenced documents available for inspection and copying for a fee from the NRC Public Document Room include NRC correspondence and internal NRC memoranda; NRC bulletins, circulars, information notices, inspection and investigation notices; licensee event reports; vendor reports and correspondence; Commission papers; and applicant and licensee documents and correspondence.

The following documents in the NUREG series are available for purchase from the Government Printing Office: formal NRC staff and contractor reports, NRC-sponsored conference proceedings, international agreement reports, grantee reports, and NRC booklets and brochures. Also available are regulatory guides, NRC regulations in the Code of Federal Regulations, and Nuclear Regulatory Commission Issuances.

Documents avallable from the National Technical Information Service include NUREG-series reports and technical reports prepared by other Federal agencies and reports prepared by the Atomic Energy Commission, forerunner agency to the Nuclear Regulatory Commission.

Documents available from public and special technical libraries include all open literature items, such as books. journal articles, and transactions. Federal Register notices. Federal and State legislation, and congressional reports can usually be obtained from these libraries.

Documents such as theses, dissertations, foreign reports and translations, and non-NRC conference proceedings are available for purchase from the organization sponsoring the publication cited.

Single coples of NRC draft reports are available free. to the extent of supply. upon written request to the Office of Administration, Distribution and Mail Services Section, U.S. Nuclear Regulatory Commission, Washington, DC 20555-0001.

Coples of industry codes and standards used in a substantive manner in the NRC regulatory process are maintained at the NRC Library. Two White Flint North, 11545 Rockville Pike. Rockville. MD 20852-2738, for use by the public. Codes and standards are usually copyrighted and may be purchased from the originating organizatlon or, if they are American National Standards. from the American National Standards Institute, 1430 Broadway, New York, NY 10018-3308.

\section{DISCLAIMER NOTICE}

This report was prepared as an account of work sponsored by an agency of the United States Government. Neither the United States Govemment norany agency thereof, nor any of their employees, makes any warranty, expressed or implied, or assumes any legal liability or responsibility for any third party's use, or the results of such use, of any information, apparatus, product, or process disclosed in this report, or represents that its use by such third party would not infringe privately owned rights. 


\section{Rapid Estimate of Solid Volume in Large Tuff Cores Using a Gas Pycnometer}

Manuscript Completed: June 1996

Date Published: September 1996

\section{Prepared by}

A. M. Geddis, A. G. -Guzman, R. L. Bassett

\section{Edited by}

C. Thies

Department of Hydrology and Water Resources

The University of Arizona

Tucson, AZ 85721

T. Nicholson, NRC Project Manager

Prepared for

Division of Regulatory Applications

Office of Nuclear Regulatory Research

U.S. Nuclear Regulatory Commission

Washington, DC 20555-0001

NRC Job Code $\mathbf{L 1 2 8 2}$ 


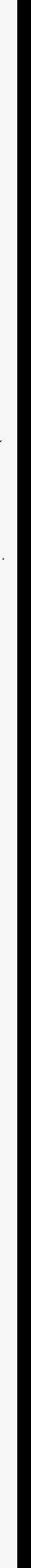




\section{DISCLAIMER}

This report was prepared as an account of work sponsored by an agency of the United States Government. Neither the United States Government nor any agency thereof, nor any of their employees, makes any warranty, express or implied, or assumes any legal liability or responsibility for the accuracy, completeness, or usefulness of any information, apparatus, product, or process disclosed, or represents that its use would not infringe privately owned rights. Reference herein to any specific commercial product, process, or service by trade name, trademark, manufacturer, or otherwise does not necessarily constitute or imply its endorsement, recommendation, or favoring by the United States Government or any agency thereof. The views and opinions of authors expressed herein do not necessarily state or reflect those of the United States Government or any agency thereof. 


\section{DISCLAIMER}

Portions of this document may be illegible in electronic image products. Images are produced from the best available original document. 


\begin{abstract}
A thermally insulated, rigid-volume gas pycnometer system has been developed. The pycnometer chambers have been machined from solid PVC cylinders. Two chambers confine dry high-purity helium at different pressures. A thick-walled design ensures minimal heat exchange with the surrounding environment and a constant volume system, while expansion takes place between the chambers. The internal energy of the gas is assumed constant over the expansion. The ideal gas law is used to estimate the volume of solid material sealed in one of the chambers. Temperature is monitored continuously and incorporated into the calculation of solid volume. Temperature variation between measurements is less than $0.1^{\circ} \mathrm{C}$. The data are used to compute grain density for oven-dried Apache Leap tuff core samples. The measured volume of solid and the sample bulk volume are used to estimate porosity and bulk density. Intrinsic permeability was estimated from the porosity and measured pore surface area and is compared to in-situ measurements by the air permeability method. The gas pycnometer accommodates large core samples $\left(0.25 \mathrm{~m}\right.$ length $\times 0.11 \mathrm{~m}$ diameter) and can measure solid volume greater than $220 \mathrm{~cm}^{3}$ with less than $1 \%$ error.
\end{abstract}





\section{TABLE OF CONTENTS}

Section

Page

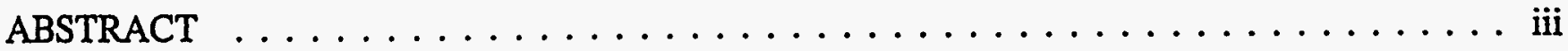

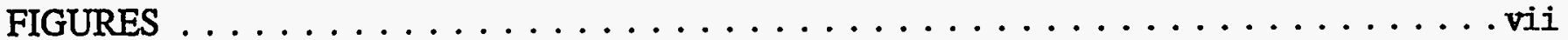

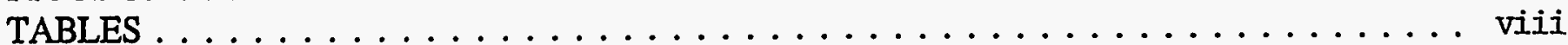

ACKNOWLEDGEMENTS $\ldots \ldots \ldots \ldots \ldots \ldots \ldots \ldots \ldots \ldots \ldots$

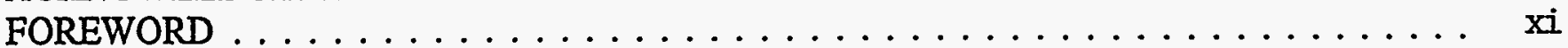

1. INTRODUCTION. ............................ $1-1$

1.1 Solid Volume in Porous Material. . . . . . . . . . . . . . . . . 1-1

1.2 Origin of Core Sample Groups. . . . . . . . . . . . . . . . . . 1-1

1.3 Parameters Estimated In This Report. . . . . . . . . . . . . . . . . . . . . . . . . . . . .

1.4 Previous Work. ............................ . . . . . . .

1.4.1 Literature Review. . . . . . . . . . . . . . . . . . . . . . 1-4

1.4.2 Commercial Pycnometers. . . . . . . . . . . . . . 1-8

2. EXPERIMENTAL INSTRUMENTATION. . . . . . . . . . . . . . . . . . . . 2-1

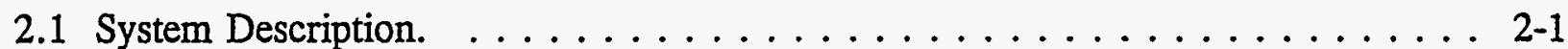

2.2 Material Properties and Hardware Specifications. . . . . . . . . . . . . . . 2-1

2.3 Pressure Transducer Calibration. . . . . . . . . . . . . . . . . . . . . . . . . . . . . . . . . . . .

2.4 System Leak Testing. . . . . . . . . . . . . . . . . . . 2-4

3. GAS PYCNOMETER THEORY AND CALIBRATION. . . . . . . . . . . . . . . . . . . 3-1

3.1 Gas Pycnometer Theory. . . . . . . . . . . . . . . . . . . 3-1

3.2 Gas Pycnometer Calibration. . . . . . . . . . . . . . . . 3-3

3.3 Bulk Volume Estimator Calibration. . . . . . . . . . . . . . . . . . 3-8

4. EXPERIMENTAL METHODS. . . . . . . . . . . . . . . . . . . . . . 4-1

4.1 Core Retrieval Method. . . . . . . . . . . . . . . . . . . . 4-1

4.2 Core Handling and Gravimetric Water Content. . . . . . . . . . . . . . . . . 4-2

4.2 .1 Bulk Volume Estimation. . . . . . . . . . . . . . . . . 4-4

4.3 Gas Pycnometer Testing Methodology. . . . . . . . . . . . . . . . . . 4-5

5. GRAPHIC RESULTS AND DISCUSSION. . . . . . . . . . . . . . . . . . 5-1

5.1 Graphic Results. .......................... $5-1$

5.1 .1 Intrinsic Permeability. $\ldots \ldots \ldots \ldots \ldots \ldots \ldots \ldots \ldots \ldots \ldots \ldots \ldots \ldots \ldots$ 
5.2 Discussion. . . . . . . . . . . .

5.2.1 Re-Tested Core Samples. . . . . . . . . . . . . . . . 5-10

6. CONCLUSIONS. . . . . . . . . . . . .

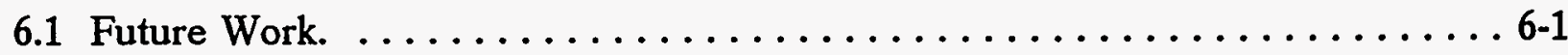

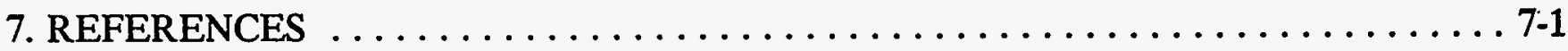

APPENDIX A: GENERAL INFORMATION $\ldots \ldots \ldots \ldots \ldots \ldots \ldots \ldots \ldots \ldots$ A-1

APPENDIX B: DATA TABLES FOR ALRS TUFF $\ldots \ldots \ldots \ldots \ldots \ldots \ldots \ldots$ B-1 


\section{FIGURES}

Figure

Page

Figure 1.1 Location map for the Apache Leap Research Site. . . . . . . . . . . . 1-2

Figure 1.2 Calibration curve of Page $(1947$, Figure 2). . . . . . . . . . . . . . . 1-6

Figure 1.3 Calibration curve of Russell $(1949$, Figure 2$) \ldots \ldots \ldots \ldots \ldots \ldots \ldots \ldots$

Figure 2.1 Schematic diagram of the gas pycnometer system $\ldots \ldots \ldots \ldots \ldots \ldots \ldots .2-2$

Figure 2.2 Druck PDCR 930 absolute pressure transducer calibration. . . . . . . . . 2-5

Figure 2.3 Leak testing of gas pycnometer system. $\ldots \ldots \ldots \ldots \ldots \ldots \ldots \ldots \ldots \ldots \ldots$

Figure 3.1 Example sensor response over 12 cycles. . . . . . . . . . . . . . .

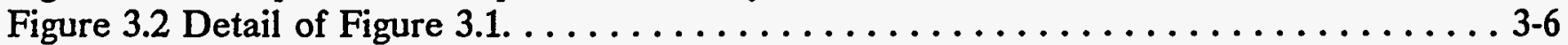

Figure 3.3 Gas pycnometer calibration curve. ..................... $3-7$

Figure 3.4 Gas pycnometer calibration error analysis. . . . . . . . . . . . . . . 3-9

Figure 3.5 Bulk volume estimator calibration curve. $\ldots \ldots \ldots \ldots \ldots \ldots \ldots \ldots \ldots$ 3-10

Figure 3.6 Bulk volume estimator calibration error analysis. .............. 3-11

Figure 4.1 Gravimetric water content $(w)$ with depth in the DSB. ............. 4 4.3

Figure 4.2 Ratio $\left(V_{2} / V_{1}\right)$ estimate as a function of cycle number. $. \ldots \ldots \ldots \ldots \ldots \ldots 4-6$

Figure 5.1 Grain density with depth in the DSB. . . . . . . . . . . . . .

Figure 5.2 Porosity and bulk density with depth in the DSB. . . . . . . . . . . .

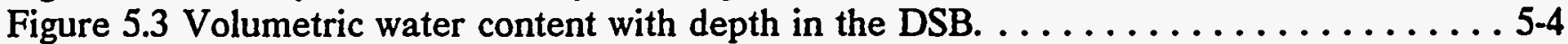

Figure 5.4 Grain density with depth in the $\mathrm{Y} 2$ borehole. $\ldots \ldots \ldots \ldots \ldots \ldots \ldots \ldots$

Figure 5.5 Porosity and bulk density with depth in the $\mathrm{Y} 2$ borehole. $\ldots \ldots \ldots \ldots \ldots \ldots 5$

Figure 5.6 Intrinsic permeability with depth in $\mathrm{Y} 2 . \ldots \ldots \ldots \ldots \ldots \ldots \ldots . . \ldots \ldots$ 


\section{TABLES}

Table

Page

Table 2.1: PVC Physical Properties and Electrical Hardware

Performance Specifications for the Gas Pycnometer System

Table 5.1: Pore Surface Area for Y2 Core . . . . . . . . . . . . . . . . . . 5-8

Table A.1: Datalogger Operating Program. . . . . . . . . . . . . . . . . . . A A

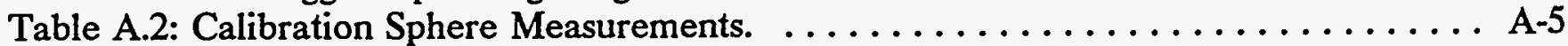

Table B.1: Gravimetric Water Content Data . . . . . . . . . . . . . . . . . . B B

Table B.2: Key to Condition Codes . . . . . . . . . . . . . . . . . . . . B-4

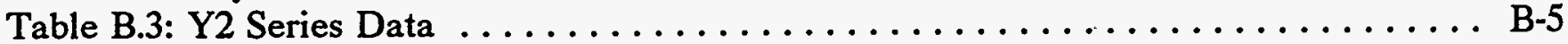

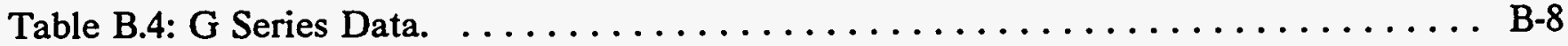

Table B.5: P Series Data. . . . . . . . . . . . . . . . . . . . . . . . . . . . . . B-12

Table B.6: Re-Tested Core Data. . . . . . . . . . . . . . . . . . . . . . . B-15 


\section{ACKNOWLEDGMENTS}

This research was funded by the US Nuclear Regulatory Commission (USNRC) under contract number NRC 04-90-051 (FIN L1282).

Dr. Randy Bassett, Dept. of Hydrology and Water Resources, The University of Arizona, provided sincere support on all fronts. He is the best manager of people I've met and a reliable source of positive input. This report is much more readable as a result of his editorial suggestions. Amado G.-Guzman made valuable suggestions regarding instrument design, theory, and error analysis. Thomas E. Detty (now at REECo) did the initial literature search and was a great friend here at The University of Arizona. Charles Lohrstorfer (also now at REECo) provided design implementation expertise "par excellance" and suffered through watching me solder the electrical pass-throughs, even though he could have been packing for Mercury, Nevada. Lorenzo Lujan of The University of Arizona Chemical Engineering Machine Shop turned the large solid rods of PVC on his lathe to exacting tolerances and allowed me to bug him about it. Also important are the friends we keep, and I think I'll keep Dave Jewett, Edwin Welles, and Betsy Woodhouse as friends.

Gregg Davidson helped plan and implement the drilling project and showed eye-opening concern for my soul. Mike Henrich, Dr. Mark Smiley, and Charles also helped make the drilling project possible. It was great fun working with them. Ernie Hardin sampled the P-series core and made innovative suggestions about core testing in general. It is a huge benefit to have such a diverse group of researchers and facilities to provide support for these little science projects. Dr. Art Warrick made insightful and valuable suggestions about the manuscript. Thanks also to Dr. Mike Sully, for involving me in the NRC project and for teaching the class (HWR 507) in which I had the greatest increase in knowledge. I am also indebted to Boyd Pendelton and Christian Williamson for many attentive hours of cycling the pycnometer through its stages; the production model will have automated valves, I promise.

Finally, to my new wife, Susan M. Harris. I thank her for her emotional support, her kind words of encouragement, and her love. She has taught me that all we need to know is ourselves; everything after that is a cakewalk.

These acknowledgments pertain to the senior author's Master's thesis work at The University of Arizona, Dept. of Hydrology and Water Resources. 



\section{FOREWORD}

This technical report was prepared by The University of Arizona under their research projects with the Waste Management Branch in the Office of Nuclear Regulatory Research (FINs L1282 and L1283). The report outlines research findings for completed laboratory testing and evaluations of site characterization methodologies, techniques, and instrumentation for unsaturated flow and transport in heterogeneous, fractured rock. The work reported focuses on a laboratory method for determining grain density by measuring the solid volume of tuff and is particularly well-suited for large core samples. Samples were collected at the Apache Leap Tuff Site (ALTS) in central Arizona that represents a hydrologic field analogue to an unsaturated zone high-level radioactive waste (HLW) repository site. Data sets from the ALTS field studies are being used to evaluate various conceptual models of flow and transport through unsaturated fractured media. This document presents information which assists in identifying key technical uncertainties associated with confirmation of DOE's site characterization and performance assessment studies for an unsaturated zone HLW repository site.

NUREG/CR-6457 is not a substitute for NRC regulations, and compliance is not required. The approaches and/or methods described in this NUREG/CR are provided for information only. Publication of this report does not ncessarily constitute NRC approval or agreement with the information contained herein. 


\section{INTRODUCTION}

\subsection{SOLID VOLUME IN POROUS MATERIAL}

The solid volume of a regularly shaped solid object (cube, sphere, right circular cylinder, etc.) can be calculated from direct measurements of the object. The solid volume is equivalent to the bulk volume for most regular solid shapes. If the mass of this object is measured, its bulk density is calculated as mass per volume. The solid volume of an irregularly shaped solid object (broken core sample, coffee cup, etc.) is more difficult to measure. An indirect measurement is needed to estimate the solid volume. For example: a known amount of liquid can be displaced by immersing the irregular object. The solid volume is not necessarily equivalent to the bulk volume in this case. The bulk volume is loosely defined as the volume enclosed by a surface covering the irregular shape. In the case of a coffee cup, the bulk volume would be much greater than the solid volume. The irregular object's bulk density can also be calculated from the ratio of its mass to bulk volume. Various terms such as material, skeletal, particle, or grain density are used to describe the ratio of mass to solid volume, all of which represent the density of the solid volume fraction of the bulk volume of an irregularly shaped object.

Porous objects can be considered as highly irregular solid shapes. For a liquid displacement method to accurately estimate a porous sample's solid volume, the fluid would have to permeate all of the pore space. If the material has a low permeability, it may take a long time for the fluid to enter all of the accessible pores. The fluid may never encounter some pores because of trapped air, pore throat restrictions, or completely sealed-off voids, all of which would be incorrectly interpreted as part of the solid volume. Further, the liquid may react with surfaces or hygroscopic minerals, causing them to increase their volume by swelling. A gas pycnometer is a device that has been used for many years to measure the solid volume of solid and porous materials. Sample materials have ranged from aerogel foam to diamonds. The pycnometry method requires that the object be placed in a gas-tight vessel, so that imposed gas pressure changes can be measured precisely. In the method presented here, the pressure and temperature of dry high-purity helium is measured before and after the imposed pressure change. Helium is able to enter much smaller pores than a permeating fluid such as water. The ideal gas law is used to compare the measured pressure changes against known volumes. This comparison is used to predict the solid volume of porous Apache Leap tuff core samples.

\subsection{ORIGIN OF CORE SAMPLE GROUPS}

Apache Leap is an elevated topographic feature protruding from a dacite tuff sheet located in central Arizona (Rasmussen et al., 1990). Its greatest relief is $<2 \mathrm{~km}$ from the Apache Leap Research Site (ALRS). The compacted pyroclastic fragments that formed this tuff give the rock an appearance and physical properties similar to fine-grained concrete. The area around the research station, including Magma Copper Company's Shaft \#9 facility, is depicted in Figure 1.1. This field research site has been funded since 1986 by the Nuclear Regulatory Commission to investigate physical properties of tuff and is operated by The University of Arizona (UA). The Apache Leap tuff has physical characteristics which resemble tuff found in the region of Yucca Mountain, Nevada, the current candidate site for high-level radinactive waste disposal. Physical parameters for 147 core samples from the ALRS have been estimated for this report. Three series of core samples are defined: the $P, G$, and $Y 2$ series. The $P$ and $G$ series represent 113 core samples retrieved from the Deep Slant Borehole Site (DSB). The third series, Y2, represents 34 core samples from the Y2 borehole that have been in storage for several years. Both of these locations are indicated in Figure 1.1, with the DSBS and Y2 holes drawn approximately to scale. The Never Sweat Tunnel (NST) monitoring station, the Experimental Watershed, the site's Weather Station (WS), and the High and Low Flow Flume (HLFF) are also indicated. 


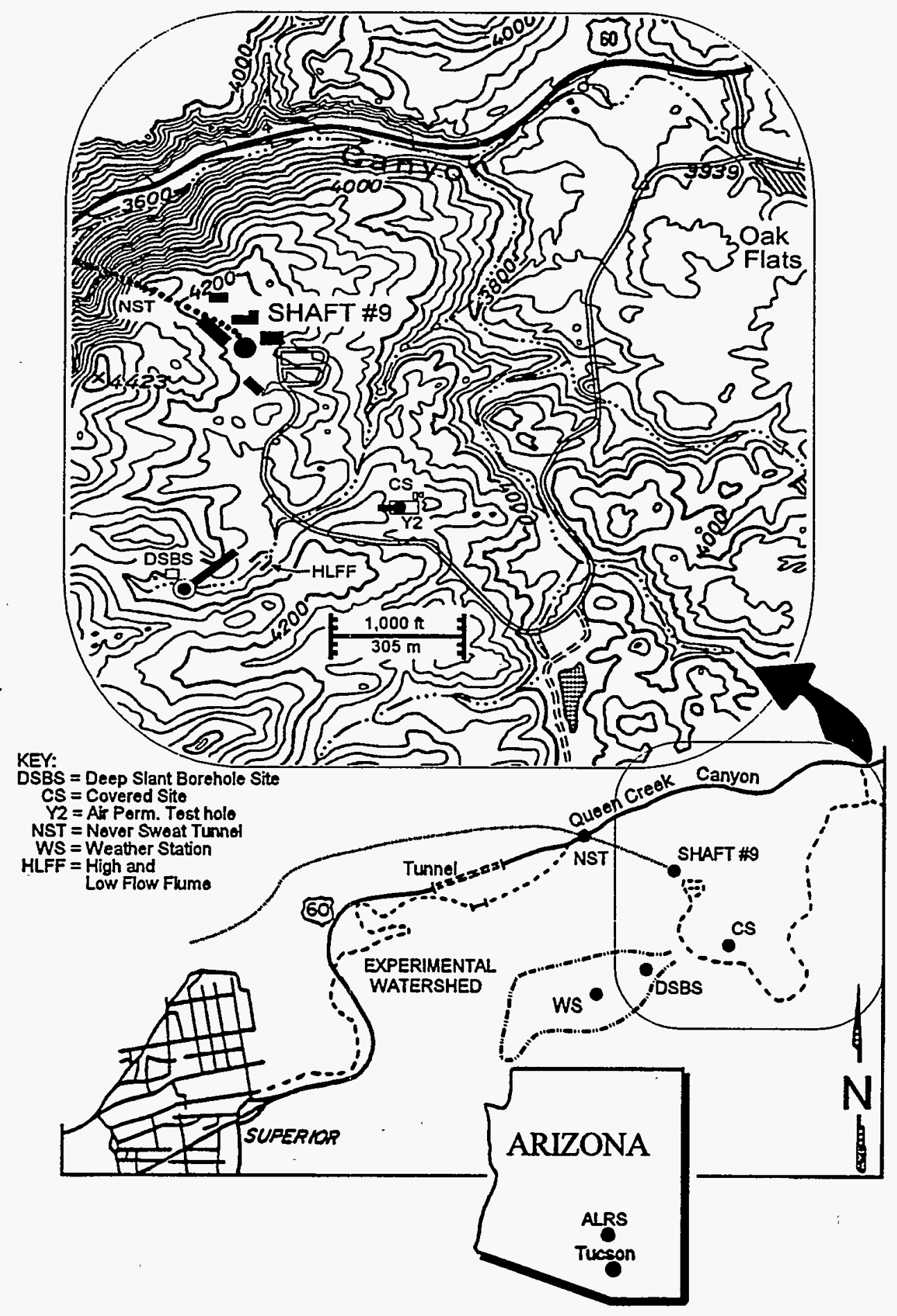

Figure 1.1. Location map for the Apache Leap Research Site. 


\subsection{PARAMETERS ESTIMATED IN THIS REPORT}

The ratio of mass to solid volume for oven dry core samples is reported as grain density $\left(p_{g}\right)$. The determination of grain density variation in tuff is particularly useful for defining major variations in lithology. Changes in lithology can indicate differences in chemical composition, mineral content, or hydraulic properties, all of which may affect physical flow characteristics of water. The bulk volume of core samples was estimated either by measuring the displaced water volume upon immersion of water-saturated samples or by direct measurement of the dimensions of samples that approximate a right circular cylinder. The difference between bulk volume and solid volume of a core sample is its porosity $(\phi)$. In this method, the effective, or connected, porosity is determined. Porosity variation in tuff yields important information about the material's ability to conduct liquid and gas. The bulk volume measurement also yields an estimate for bulk density $\left(\rho_{b}\right)$ when divided into oven dry mass. An estimate of bulk density aids in describing the distribution of various chemical species in many bulk transport schemes. These three parameters are related mathematically through Equation (1):

$$
\rho_{b}=\rho_{g}(1-\phi)
$$

The intrinsic permeability $(\mathrm{k})$ of a porous material may be closely related to its porosity. Permeability of the core samples is estimated using an empirical relationship by Kozeny-Carman (de Marsily, 1986). The relationship uses powers of porosity and pore surface area in the calculation of permeability and was established using nonindurated sediments. Volcanic rock contains vesicular porosity not found in most granular material, and significant error may result when applying the relationship to tuff. Pore surface area for $\mathrm{Y} 2$ core has been measured in a previous investigation (Rasmussen et al., 1990). The Kozeny-Carman permeability is compared to in-situ measurements made in Y2 by the air permeability method (Guzman, 1995).

\subsection{PREVIOUS WORK}

The following review represents references available in the technical literature; most are from soil science/agricultural applications or engineering journals. There has not been a great deal of published research specifically on this method; rather, it is used as a tool in part of a larger work.

Many gas pycnometers reported in the literature lose accuracy from improper selection of construction materials; either the material is thermally too conductive or too flexible. Instrument error can be minimized if the pycnometer system is operated under isothermal conditions and if low pressures are used. Flexible materials tend to yield error due to deformation of the system, which is assumed to have a constant volume. Rigid materials are required to accurately employ gas pycnometer technology.

Error resulting from the impact of heat flow on pressure measurement in the system tends to be a random phenomenon. It is associated with operation of the instrument in a regime not covered by the calibration. This situation could arise as the result of a misplaced hand, coffee cup, or other heat source. Internal energy of the gas will change as heat is conducted in and out of the system. This will alter the pressure reading in poorly insulated devices. A gas pycnometer made of aluminum has shown a pressure response to the heat of a hand (Detty, personal communication, 1991). This behavior is similar to the response of a constant volume gas thermometer. Thermal equilibrium between initial and final states of the system (at each measurement point) is required to cancel temperature from the ideal gas law. Most investigators have not measured temperature or have assumed it is constant between measurement points. Several soil science-based applications in the literature attempt to develop portable gas pycnometers. These instruments could be especially susceptible to error as temperature fluctuations are greater in the field than in the 
laboratory. The response of these devices must differ in and out of direct sunlight, for example. These sources of error affect the precision of gas pycnometer measurements.

The choice of a uniform bulk.volume sample size also helps reduce error. This results when the pycnometer is calibrated to respond most accurately over a narrow range of solid volume, as is found in uniform bulk volume samples of similar media. A single point in the middle of this range is checked daily or prior to use, a technique employed by many investigators. Unfortunately, the uniform bulk volume chosen is usually small, on the order of $100 \mathrm{~cm}^{3}$ or less. Uniformly porous material would yield the same porosity regardless of bulk volume, but most geologic media are not uniformly porous. The small sample chambers may require precise coring of tuff material, for example. Brittle phenocrysts might be undersampled in an attempt to cut small right circular cylinders. Information on larger scale properties could be lost. In addition, several of the investigators use barometric pressure as a reference pressure. They then assume it is constant from test to test. The resulting error is considered negligible and is typically not corrected for. Some commercially available pycnometers employ chambers that are sized to bracket-selected solid volume ranges. The error associated with each range is reported, and the devices are accurate and precise. The largest sample chamber among the most widely used devices is only $150 \mathrm{~cm}^{3}$. Commercial gas pycnometers cost $\$ 7,000$ or more. The pycnometer designed for this study has a sample chamber capacity of $2,300 \mathrm{~cm}^{3}$.

\subsubsection{Literature Review}

Pycnometry is often thought of as the liquid method described by Blake and Hartage (ASTM, 1986). They employed a small glass flask $(25 \mathrm{~mL}-100 \mathrm{~mL})$ of precisely known volume which is fitted with a ground-glass stopper. A known weight of sieved soil is added, and the flask is filled with water (or some other fluid of known density). The difference between the expected weight of the flask if it contained only water and the weight of the flask containing both water and soil is determined. The soil solid volume is calculated using the density of water. This method is restricted to measuring a small volume of loose material. As mentioned earlier, the ability of water to enter very small pores is restricted by its surface tension. Füthermore, entrapped air may prevent complete filling of all pores. The volume of solid would be overestimated in a material such as tuff, resulting in a low estimate of grain density.

Torstensson and Eriksson (1936) described a laboratory method for determining porosity of the soil with a porosimeter. The porosimeter is actually an air pycnometer. Soil cylinders were used to sample a range of soil textures. A glass tube is inserted into the sample chamber and is connected to the pressure source with rubber vacuum tubing. Positive or negative air pressure can be imposed by moving a mercury manometer on a graduated slide. The use of glass can allow heat to move across system boundaries, and the rubber material might experience a change in volume as the pressure is altered. In fact, the two types of pressure (positive and negative) gave two different estimates of solid volume. This was attributed to the effect of the pressure on a flexible rubber packing used to hold a sample cylinder in the sample chamber. The porosity of oven-dried samples, as measured by this device, is compared to porosity calculated "in the usual way" by: (1) determining bulk density, and (2) determining grain density with the liquid pycnometer method. The two methods compare well (within $3 \%$ ) with the porosimeter method predicting a larger grain density than the liquid pycnometer method. The lower value for grain density measured by the liquid method is attributed to floating plant residues in the fluid. Another reason may be that the air in the porosimeter enters more of the pore space, correctly measuring less solid volume, causing the grain density to be calculated higher. They do not measure nor discuss the effect temperature may have on their method. 
Visser (1938) described a gas pycnometer for field use, following the example of Torstensson and Eriksson (1936). This intricate method uses water as the pressure monitoring fluid, and the test is performed with air at approximately twice atmospheric pressure. The volume of the empty sample chamber is estimated by measuring the movement of the water meniscus at two different pressures in a glass tube of known internal diameter. Solid blanks of known volume are used "to ensure proper operation of the instrument". They are attempting to measure the saturated, and then oven-dry volume of agricultural soil samples to determine the entrapped air volume. The values of porosity so obtained compare within $1 \%$ to the mass (volume) of water evaporated from saturated replicate samples. This is used as evidence for the absence of entrapped air during saturation of a diseased soil plot.

Stevens (1938) described a laboratory device for determining effective porosity by the gasexpansion method. In this method, air is drawn out of a small $(<25 \mathrm{~mL})$ sample chamber by moving a mercury reservoir vertically. Glass and rubber tubing are used in this design also. The author recognizes the need for an accurate bulk volume measurement to reduce error in the porosity estimate. Comparison with a mercury intrusion method is reported to agree within $\pm 0.3 \%$. The disadvantages of using mercury, which prevents further testing such as permeability, are mentioned. These references show that accurate estimates of porosity have been possible for more than 50 years.

Kummer and Cooper (1945) described a laboratory device that uses mercury as the pressure monitoring fluid and compressed air to generate a $160 \mathrm{kPa}$ operating pressure. Metal cylinders were used to hold the soil samples in the chamber, and copper tubing was used to conduct the gas into the sample chamber. A calibration step is included in which precisely weighed amounts of water are added to a known volume container. Daily adjustment for barometric pressure and temperature is said to be required, although temperature is not measured nor included in any of their analyses. The adjustment is described as a single point check of the calibration, followed by a change in the offset of the scale to compensate for any shift. Saturated soil samples are compared with the blotter tension method of Leamer and Shaw (1941) to determine non-capillary porosity. The authors reported that the porosity determined by the tension method needs to be increased by an amount equivalent to the lack of saturation (or entrapped air) in the saturated samples. The air pycnometer is again able to measure greater effective porosity by encountering more pores.

Page (1947) and Russell (1949) both presented pycnometers similar to those described previously and included calibration curves in their reports. Those calibration curves have been included in this report to demonstrate the type of behavior that occurs in some pycnometer applications. Figure 1.2 shows a calibration curve taken from Page (1947), and Figure 1.3 illustrates a calibration curve taken from Russell (1949). The calibration curves presented by both authors relate the percent of air-filled pores in a sample to the pressure indicated by their air pycnometer gage. The relationship between pressure change and volume change of a confined gas is linear. The curves are not linear as the ideal gas law would predict.

The portable pycnometer described by Page (1947) had metallic bellows that were soldered together to make a gage. This large reservoir of air may have been affected by heat sources in the environment surrounding the device, particularly in field applications if direct sunlight fell upon the device. Temperature variations were not considered significant by the author, and accuracy is reported as $\pm \mathbf{0 . 3 8 \%}$ of the free pore space. Comparison with the blotter method of Leamer and Shaw (1941) again shows that the pycnometer measures greater porosity, as complete saturation of soil samples is rarely achieved with water.

Russell's (1949) design was also a field pycnometer. Metallic bellows are used to change the volume of the system, and the resulting pressure change is measured with a mercury manometer. 


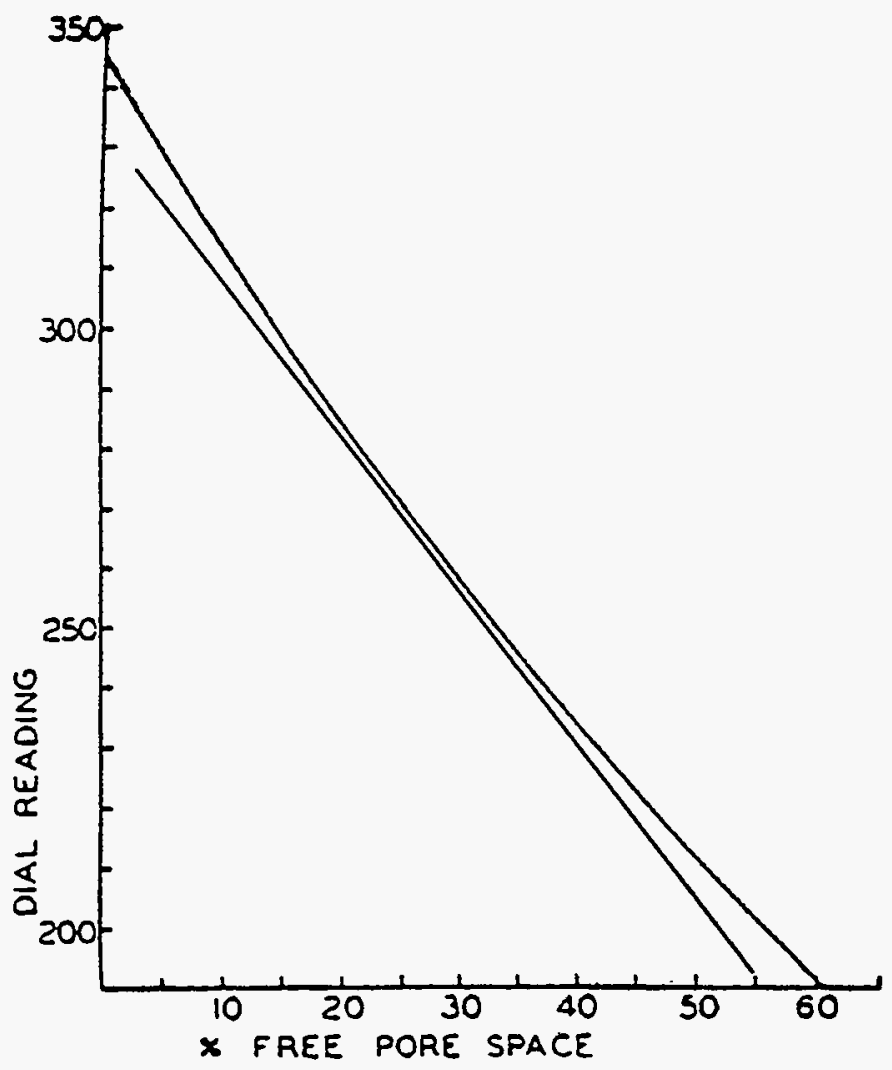

Figure 1.2. Calibration curve of Page (1947, Figure 2). The curve relates volume of pores to the pressure response of the instrument. The curve is not linear as the ideal gas law would predict (note line added for emphasis of this point) (used with permission).

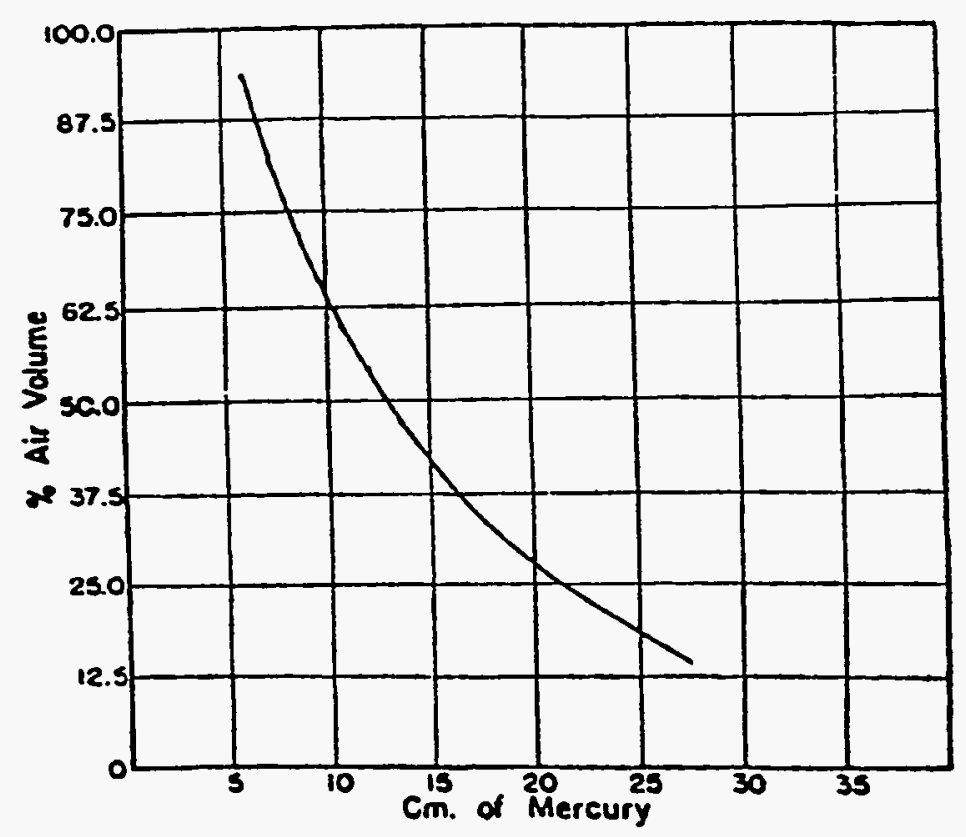

Figure 1.3. Calibration curve of Russell (1949, Figure 2). The curve is not linear as the ideal gas law would predict (used with permission). 
He mentioned that temperature is required to be constant between measurement points and noted that the sealed system will function as a gas-filled thermometer in the presence of significant temperature changes. He did not, however, include temperature in his analyses. Barometric pressure was used as a reference pressure in his tests and was assumed constant between samples. Both pycnometers described by Page (1947) and Russell (1949) were constructed with all metal components. Copper tubing was used to conduct gas from the pressure-generating device into the sample chamber and to the pressure gage.

Joyce (1961) applied pycnometer theory to the volume determination of surface active materials and plastic foams. This publication represented the introduction of the Beckman Air Comparison Pycnometer, which is discussed below (see Section 1.4.2, Commercial Pycnometers). The author provided an excellent review of the engineering limitations of air pycnometry, and deformation of the sample by increased pressure is discussed. This would rarely occur in geologic materials. Adsorption of air by materials such as activated carbons and clays is found to cause a drift in the readings, and helium is suggested as an inert alternative to air.

DeBacker (1967) presented a schematic diagram of a piston displacement instrument containing a pressure cell. It was used to evaluate the effect of trapped air on water content during sorptiondesorption cycles. A mercury manometer was used to measure pressure, but temperature was not measured. The need for isothermal conditions was indicated.

Hopmans and Dane (1986) imposed an isothermal environment in their gas pycnometer application. They attempted to determine the influence of entrapped air on the temperature coefficient of soil water pressure head. This more recent investigation employed electronic pressure transducers inside their constant temperature incubator. Temperature effects probably do not significantly impact their measurements. Temperature is cancelled out of the ideal gas law in their analyses and calculations.

Stonestrom and Rubin (1989) assumed isothermal conditions in their experiment and fabricated an air pycnometer from a syringe. The use of this instrument is part of a larger experiment to correlate change in trapped-air volume with change in water content using a pressure cell. The syringe is used to induce small pressure changes $(0.2 \mathrm{kPa}$ to $0.6 \mathrm{kPa})$ in the sample's accessible airfilled voids at a given water content. The syringe was hand-operated, and no mention was made of any possible heat transfer to the syringe body.

The above attempts at applying gas pycnometry to estimate void volume in porous material have provided the investigators with acceptable results. Instrument response was calibrated over a narrow range of expected porosities for a single bulk volume size, and consequently their methods worked quite well. When calibration was performed with known volumes of water, the authors did not discuss the impact of variable partial pressure of water vapor on the pressure measurement. In most cases, the pressure change was brought about by altering the volume of the system, which is a difficult mechanical process to control. In all cases, there is little discussion of environmental temperature effects.

The most thorough analysis published to date appears to be by Bielders et al. (1990). They measured the particle density of volcanic soils with a Beckman Air Comparison Pycnometer. They found that air pycnometry measurements gave larger values for particle density when compared to helium pycnometry. This was attributed to gas adsorption phenomena and found to be linearly related to the surface area of the soil samples as measured by ethylene glycol monoethyl ether. When air was used, the endpoint drifted to lower and lower pressure. The lower pressure implies a smaller solid volume, which in turn would cause the higher particle density value (for a given mass of sample). They tested silica gel desiccant and estimated density as large as $20 \mathrm{~g} / \mathrm{cm}^{3}$, which 
is approximately ten times larger than typical values. This is used to identify water vapor as the primary adsorbed gas.

\subsubsection{Commercial Pycnometers}

Commercial pycnometers are used for process and manufacturing control in a wide range of applications. There are several commercially available gas pycnometers. Micromeritics manufactures the MultiVolume Pycnometer 1305 and the AccuPyc 1330. Beckman Instruments provides the Model 930 Air Comparison Pycnometer mentioned above. Use of product or trade names in this report does not constitute endorsement by The University of Arizona nor by the Nuclear Regulatory Commission and is for identification purposes only. The specifications for each pycnometer are reported from recent product information circulars.

The Beckman Model 930 Air Comparison Pycnometer uses two chambers, each with its own piston. The pressure difference between the two chambers is measured with a differential pressure gage. The system is sealed, and both pistons are moved to keep a zero pressure difference between each chamber. The solid volume is determined from the position of the measuring piston, as read on a linearly calibrated scale. Two calibration spheres of different volume are provided. Sample bulk volume for the Model 930 is $50 \mathrm{~cm}^{3}$, with a volumetric accuracy of $<0.1 \mathrm{~cm}^{3}$. This corresponds to an accuracy of $0.2 \%$ for a full sample chamber. The accuracy decreases when smaller volume samples are tested. Air is used as the test gas, and an optional purge manifold is provided for use with other gases such as helium (Beckman Instruments, Inc., 1981).

The Micromeritics MultiVolume Pycnometer 1305 can test samples with a bulk volume range of 0.5 to $150 \mathrm{~cm}^{3}$, with an accuracy of $<0.6 \mathrm{~cm}^{3}$. This corresponds to an accuracy of $0.4 \%$ for a 150 $\mathrm{cm}^{3}$ sample volume, and this accuracy is maintained for smaller volume samples by reducing the sample chamber volume. Three sample chambers are provided: 0.5 to $5 \mathrm{~cm}^{3}, 5$ to $35 \mathrm{~cm}^{3}$, and 35 to $150 \mathrm{~cm}^{3}$. It is suggested that helium be used in the range of $230 \mathrm{kPa}$ to $260 \mathrm{kPa}$ absolute pressure (Micromeritics Instrument Corporation, 1993).

The AccuPyc 1330 gas pycnometer tests samples with a bulk volume range of 0.5 to $100 \mathrm{~cm}^{3}$. Sample chamber modules can be purchased specific to the bulk volume being tested. This device is automated and converges on a solid volume estimate after five successive measurements are within a user-specified tolerance. Accuracy is reported to be within $0.03 \%$ of the solid volume estimate, plus $0.03 \%$ of the nominal full-scale sample chamber volume. This translates to $0.06 \mathrm{~cm}^{3}$, or $0.06 \%$ for a $100 \mathrm{~cm}^{3}$ sample volume. Precision is also reported in the product information for the Model 1330. It is claimed to have "typical reproducibility within $\pm \mathbf{0 . 0 1 \%}$ of the nominal fullscale sample chamber volume...guaranteed to within $\pm 0.02 \%$ of the nominal full-scale volume on clean, dry, thermally equilibrated samples." Research-grade helium is recommended as the gas to be used for testing (Micromeritics Instrument Corporation, 1993). 


\section{EXPERIMENTAL INSTRUMENTATION}

\subsection{System Description}

A schematic diagram of the gas pycnometer system with cylinder dimensions and major components is given in Figure 2.1. The sample chamber $\left(\mathrm{V}_{2}\right)$ is approximately 1.5 times the volume of the reservoir chamber $\left(V_{1}\right)$ (i.e., $\left.1.5 V_{1}=V_{2}\right)$. The internal volume of each cylinder is approximately $1,800 \mathrm{~cm}^{3}$ and $2,700 \mathrm{~cm}^{3}\left(\mathrm{~V}_{1}\right.$ and $\left.\mathrm{V}_{2}\right)$, with the plugs inserted. This volume includes the connecting hardware associated with each chamber. The chambers were machined from solid cylinders of PVC using a lathe in the Chemical Engineering Machine Shop, (UA). The stock material was Geon 8761 PVC (Type I, Grade 1, normal impact, low shear cube compound for pipe extrusion). Precise machining is required only to provide gas tightness as the solid volume measurement is made relative to the ratio $V_{2} / V_{1}$ (this is discussed further in Chapter 3). The resulting chambers are extremely rigid as required for this application, and the cylinders are firmly secured adjacent to one another in a horizontal position. Core samples are placed into the sample chamber lengthwise. The plug of the reservoir chamber is secured in place with evenly torqued bolts and not opened during the period of calibration and core testing for this project.

A U-shaped clamp (not shown in Figure 2.1, see slots on base of sample chamber) is placed over the sample chamber cylinder, and a large acme-threaded screw is tightened to approximately 35 foot pounds against a metal plate (also not shown) affixed to the back of the plug. Operation of the gas pycnometer system for the purposes of calibration and core testing is discussed in Chapter 4.

\subsection{Material Properties and Hardware Specifications}

A list of material properties for the PVC resin and performance specifications for the pycnometer system's electrical components are presented in Table 2.1. Thermal conductivity of the PVC is reported as $\mathrm{K}_{\mathrm{T}}=1.2 \mathrm{BTU} \mathrm{hr}^{-1} \mathrm{in}^{-1}{ }^{\circ} \mathrm{F}^{-1} \mathrm{ft}^{-2}$ (International Plastics Selector, 1980). Typical units for thermal conductivity are BTU hr $\mathrm{in}^{-1} \circ \mathrm{F}^{-1}$ or W m $\mathrm{m}^{-1}{ }^{\circ} \mathrm{C}^{-1}$ (Halliday and Resnick, 1981). The value for $\mathrm{K}_{\mathrm{T}}$ is actually a heat flux per unit dimension, based on the geometry of a PVC tube (Personal Communication, R. Krolosinski, Plastics Engineer, B.F. Goodrich Company, 1993). The parameter $\mathrm{K}_{\mathrm{T}}$ describes the number of BTUs transferred across a tube wall per hour, per inch of tube wall thickness, per $^{\circ} \mathrm{F}$ temperature differential across the tube wall, per square foot of transfer area. The actual heat loss is found by replacing the unit wall thickness, unit transfer area, and unit temperature gradient, with the actual system conditions, over a given time period. For example, if the tube wall thickness is doubled, the heat loss is reduced by one-half.

This implies that heat loss during a 60-second period, from a tube similar to $\mathrm{V}_{2}$, with a transfer area of approximately $1.2 \mathrm{ft}^{2}\left(0.11 \mathrm{~m}^{2}\right)$, a 2.0 inch $(5.1 \mathrm{~cm})$ wall thickness, and a $1.8{ }^{\circ} \mathrm{F}\left(1{ }^{\circ} \mathrm{C}\right)$ change in temperature established and maintained across the tube wall is approximately $5 \times 10^{-3}$ BTUs, or 5 Joules. This heat loss is negligible with regard to deviation of the gas from ideal behavior, and the testing chambers are considered to be thermally well-insulated from their surroundings. Further, the temperature inside the sealed testing chambers is nearly identical to the temperature outside as the system is purged with dry high purity helium at ambient temperature, and the sample chamber is opened after each core is tested. A $1.0^{\circ} \mathrm{C}$ temperature gradient has never been observed across system boundaries. At the end of a test, the temperature inside $V_{2}$ has not changed more than $0.5^{\circ} \mathrm{C}$ relative to the laboratory room air temperature. The temperature does drift throughout the work day, but over a time period much longer than that required to test a core sample. 


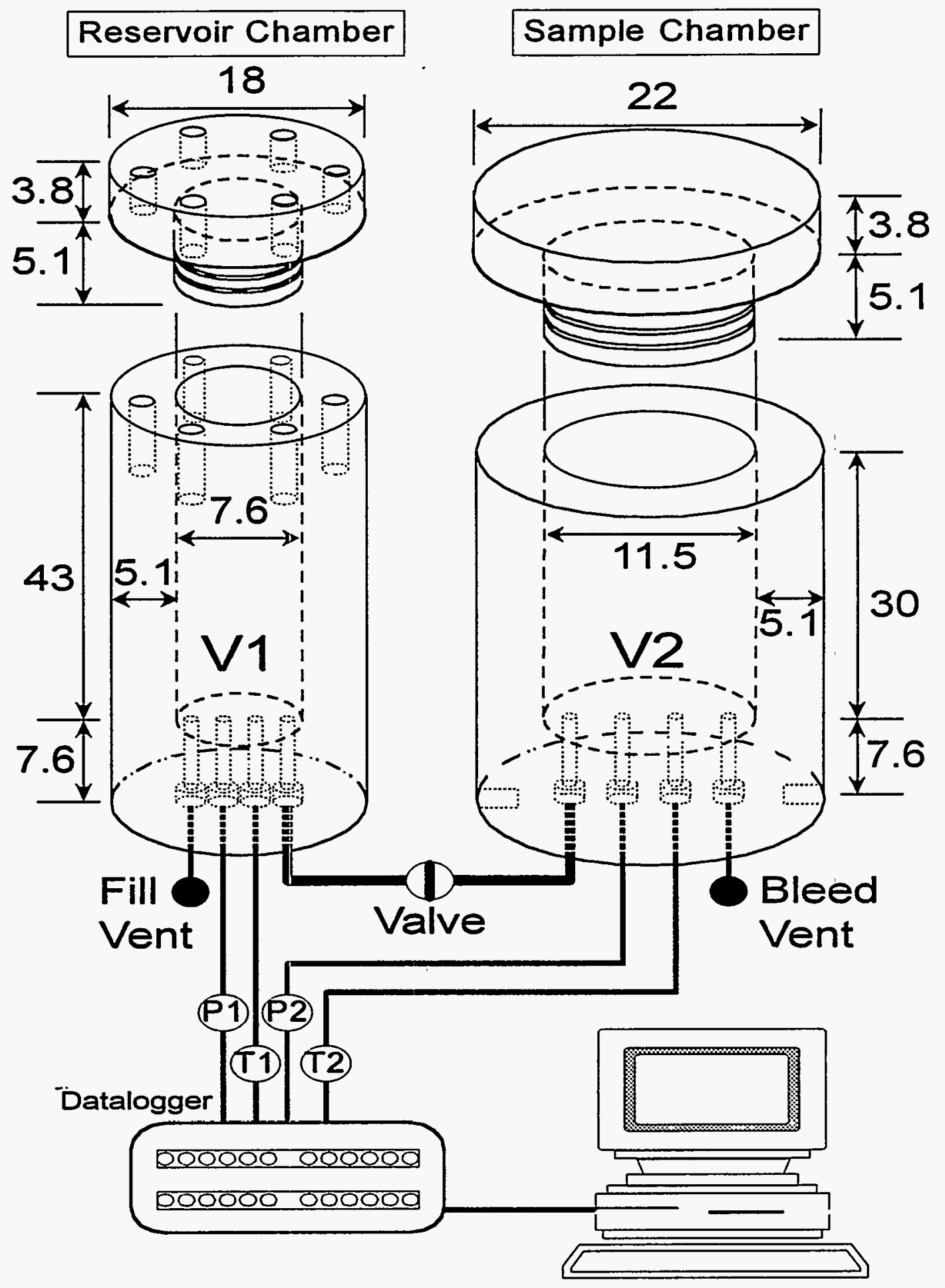

Figure 2.1. Schematic diagram of the gas pycnometer system (dimensions are in centimeters). 
Table 2.1. PVC Physical Properties and Electrical Hardware Performance Specifications for the Gas Pycnometer System (see text for discussion).

\begin{tabular}{|c|c|c|c|}
\hline SYSTEM PROPERTY & VALUE & UNITS & COMMENTS \\
\hline $\mathrm{K}_{\mathrm{T}}$, Thermal Cond. & 1.2 & $\mathrm{BTU} / \mathrm{hr} /{ }^{\circ} \mathrm{F} / \mathrm{in} / \mathrm{ft}^{2}$ & ${ }^{*}$ ASTM C $177(k) \dagger \neq$ \\
\hline $\mathrm{L}_{\mathrm{E}}$, Linear Expansion & $5.2 \times 10^{-5}$ & $\mathrm{~cm} / \mathrm{cm} /{ }^{\circ} \mathrm{C}$ & ASTM D 696t\# \\
\hline Flexural Strength & 103 & $\mathrm{MPa}$ & ASTM D 790t‡ \\
\hline Tensile Strength & 50 & $\mathrm{MPa}$ & ASTM D 638tł \\
\hline Unconnected Porosity & 20 & $\%$ & $t$ \\
\hline Density & 1.8 & $\mathrm{~g} / \mathrm{cm}^{3}$ & ASTM D 792 \\
\hline Druck PDCR 930 & 0.69 & $\mathrm{mV} / \mathrm{psi} / \mathrm{V}$ & Press. Transducer $\neq$ \\
\hline Omega ADCR 590 & infinite & $0.01 \mathrm{mV} / 0.01 \mathrm{~K}$ & Thermistor \\
\hline 21X Micrologger & $+/-50 \mathrm{mV}$ & $0.003 \mathrm{mV}$ & Data Acquisition \\
\hline
\end{tabular}

† International Plastics Selector, 1980.

¥ Manufacturer's Circular.

* ASTM C 177(k) describes the achievement and measurement of steady-state heat flux through flat-slab specimens using a guarded-hot-plate apparatus (ASTM, 1993). The units for thermal conductivity are reported from the manufacturer (Personal Communication, R. Krolosinski, Plastics Engineer, B.F. Goodrich Company) to be: BTUs of heat conducted per hour across the wall of a tube, per ${ }^{\circ} \mathrm{F}$ temperature differential across the tube wall, per inch of tube wall thickness, per $\mathrm{ft}^{2}$ of transfer area. The same units can also be found in $\dagger$ and $\ddagger$. These units are discussed and converted to the more appropriate metric units in the text.

The linear expansion coefficient of the PVC is $\mathrm{L}_{E}=5.2 \times 10^{-5} \mathrm{~cm} / \mathrm{cm}{ }^{\circ} \mathrm{C}$ (see Table 2.1). The units are expressed as length of expansion per length of PVC tubing, regardless of wall thickness. The sample chamber is conservatively approximated as a $30 \mathrm{~cm}$ long tube. The wall thickness of the tube is $5 \mathrm{~cm}$. For a $0.5{ }^{\circ} \mathrm{C}$ change experienced throughout the PVC, the coefficient implies a change in length of $0.001 \mathrm{~cm}$. This translates to a change in volume of about $0.1 \mathrm{~cm}^{3}$ for the sample chamber.

The flexural and tensile strengths of the hypothetical tube, as reported in Table 2.1, are 103 $\mathrm{MPa}$ and $50 \mathrm{MPa}$, respectively. The maximum testing pressure in the reservoir is typically $0.2 \mathrm{MPa}$ $(200 \mathrm{kPa})$. Increase in the volume of the gas pycnometer system as a result of the low pressures employed during testing is assumed negligible. The effect is further minimized by the fact that pressures used for calibration are identical to those used for core testing, which would account for 
any volume change. In addition, the PVC behaves rheologically, which means there is no permanent deformation below the strength limits.

The Druck PDCR 930 (Druck, Inc., 1994) absolute pressure transducers are powered with 5V by a Campbell Scientific $21 \mathrm{X}$ Micrologger. The $5 \mathrm{~V}$ supply reduces the full range output of the sensors to $50 \mathrm{mV}$. The reduced sensitivity equals $0.01 \mathrm{mV}$ at atmospheric pressure $(\sim 90 \mathrm{kPa})$ and approximately $0.05 \mathrm{mV}$ at maximum operating pressure $(-200 \mathrm{kPa})$. The data logger is able to resolve $\pm 50 \mathrm{mV}$ into $0.003 \mathrm{mV}$ intervals (Campbell Scientific, Inc., 1990). This allows measurement of absolute pressure to $\pm 0.02 \mathrm{kPa}$ at full scale pressure transducer output. Thirteenbit analog to digital conversion by the datalogger allows five digits to be retrieved from data logger memory.

The Omega $\mathrm{AD} 590$ solid state temperature sensors claim $1 \mu \mathrm{A} / \mathrm{K}$ resolution and perfect linearity (Analog Devices, 1993). The output of two such sensors was monitored over a period of several days. They were found to differ from each other by approximately $4^{\circ} \mathrm{C}$. An offset coefficient for the thermistors was calculated by comparing their output to several glass thermometers. The thermometers reported a temperature between the output of the two sensors, and each thermistor was adjusted accordingly. A program to operate the above sensors on the datalogger, including the calibration coefficients, is included in Appendix A, Table A.1. LEMO, Inc. (1993) underwater electrical passthroughs are used to get the temperature sensors inside the testing chambers, providing leak-free insulated access for gas temperature measurement.

\subsection{Pressure Transducer Calibration}

Pressure transducer calibration took place in two stages. First, the pressure transducers were calibrated with a PRINCO fortin type mercury barometer (provided by the Dept. of Physics and Atmospheric Sciences, UA). This device is capable of measuring the absolute air pressure to approximately \pm 0.02 inches $\mathrm{Hg}(\sim 0.08 \mathrm{kPa})(\mathrm{PRINCO}, 1983)$ and is corrected for temperature and gravity. (The power supply and data logger used to calibrate the transducers were also used while calibrating the gas pycnometer and during core testing to provide constant electrical source and monitoring conditions.) Normal atmospheric pressure fluctuation was monitored with the barometer, and the pressure transducer output in $\mathrm{mV}$ was recorded over a three-day period in the lab (the transducers were sheltered from moving air during this period). Plot B in Figure 2.2 shows these data, which were used to generate an estimate of atmospheric pressure during applied (gage) pressure calibration.

Second, an applied pressure calibration was performed on a tandem mercury and water manometer. The manometer design was adapted from a similar instrument in the Dept. of Soil and Water Science, UA. Plot A in Figure 2.2 illustrates the calibration curves for the applied pressure calibration. Gathering of data points on the low pressure end of the curves represents pressure generated by the water side of the manometer. Atmospheric pressure in the laboratory is typically near $93 \mathrm{kPa}$, and the absolute pressure range of transducer calibration is from atmospheric to $213 \mathrm{kPa}$. The maximum reservoir chamber pressure during calibration of the gas pycnometer, and core testing is approximately $117 \mathrm{kPa}$ gage (210 kPa absolute). Transducer calibration was performed over this range to ensure measurement accuracy. Each point in Figure 2.2 represents 20 or more measurements over a 5 -second time interval. These data were averaged to eliminate random electrical noise.

\subsection{System Leak Testing}

The system has been pressure tested many times and is found to leak at an acceptable rate. Gas tightness is attained using double $0.476 \mathrm{~cm}\left(3 / 16^{n}\right)$ O-rings on each chamber plug (see Figure 

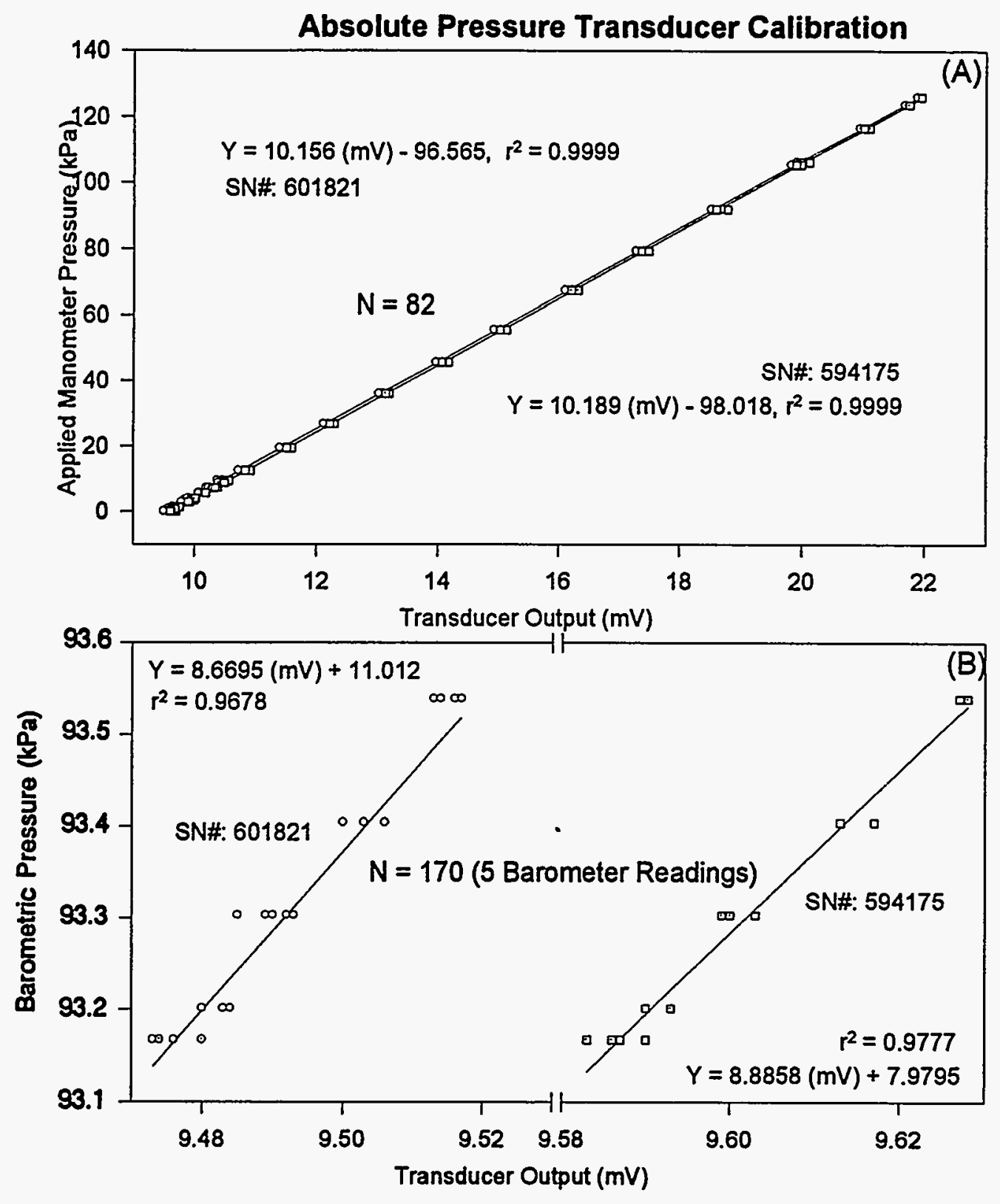

Figure 2.2. Druck PDCR 930 absolute pressure transducer calibration. In Plot (A), pressure was applied with a manometer. In Plot (B), barometric pressure was monitored in the lab for three days to establish an absolute pressure offset for the applied (gage) pressure calibration. 
2.1). The plastic connecting hose is $1 / 2^{n}$ O.D., $4,000 \mathrm{kPa}(600 \mathrm{psi}$ ) rated, rigid-wall brake line material, and is kept as short as possible. The hose and its fittings are insulated with expandable spray foam and encased in clear polycarbonate plastic to protect the connections. The connecting hose is assumed not to expand during calibration and core testing and to be a poor conductor of heat. Access ports are $0.635 \mathrm{~cm}(1 / 4$-inch) holes drilled through the base of each cylinder. These are enlarged and tapped directly into the PVC on the exterior as required (see Figure 2.1). Tank valve stems are used as fill and bleed vents.

Examples of leak tests are provided in Figure 2.3. Plot (A) illustrates the results of a 24-hour test period during which pressure was increased in both cylinders and the connecting valve was open. The pressure was increased to approximately $10 \mathrm{kPa}$ greater than maximum core testing pressure. The temperature traces indicate the amount of unresolvable separation between thermistors, which appears to be on the order of $0.2{ }^{\circ} \mathrm{C}$. Spikes on the temperature traces are artificial $+0.25 \mathrm{~K}$ markers to indicate midnight during overnight testing. The total system leak rate is very small, on the order of $1.4 \mathrm{~Pa} /$ minute. This is calculated as the slope of a line from the first to the last point of the test. Most core tests require about 1 minute to perform, and this pressure increment cannot be resolved, with the pressure transducers used, during that time. Figure 2.3, Plot (B), represents four overnight tests with the valve closed. One of the cylinders was pressurized and the record of that cylinder's pressure is shown. The other cylinder was left near atmospheric pressure; each cylinder was pressurized twice for Plot (B). The very slow leak rate could be the result of molecular diffusion effects of helium but has not been investigated further. For the measurements conducted during this investigation, it is assumed that the gas pycnometer system does not have any appreciable leakage. 


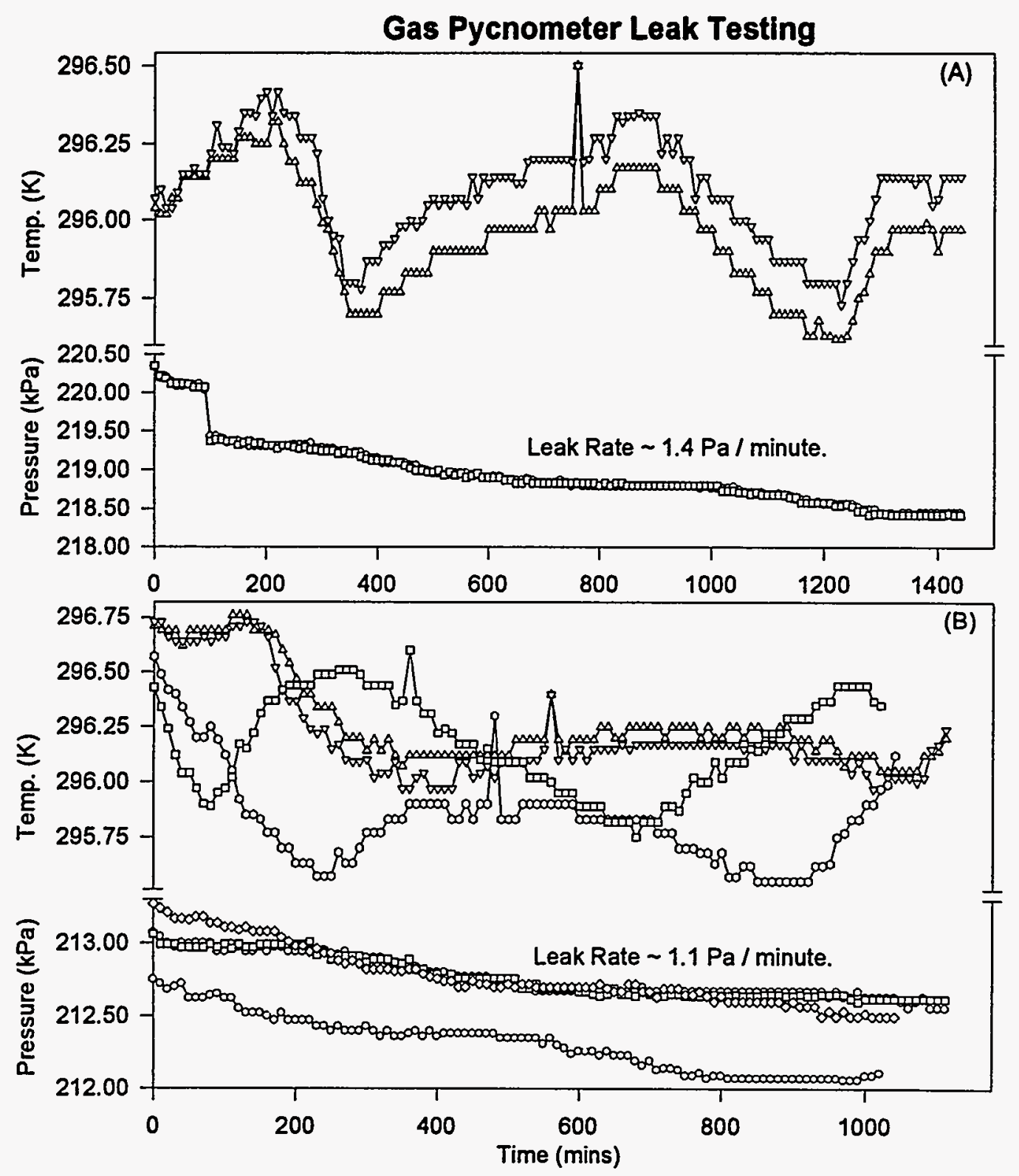

Figure 2.3. Leak testing of gas pycnometer system. Spikes on temperature traces are artificial $+0.25 \mathrm{~K}$ markers indicating midnight during overnight testing. In Plot $(A)$, the connecting valve is open; in Plot (B), the valve is closed and each cylinder was pressurized twice. 


\section{GAS PYCNOMETER THEORY AND CALIBRATION}

\subsection{GAS PYCNOMETER THEORY}

As was mentioned earlier, gas pycnometry has been used for many years to measure the volume of solid material sealed in a gas tight system. This is accomplished by monitoring imposed pressure changes and solving the ideal gas law. The ideal gas law predicts a constant relationship between pressure, volume, and temperature of a confined gas. This well-known law is:

$$
\mathrm{PV}=\mathrm{nRT}
$$

where:

$$
\begin{aligned}
& \mathbf{P}=\text { Absolute Pressure }[\mathrm{Pa}] \\
& \mathrm{V}=\text { Volume }\left[\mathrm{m}^{3}\right] \\
& \mathbf{n}=\text { moles of } \mathrm{gas}^{-} \\
& \mathrm{R}=8.314\left[\mathrm{~m}^{3} \mathrm{~Pa} \mathrm{~mol}^{-1} \mathrm{~K}^{-1}\right], \text { and } \\
& \mathrm{T}=\text { Temperature }[\mathrm{K}] .
\end{aligned}
$$

Gas confined in the pycnometer exists in two different states when temperature and pressure are measured: an initial state and a final state. The initial state occurs when the connecting valve is closed (see Figure 2.1), the reservoir chamber $\left(V_{1}\right)$ pressure has been increased to 2 atmospheres (absolute), while the sample chamber $\left(V_{2}\right)$ is left at atmospheric pressure. The final state is imposed after the connecting valve is opened and the two chambers are allowed to come to equal pressure. The gas in $V_{1}$ expands into $V_{2}$. To apply the ideal gas law to this system, internal energy of the gas must be constant over the imposed pressure change. By this, it is meant that the system does no work on, and transfers no heat to, its surroundings. Then, according to the first law of thermodynamics, the internal energy remains constant through the change (Ohanian, 1985). If internal energy is not constant, the ideal gas law does not hold, and the relationship between pressure, temperature, and volume of the gas is not linear.

Internal energy of a gas is monitored by measuring its temperature. The first law requirements are also met if the temperature is equal at the initial and final states (in a constant volume system). When the valve is opened, however, the expanding gas causes the temperature in the system to drop. In poorly insulated devices, this results in a heat flux into the system. If the initial temperature was dependent on ambient conditions, then a single test cycle would require a period of time to allow the system to return to the initial (ambient) temperature prior to measurement of the final state. This may not occur for some time, or not at all, if the ambient temperature conditions are not constant. Heat sources in the immediate environment can also cause the temperature to vary between initial and final states. The pycnometer designed and employed for this report imposes the requirements of the first law on the gas. The system does not change volume between initial and final states, so the gas cannot do work on its surroundings. The thickwalled construction and insulated connecting tube does not allow any heat to be transferred across system boundaries. Internal energy of the gas remains constant over the change from initial to final states.

There is a temperature change in the system simultaneous with the change from initial to final states. A temperature measurement, therefore, should be incorporated into the ideal gas law to properly describe the volume change of gas. The temperature has not been incorporated into any previous analysis reported in the literature. The standard method described by Danielson and Sutherland (ASTM, 1986) uses Boyle's law to relate the change in gas volume between initial and final pressure states. Boyle's law is the ideal gas law without temperature. In the following analysis, 
the temperature is left in the ideal gas law allowing for a more complete monitoring of system conditions.

As mentioned previously, $P_{1}$ is arbitrarily increased to near 2 atmospheres, and $P_{2}$ remains at atmospheric pressure. Therefore, the initial system can be described as follows. In the reservoir chamber:

$$
\frac{P_{1} V_{1}}{T_{1}}=n_{1} R
$$

and in the sample chamber:

$$
\frac{P_{2} V_{2}}{T_{2}}=n_{2} R
$$

If the valve between the two chambers is opened, the final system can be described as:

$$
\frac{P_{3} V_{3}}{T_{3}}=n_{3} R \text {. }
$$

The volume of gas in $V_{1}$ expands into a new volume defined as $V_{3}$, which is simply $V_{1}$ and $V_{2}$ connected, i.e., $V_{3}=V_{1}+V_{2}$. Notice that the amount of gas does not change after the valve is opened, i.e., $n_{1} R+n_{2} R=n_{3} R . V_{3}$ is eliminated in Equation (6) after substituting:

$$
\frac{P_{1} V_{1}}{T_{1}}+\frac{P_{2} V_{2}}{T_{2}}=\frac{P_{3}\left(V_{1}+V_{2}\right)}{T_{3}}
$$

$V_{1}$ and $V_{2}$ are not accurately known and need not be determined individually, providing the response of the device is calibrated, against their ratio, using precisely known volumes. Solving for $V_{2} / V_{1}$ results in:

$$
\text { Ratio }=\frac{V_{2}}{V_{1}}=\frac{\left(P_{3}-P_{1} \frac{T_{3}}{T_{1}}\right)}{\left(\frac{T_{3}}{T_{2}} P_{2}-P_{3}\right)}
$$

$T_{3}$ is the temperature of $V_{3}$ at $P_{3}$. It is measured separately in both cylinders and averaged $\left(T_{3}=\right.$ $\left.\left(T_{1, f}+T_{2, f}\right) / 2\right)$. Similarly, $P_{3}$ is measured separately in both cylinders and averaged $\left(P_{3}=\left(P_{1, f}+\right.\right.$ $\left.\mathrm{P}_{2, f} / 2\right)$. All variables on the righthand side of Equation (7) can be measured. This equation is solved over each testing cycle of opening the valve. Each core is tested through approximately 10 cycles (see Section 4.4.3, Core Testing Methodology). The temperature ratios, $T_{3} / T_{1}$ and $T_{3} / T_{2}$, are typically close to $1.000+/-0.001(0.1 \%)$.

There are a variety of phenomena that take place in the application of gas pycnometry which could cause the pressure and temperature measurements to deviate from the ideal. For example, as the gas expands and temperature drops, heat can leave both the insulating material and the sample. There appears to be no way to prevent this and still perform the measurement. Core testing was performed under the same conditions as the calibration in an attempt to minimize the 
impact of the measurement itself on the result. Frictional heating could occur as the helium molecules collide with pore walls, but this is considered negligible.

The largest source of nonideal behavior reported in the literature is associated with the adsorption of water vapor by surface active materials, such as clays, that may be found in a sample (Bielders et al., 1990). Dry high purity helium ( 99.995 mole \%) is used in both the core testing and calibration performed for this report. The helium is passed through a Drierite water trap prior to filling the reservoir chamber. The trap and filling hose also allow the helium to equilibrate with room temperature after expansion out of the storage cylinder. It is assumed that water vapor effects do not impact the measurement performed for this report. There are several reasons for choosing helium. Most importantly, helium is an inert monatomic gas that closely obeys the ideal gas law (Matheson Gas Data Book, $6^{\text {th }}$ ed., 1980). The helium molecule is small, allowing it to access pores and microfractures on atomic length scales. Furthermore, the root-mean-squared velocity of a gas is inversely proportional to its mass (Ohanian, 1985). Because helium is very light its velocity is very large. The wave of pressure that sweeps through a sample is assumed to equilibrate instantaneously throughout the accessible pore space.

\subsection{GAS PYCNOMETER CALIBRATION}

The internal volume of the reservoir chamber, sample chamber, and connecting hose are not precisely known and would be difficult to determine accurately. Fortunately, the ratio of Equation (7) obviates the need for this measurement. Calibration of the gas pycnometer entails altering the internal volume of the system by placing spheres of known volume into the sample chamber. The ratio $V_{2} / V_{1}$ is calculated at each volume increment. When core is tested, the ratio is again calculated, and the volume of solid is back calculated from the calibration curve.

The diameter of 22 nearly identical spheres (two sets of 11) were measured 5 times on different axes. A calibrated micrometer that had an instrument error of \pm 0.0005 inches $\notin 0.0013$ $\mathrm{cm}$ ) was used. The average volume of all the spheres is $28.77 \mathrm{~cm}^{3} \pm 0.16 \mathrm{~cm}^{3}$. However, each sphere's individually measured volume was used in the calibration calculations. The average diameter of all 22 spheres is $3.802 \mathrm{~cm} \pm 0.004 \mathrm{~cm}$, including the micrometer uncertainty. This deviation in the diameter measurement represents a volume of $0.18 \mathrm{~cm}^{3}$ in the worst case. The sphere measurements and worst case calculation can be found in Table A.2 of Appendix A.

The spheres are actually miniature pool balls manufactured by the Belgian Aramith Company. They are precision ground to perfect spheres (product information sheet) and are made from a cast phenolic resin, the exact properties of which are proprietary to Belgian Aramith (Muller Sporting Goods sales representative). The spheres are assumed to have zero-connected porosity, as this is a characteristic of solidified phenolic resins. The spheres are also assumed to have a low heat capacity when compared to the various metallic materials that were considered for the calibration. The advantage of low heat capacity is rapid thermal equilibrium with the surroundings. They do not retain heat loss and become progressively cooler during calibration, to the extent that a metallic substance would. Additionally, they do not carry heat into the sample chamber. The spheres were used to calibrate both the gas pycnometer and the bulk volume estimator (see next section).

The reservoir chamber plug was inserted and the 6 plug bolts were tightened with a calibrated torque wrench to $45 \mathrm{ft}$. lbs. each (see Figure 2.1 for reference). The reservoir chamber plug was left in place during the entire calibration and core testing period. The sample chamber plug is inserted and a metal, U-shaped clamp is placed over the sample chamber. A 3/4-inch acmethreaded screw is tightened to $35 \mathrm{ft} \mathrm{lbs}$. against a metal plate mounted on the back of the sample chamber plug (not shown in Figure 2.1). The torque is applied to $\pm 3 \mathrm{ft} l \mathrm{lbs}$. each time the plug is inserted. The screw prevents the plug from moving when the chamber is pressurized. 
Calibration of the gas pycnometer proceeds as follows. A single valve opening cycle is described in detail. The cycle begins with the connecting valve open. The entire system is bled to atmospheric pressure through the bleed valve on $\mathrm{V}_{2}$. The connecting valve is closed, and a small amount of gas is trapped in the valve body. This gas volume is consider part of $\mathrm{V}_{2}$, as it remains at $P_{2}$ (atmospheric pressure). The reservoir chamber pressure $P_{1}$ is increased to approximately 210 $\mathrm{kPa}, \pm 5 \mathrm{kPa}$, through the fill vent (see Figure 2.1). An exact pressure is not required. The system is allowed to stabilized, a condition defined as no change in temperature or pressure with each 2second measurement update from the data logger. The temperature readings take longer to stabilize than the pressure. The readings are typically stable after 10-15 seconds, but approximately 30 seconds are allowed to pass to ensure the readings are not changing. $P_{1}, T_{1}, P_{2}$, and $T_{2}$ are recorded at this time.

These values are recorded by striking a key on the computer (see Figure 2.1). This initiates an automatic data collection sequence where each sensor output is measured in the following order: $\mathrm{P}_{1}, \mathrm{P}_{2}, \mathrm{~T}_{1}$, and $\mathrm{T}_{2}$. All four sensors are read once in 0.2 seconds. Each sensor output is measured ten times (in 2 seconds), and the average value is stored in the data logger memory. This is done to reduce random electronic noise. The program used to collect data by this method on a Campbell Scientific 21X Micrologger is included in Appendix A, Table A.1.

The valve is opened. Thirty to 40 seconds after opening the valve, $P_{1, f}, P_{2, f}, T_{1, f}$, and $T_{2, f}$ are recorded with the same stability requirements, using the same automatic sequence. The ratio of Equation (7) can now be calculated. The system pressure is bled to atmospheric through the bleed vent, the valve is closed, and the next cycles starts without removing the sample chamber plug.

This "fill-open valve-bleed-close valve" cycle was performed manually over 4,000 times for this project. An example of the response obtained from all 4 sensors, at 5-second intervals, is shown in Figure 3.1. The temperature trace appears unstable for the first few cycles, but quickly becomes stable by the fifth cycle. The first few cycles may be affected by the presence of laboratory air in the system and is discussed further in Section 4.4.2, Core Testing Methodology. As $P_{1}$ is increased, $\mathrm{T}_{1}$ increases. When the valve is opened, expansion creates a pressure drop in the reservoir and an increase in the sample chamber. The temperature change follows suit. Figure 3.2 shows a detailed portion of Figure 3.1. Location of measurement points for the ratio calculation are indicated as labeled circles. The pressure is stable well before the measurement point. The temperature becomes stable after 10-15 seconds.

This cycle was repeated 20 times with the system empty. The sample chamber was opened, one calibration sphere was inserted, and the system was again sealed with the U-shaped clamp and screw. The cycle was performed approximately 20 times for each sphere added to the sample chamber. A total of 22 spheres were eventually included in the sample chamber. This represents calibration of the gas pycnometer over a range of approximately $640 \mathrm{~cm}^{3}$, and the result is shown in Figure 3.3. Maximum and minimum solid volume predicted for any sample tested is covered in the calibration range. The average solid volume is near $300 \mathrm{~cm}^{3}$ which occurs in the middle of the range. Note that the 23 apparent points in this figure represent 469 cycles of the pycnometer. No raw data were excluded or otherwise rejected from this calibration curve. The instrument is believed to respond linearly over the range of laboratory conditions encountered. The calibration curve used for core testing is:

$$
\text { Volume of Solid }=-1,798.86\left(\frac{V_{2}}{V_{1}}\right)+2,687.14, r^{2}=0.9999
$$




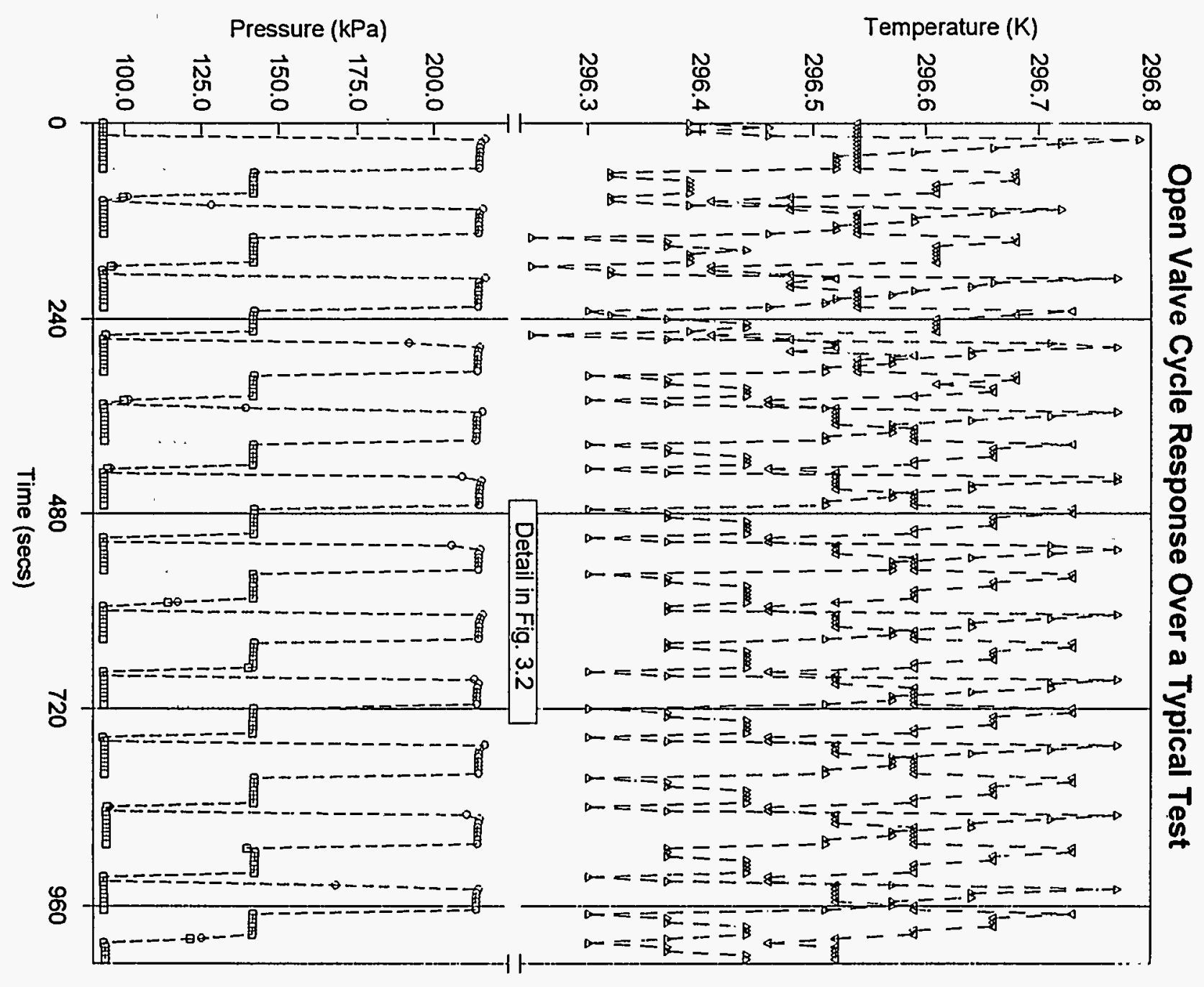


Open Valve Cycle Response, Detail of Fig. 3.1

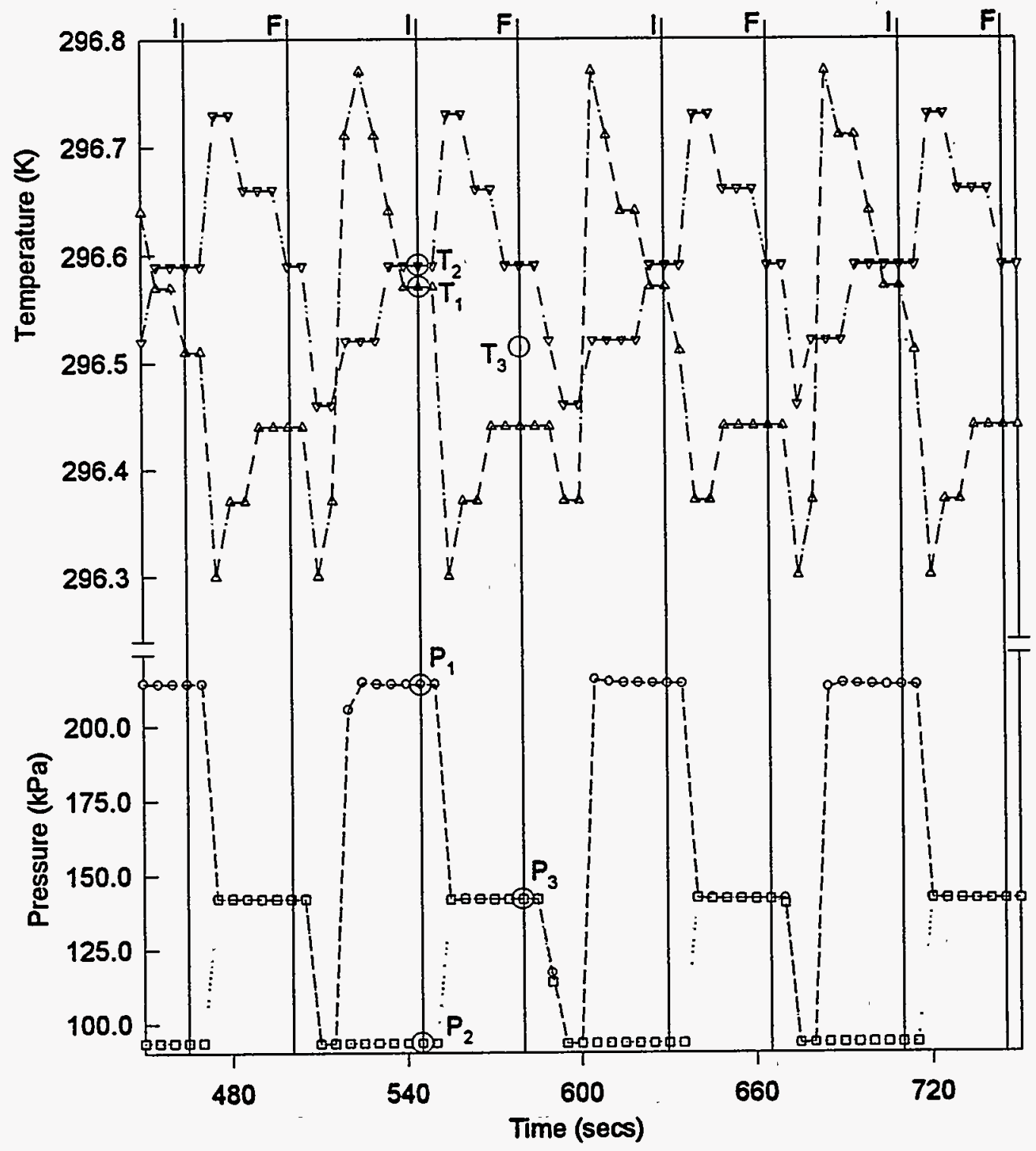

Figure 3.2. Detail of Figure 3.1. Vertical lines show measurement locations for initial and final conditions. Labeled circles indicate where measurements are taken to calculate the ratio, $V_{2} / V_{1}$, for a single cycle. 


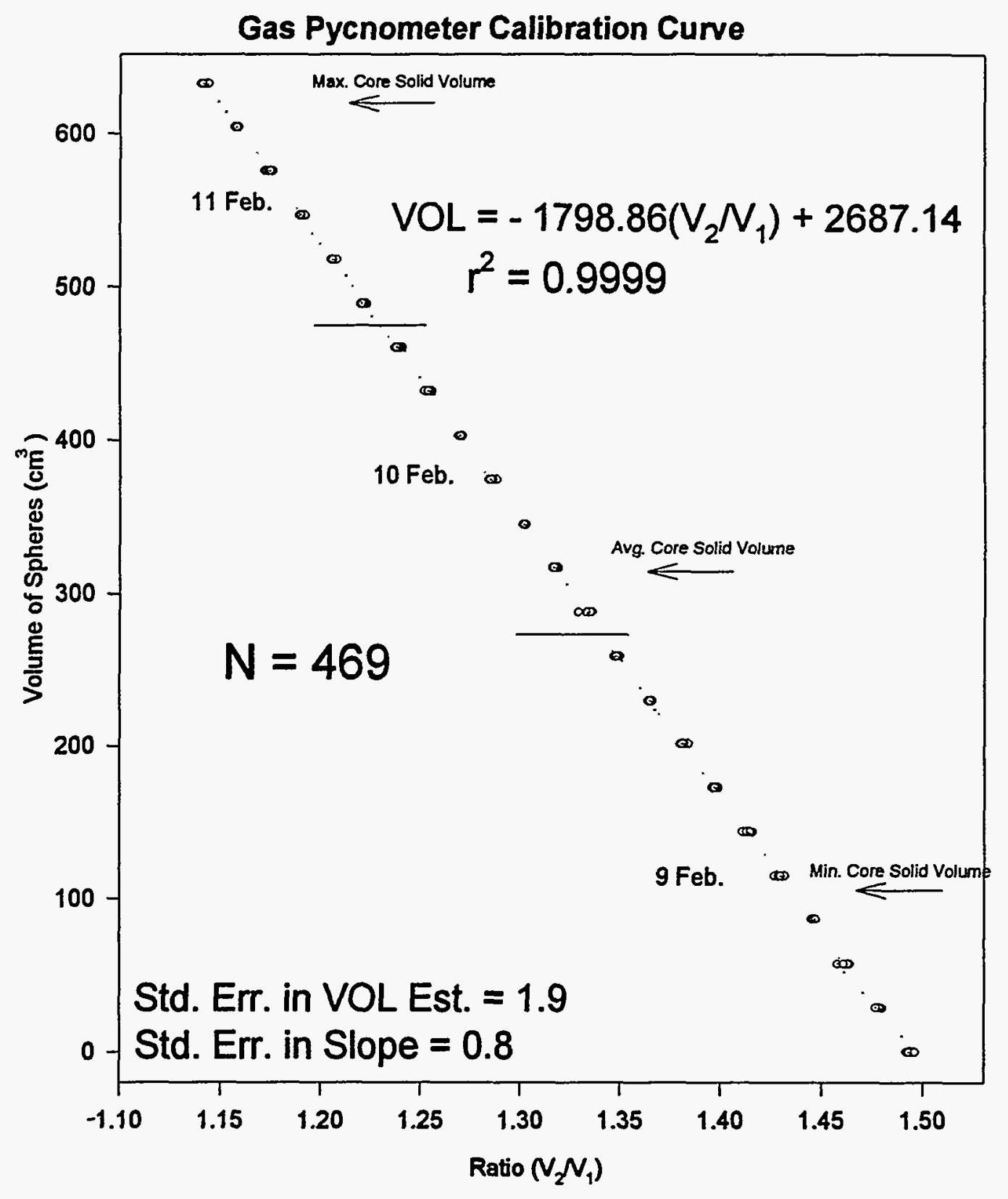

Figure 3.3. Gas pycnometer calibration curve. The instrument was cycled 469 times over a threeday period. The curve is linear as the ideal gas law would predict. 
Plot (A) in Figure 3.4 depicts the difference between measured and predicted sphere volume as a function of measured sphere volume. Predicted sphere volume is calculated with Equation (8). There seems to be some diurnal pattern to the error, but no removable trend. Plot (B) shows these errors to be normally distributed about their mean. There does not seem to be a trend in error with solid volume measured, and the error is considered random. One standard deviation is equal to $1.88 \mathrm{~cm}^{3}$, which is $1.24 \%$ of the smallest solid volume predicted $\left(151.3 \mathrm{~cm}^{3}\right.$ for $\left.\mathrm{g} 12 \mathrm{~b}\right)$. This percent error decreases to $0.62 \%$ for an average solid volume of $300 \mathrm{~cm}^{3}$. The standard deviation is termed the "Std. Err. in VOL Est." in Figure 3.3. The random error can be decreased by testing a sample through multiple cycles and averaging. The total error is the sum of the instrument error and the random error. The instrument error is a function of the thermistor and pressure sensor calibrations and the change in volume of the assumed rigid system. The sensors respond linearly over the range of measurement. The error reported for the pressure transducer offset was $0.08 \mathrm{kPa}$, which is $0.08 \%$ of $95 \mathrm{kPa}$, the minimum pressure used. The error in the thermistor offset was $\pm 0.2^{\circ} \mathrm{C}$ at $295 \mathrm{~K}$, which equals $0.07 \%$. The system is assumed rigid, so the sum of these three sources of instrument error is $0.15 \%$. The total error, therefore, is estimated at $2.2 \mathrm{~cm}^{3}\left(1.88 \mathrm{~cm}^{3}+0.15 \%\left(220 \mathrm{~cm}^{3}\right)\right)$, which implies an estimate of solid volume $>220 \mathrm{~cm}^{3}$ with $<1 \%$ error.

\subsection{BULK VOLUME ESTIMATOR CALIBRATION}

A rather simple device was constructed that connects a buret to a graduated cylinder on a ring stand in order to measure bulk volume. They are mounted vertically, adjacent to one another, and are connected by means of a flexible hose at their base. The inside diameter of the graduated cylinder is approximately $1 / 2$ inch $(1.3 \mathrm{~cm})$ greater than the outside diameter of the core samples. Water flows into the buret when the graduated cylinder is partially filled. When an object is immersed in the graduated cylinder, the water level rises in both tubes to an equal height. The fine gradations on the buret allow the operator to read the change of water volume to $\pm 0.1 \mathrm{~mL}$ (in the buret). The immersion of one calibration sphere in the graduated cylinder displaces the water in the buret approximately $1.0 \mathrm{~mL}$. An average sphere volume of $28.8 \mathrm{~cm}^{3}$ was assumed, which corresponds to an instrument error of $\pm 2.88 \mathrm{~cm}^{3}$.

The device was calibrated by placing groups of spheres into the graduated cylinder and recording the change of water volume in the buret. In this way, the bulk volume estimate is independent of the amount of water initially in the device. This procedure was repeated 6-8 times for groups of 5 through 22 spheres and resulted in 107 calibration points. These points are shown in Figure 3.5. The calibration range covers bulk volume estimates from $143 \mathrm{~cm}^{3}$ to $634 \mathrm{~cm}^{3}$, which includes the minimum and average bulk volumes estimated.

One core sample, g-58, fell outside of this range with a bulk volume estimated to be $690 \mathrm{~cm}^{3}$. The calibration curve for the bulk volume estimator is:

$$
\text { Bulk Volume }=29.17 \text { (DISP) }-1.667, \mathrm{r}^{2}=0.9994
$$

in which:

DISP $=$ the volume of water displaced in the buret $(\mathrm{mL})$.

Plot (A) in Figure 3.6 depicts the difference between measured and predicted sphere volume as a function of measured sphere volume. Predicted sphere volume is calculated with Equation (9). The error appears to be randomly distributed as a function of measured sphere volume. Plot (B) also shows these errors to be randomly distributed about their mean and approximately normal. One standard deviation is equal to $3.62 \mathrm{~cm}^{3}$, which is $2.17 \%$ of the smallest bulk volume predicted 


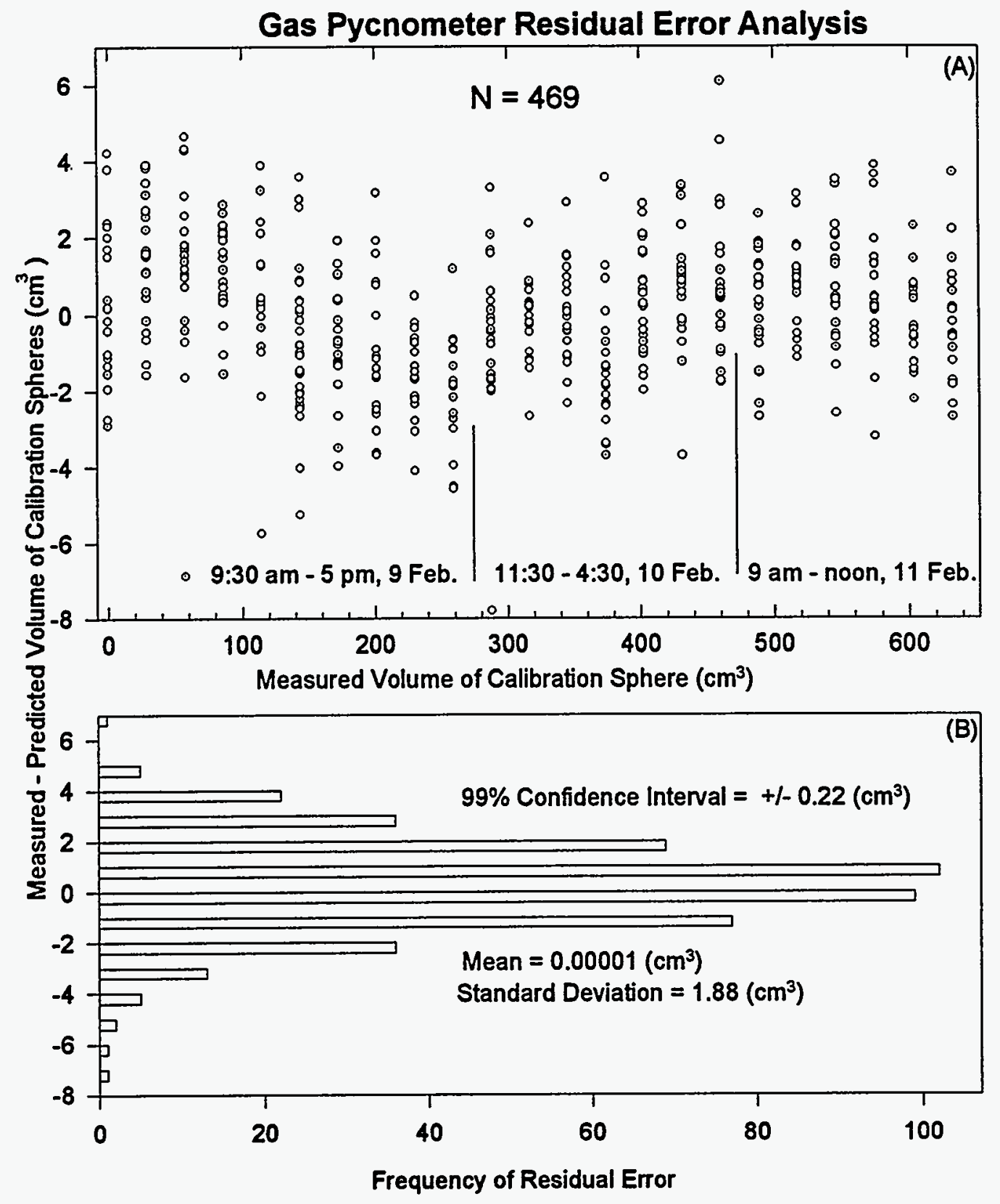

Figure 3.4. Gas pycnometer calibration error analysis. Plot (A) illustrates measured minus predicted volume of calibration spheres, as a function of measured sphere volume. Plot (B) is a histogram of the error frequency. 


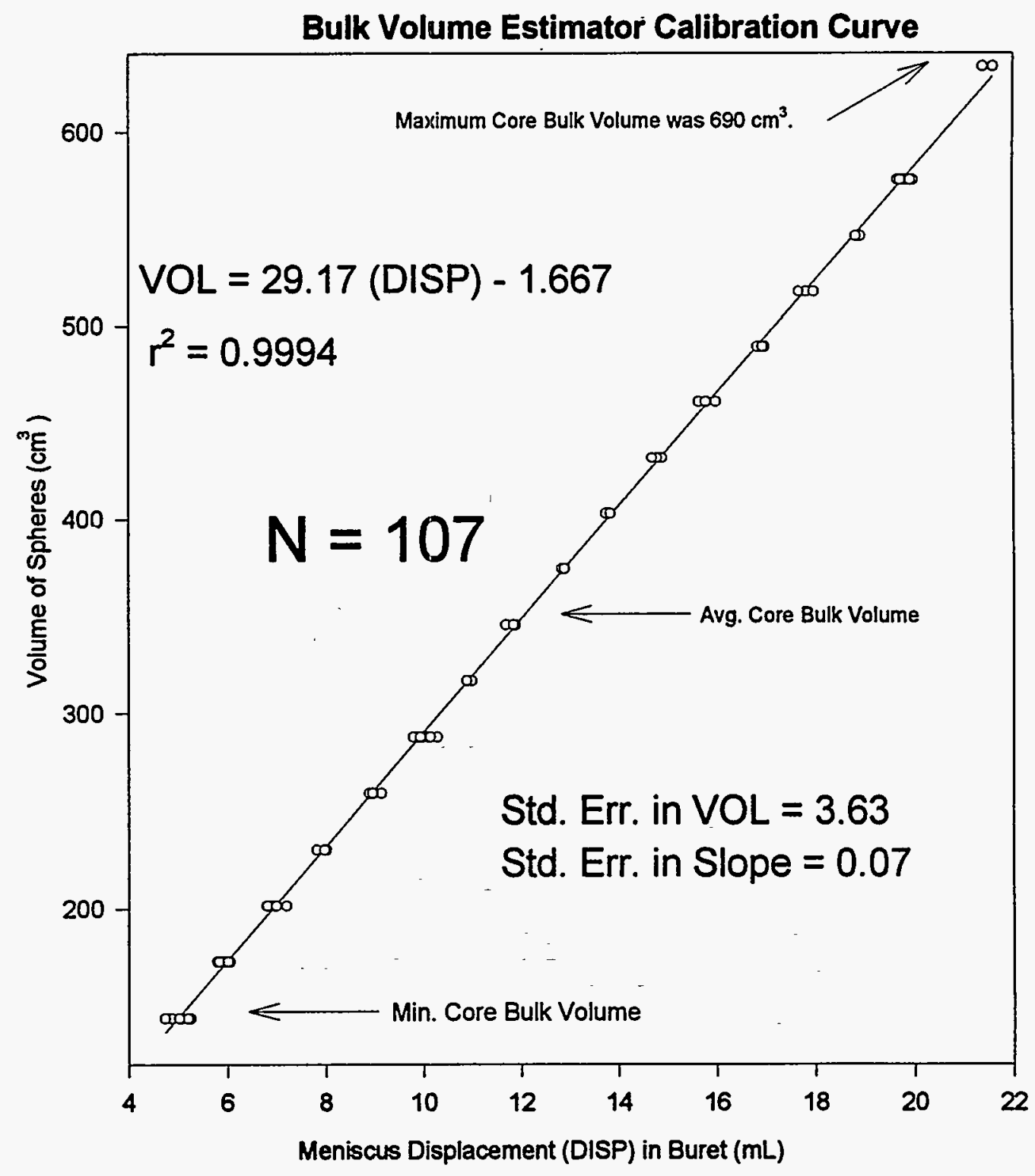

Figure 3.5. Bulk volume estimator calibration curve. The phenolic resin calibration spheres were used to generate 107 calibration points. The calibration covers a bulk volume range of $143 \mathrm{~cm}^{3}$ to $634 \mathrm{~cm}^{3}$. One core sample fell outside of this range. 


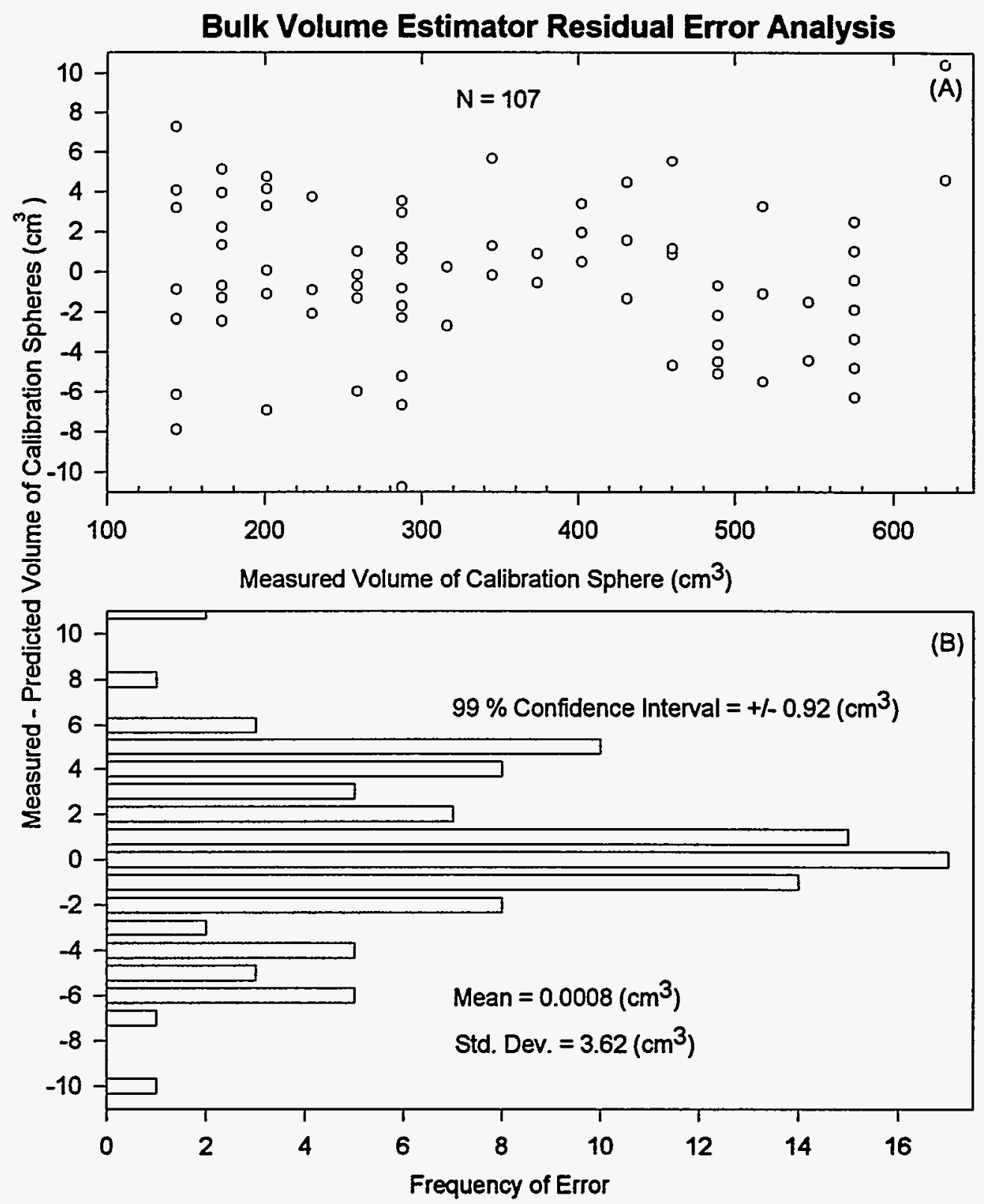

Figure 3.6. Bulk volume estimator calibration error analysis. Plot (A) represents measured minus predicted volume of calibration spheres as a function of measured volume. Plot (B) is a histogram of the error frequency. 
$\left(167 \mathrm{~cm}^{3}\right.$ for sample $\left.\mathrm{g} 12 \mathrm{~b}\right)$. This percent error decreases to $1 \%$ for an average bulk volume of 360 $\mathrm{cm}^{3}$. The standard deviation is termed the "Std. Err. in VOL Est." in Figure 3.5. The random error can be decreased by multiple testing of a sample. The total error is the sum of the instrument error and the random error. The total error for the bulk volume estimator is $\pm 6 \mathrm{~cm}^{3}$. 


\section{EXPERIMENTAL METHODS}

As mentioned earlier, 147 core samples have been processed through the gas pycnometer. The samples represent Apache Leap tuff from two locations at the ALRS: the Deep Slant Borehole site (DSB) and the Covered Site (CS) (see Figure 1.1). The samples are split into three groups: the $G$ series and $P$ series are from the DSB, and the Y2 series is from the CS. The core was retrieved using two different drilling methods. The core retrieval methods, core handling, and details of the gas pycnometry method are described below.

\subsection{CORE RETRIEVAL METHOD}

Thirty-four Y2 series core samples were retrieved from The UA Core Storage Facility. They have been stored in boxes since 1986 when they were retrieved from the CS using conventional drilling technology. The Y2 borehole was drilled using water as the cooling and chip-circulating fluid. It was drilled at $45^{\circ}$ below horizontal for approximately $30 \mathrm{~m}$ (i.e., to a $20 \mathrm{~m}$ depth). Samples were obtained for this report that cover the length of the hole on an average $75 \mathrm{~cm}$ spacing. Core depths are approximate $( \pm 20 \mathrm{~cm})$ as a result of previous sampling from these boxes. Core from this hole has been extensively tested (Rasmussen et al., 1990).

The DSB was cored during November and December 1992/1993. Gregg Davidson, Mike Henrich, Dr. Mark Smiley, and the author worked 12 hours on, 12 hours off, for nearly a month of drilling. An Ingersoll-Rand T4W with an angle package was employed by Tonto Drilling to core at $45^{\circ}$ below horizontal for $202 \mathrm{~m}$ (i.e., to a $143 \mathrm{~m}$ depth). The $\mathrm{G}$ series samples were obtained at approximately 10-ft intervals, and the indicated depth represents the middle of a sample. The depth of each sample is accurate to $\pm 10 \mathrm{~cm}$. The $P$ series was sampled at duplicate locations and to fill in depth intervals where no $G$ series sample was taken. The hole was drilled in a canyon stream bed that is located approximately $460 \mathrm{~m}$ (1500 feet) west of the CS (see Figure 1.1). The stream bed is dry most of the year, but flowed continuously during the drilling project. Surface facilities were constructed for the drilling project that now support a broad range of activity (a shed was constructed by TUFF Shed, Inc., Tucson, Arizona).

The first $230 \mathrm{ft}(70 \mathrm{~m})$ of core from the DSB was retrieved while overreaming and casing the formation by the ODEX method (or TUBEX; see manufacturer literature). The coring process can be visualized as follows: At the base of the hole, an annulus of tuff is being ground away, and a 2.5 in $(6.4 \mathrm{~cm}$ ) diameter core emerges into a sealed (dead air volume) core barrel. Air that has been injected with $\mathrm{SF}_{6}$ at approximately $1 \mathrm{ppm}$ is used as the cooling and chip-circulating fluid. The $\mathrm{SF}_{6}$ acts as a tracer of atmospheric air for future gas sampling tests. This air is forced down the inside of the drill rod. Ambient downhole gage pressure is on the order of $600 \mathrm{kPa}(90 \mathrm{psi})$, which is enough to blow the ground tuff powder back to the surface.

Core was retrieved from the hole by wire-line overshot, designed to break the core off near its base. The core barrel can hold a $10 \mathrm{ft}(3 \mathrm{~m})$ length of core. After $20 \mathrm{ft}(6 \mathrm{~m})$ of coring, the drill rods are removed from the hole, and a different drill bit is used to overream the hole an additional 1 inch in diameter. The ODEX casing is moved down right behind the reaming bit. In this way, the $\mathrm{SF}_{6}$-laced air can circulate back up the hole, in the annulus outside of the drill pipe and inside the ODEX casing, without contacting the formation. The lower $2 / 3$ of the hole was cored straight through without casing the formation.

Orientation of the core for vertical was performed after each core run. A small $(<10 \mathrm{~cm})$ piece of core was retained from the end of one run to orient the top of the next core run when possible. Orientation of the core was also performed using an "off-center weighted" wire line dummy which was lowered to the bottom of the hole through the coring rods. The dummy maintained orientation 
with vertical. Playdough was affixed to its tip to form an impression of the stub left behind after the overshot break. Fun-Doh was found to be inferior to Playdough. It tended to lose shape upon drying and to be more crumbly, leaving residue on the top of the next core barrel. The colors were not as bright either.

Several single shot measurements were taken at various depths along the hole. This instrument exposes photographic film to a compass/leveling bulb that indicates orientation of the hole in space. The compass reading was unreliable as it was taken inside the metal ODEX casing. The dip reading indicates that the hole dives a few degrees beyond $45^{\circ}$. The hole was drilled toward the northeast $\left(\mathrm{N}_{55^{\circ}} \mathrm{E}\right)$, perpendicular to the strike of a fracture set. The set is evident in aerial photographs. This was done in an attempt to pierce many of the fracture planes normally. Most of the core was retrieved in a broken condition, partly due to the drilling. Many evidently "natural" fractures were encountered.

Immediately upon removal of tuff from the core barrel, the sample was taken into the TUFF shed. The core was marked for vertical and depth with wax pencil and was logged on audio cassette and video taped. Every other $20 \mathrm{ft}(6 \mathrm{~m})$ section was cut into 4 -inch $(10 \mathrm{~cm})$ lengths. The core was cut with a rock saw after logging and prior to sealing for storage. This was done in preparation for squeezing the water out of the core in a press (see G. Davidson, Ph.D. dissertation in progress, 1995). The entire $662 \mathrm{ft}$ of core was wrapped in Barex, a puncture-resistant, cellophane-type material, and sealed in a ProtecCore envelope. This was done in $75 \mathrm{~cm}$ lengths, typically 3 to a core barrel. The ProtecCore is a foil and plastic laminate material which is designed to be a vapor barrier over extended periods when properly sealed. The envelope was flushed with high purity $\mathrm{N}_{2}$ and sealed with a hot iron. These envelopes have been stored in boxes at The UA Core Storage Facility. A full core barrel was sealed in the protective envelope within 20 minutes after removal from the base of the hole.

\subsection{CORE HANDLING AND GRAVIMETRIC WATER CONTENT}

The Y2 core samples were scrubbed lightly with a wire brush while being rinsed under Tucson tap water. Any remaining dust and dirt from drilling, and any loose pieces of tuff material, were removed. This was done to assist in establishing a relatively constant dry weight by removing small bits of material that would eventually fall off over time as a result of handling. Additionally, lithologic contrast in the core record is much more evident on the cleaned samples.

Fifty-three samples of tuff were retrieved during the DSB drilling project. They were labeled g1-g53 (sample g12 broke cleanly into two pieces that were labeled g12a and g12b). The samples were wire brushed (dry) to remove any loose material and weighed within 30 minutes after removal from the base of the borehole. The samples were later dried in an oven and reweighed to determine gravimetric water content. Oven-drying core involves heating the samples at $105^{\circ} \mathrm{C}$ to a constant weight (Gardner, ASTM, 1986). Figure 4.1 shows gravimetric water content for the original $53 \mathrm{G}$ series samples.

Gravimetric water content for the core samples was determined using the following equation (Gardner, ASTM, 1986):

$$
w=\frac{\text { Mass }_{\text {wet }}-\text { Mass }_{\text {dry }} \text { ) }}{\text { Mass }_{\text {dry }}}
$$




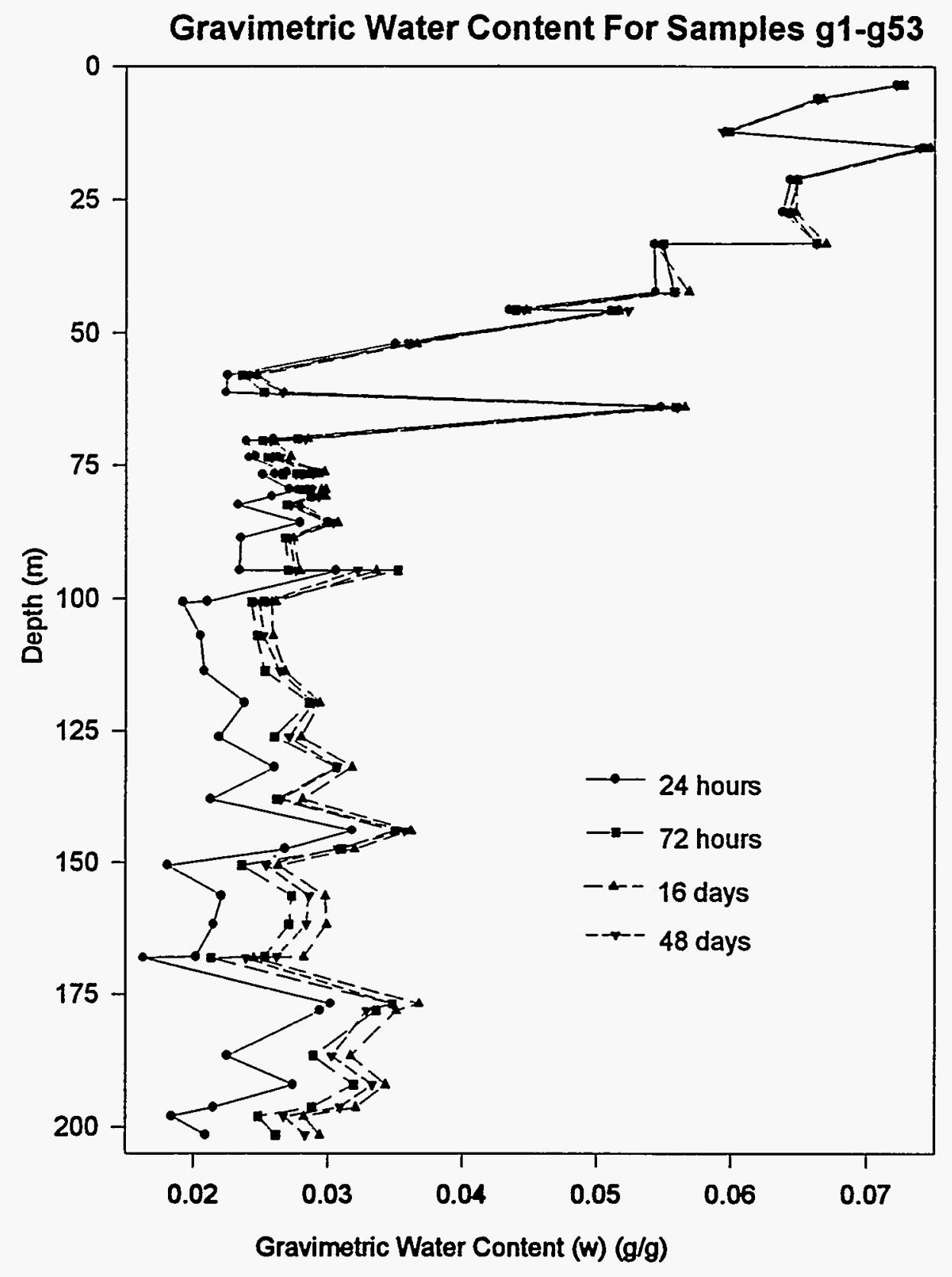

Figure 4.1. Gravimetric water content (w) with depth in the DSB. Gravimetric water content after $\mathbf{4 8}$ days of drying was slightly less than at 16 days for most samples below the $50 \mathrm{~m}$ depth. 
The data used to generate Figure 4.1 can be found in Table B.1 of Appendix B. The spike near $65 \mathrm{~m}$ was from a sample that was taken immediately below a wet fracture. The fracture aperture was on the order of $20 \mathrm{~cm}$ and appeared to contain water-washed pebbles at the point where the borehole intersected it. The decrease in gravimetric water content from the surface down to 60 $\mathrm{m}$ (see Figure 4.1) could be the result of water flowing in the stream bed and infiltration down to that point. Volumetric water content is calculated and discussed in Section 5.1. The weight of most samples increased an average of $0.6 \mathrm{~g}$ between 16 days and 48 days of drying. This results in the calculation of a lower gravimetric water content. There is no explanation of this anomalous behavior. The 16-day data are assumed to be the true gravimetric water content. After the gravimetric analysis, the core samples were rinsed with Tucson tap water while being lightly scrubbed with a wire brush. The core was stored in cardboard core storage boxes.

Fourteen additional $\mathrm{G}$ series cores and the $42 \mathrm{P}$ series cores were removed from their protective packages after approximately 8 months in storage. Water had condensed on the inside of the protective envelope, and no attempt was made to determine gravimetric water content of these samples. The $14 \mathrm{G}$ series samples were labeled g54-g67. They were rinsed with Tucson tap water while being scrubbed with a wire brush. The $P$ series core were sampled from storage by $E$. Hardin for the purpose of resistivity measurements and could not be wetted. The P series samples were dry brushed with a nylon brush.

Both of these subsets were taken from envelopes containing cut core; thus, their shape closely approximates a right circular cylinder. This allows their bulk volume to be estimated by measuring their length and diameter. Several of the original $53 \mathrm{G}$ series samples were also from core that was cut in the field. None of the Y2 series core was cut.

\subsubsection{Bulk Volume Estimation}

An estimate of bulk volume was made for any core sample that closely approximated a right circular cylinder by measuring its length and diameter with a vernier caliper. The error involved in this method is a function of the condition of the core. If a sample is rough or chipped, the estimate is not very accurate. The error is probably similar in magnitude to the bulk volume estimator error, but has not been quantified. The bulk volume of all the $G$ series and Y2 series core samples was estimated by the immersion method using the bulk volume estimator. This means that cut $G$ series samples had their bulk volume estimated by both methods. Bulk volume of the $P$ series cores was estimated by direct measurement only.

After a $\mathbf{G}$ series or $\mathrm{Y} 2$ series core sample was tested in the gas pycnometer, it was soaked in Tucson tap water for several days. The sample was removed from the water immediately prior to bulk volume estimation by the immersion method. The surface was quickly blotted to remove excess water. Core was immersed 5 or 6 times, and the water volume displaced in the buret was recorded each time. The core was held lengthwise with a single loop of $30 \mathrm{AWG}$ electrical wire, the immersed volume of which is $<0.2 \mathrm{~cm}^{3}$. The bulk volume was then calculated using Equation (9) and the average displacement. The core was assumed to have acquired a saturated rind as a result of the soaking. This was done to reduce the amount of water a core might imbibe while being tested. To test this assumption, several samples were removed from the soaking tub, blotted, and immersed in the graduated cylinder. For each of these test pieces, the height of water in the buret was recorded initially and every 20 minutes for several hours. There was no significant change in the height of the water in the buret, and the samples were assumed not to imbibe any water in the several seconds required to estimate bulk volume by the immersion method.

The immersion bulk volume estimate is in lieu of developing core saturation procedures for measuring bulk volume with the gas pycnometer. At the pressure of operation, entrapped air could 
affect this measurement if the samples were not completely saturated. In fact, this behavior is required for part of the entrapped air tests performed in the literature (see, for example, Stonestrom and Rubin, 1989). The water in the samples would move into the pores occupied by air at atmospheric pressure. This type of bulk volume estimate would also require a calibration of the pycnometer with water saturated air. Investigation of this additional behavior was deemed outside the scope of this research. Sealing the core with any substance that alters the tuff renders it useless for future testing in the pycnometer, or other comparative testing, and was not employed.

\subsection{GAS PYCNOMETER TESTING METHODOLOGY}

Approximately one year after the gravimetric analysis, all core samples were placed in the drying oven. The pycnometer was designed and built during this year. The 14 additional $G$ series samples had been air-dried in cardboard core storage boxes for 4 months prior to being placed in the oven. The P series core had some resistivity work performed on them and had been stored in the drying oven for nearly a month prior to oven drying for pycnometer testing. After 5 days, several test pieces from all three core series were weighed. They were weighed again on each of the 5 following days and their weight was found to be constant.

Each core was weighed immediately after removal from the drying oven. Samples were then placed into one of two sealed cooling chambers that were partially filled with Drierite desiccant. The core was allowed to cool overnight (18 to $20 \mathrm{hrs}$ ) prior to testing in the gas pycnometer. The pressure in one of the dry boxes was lowered approximately $20 \mathrm{kPa}(3 \mathrm{psi})$ below atmospheric pressure to remove a portion of the laboratory air that may have carried water vapor into the chambers. After the cooling period, the temperature inside the drying boxes was found to be identical to laboratory ambient temperature as reported by two mercury thermometers. The samples were then removed from the drying boxes, one at a time, and reweighed immediately prior to pycnometer testing. There was no change in sample weight during the cooling period in the samples from either box.

Core testing with the gas pycnometer is performed with the same pressure conditions and in the same temperature range as the calibration. Core samples are sealed in the sample chamber in an identical fashion as described in Section 3.2, Gas Pycnometer Calibration. The core samples are tested through approximately 10 cycles of the pycnometer. After each set of cycles, the core is removed and the inside of the sample chamber is wiped with a clean dry cloth. This is done to remove any small pieces of tuff material that might accumulate in the chamber and interfere with the O-rings (see Figure 2.1). The ratio is calculated using Equation (7), and the solid volume is estimated using Equation (8), for each cycle. Figure 4.2 shows the ratio estimate for 23 randomly selected $\mathrm{G}$ series core samples and indicates that the ratio estimate is fairly constant from cycle to cycle. The first ratio estimate of many tests appears slightly greater than the second or remaining ratio estimates. This is discussed below in Section 5.2.1, Re-Tested Core Data. The cycle number can be thought of as testing time, as each trace in the figure required approximately 20-30 minutes to generate. There does not appear to be any noticeable trend in the ratio estimate for successive cycles in the gas pycnometer. 


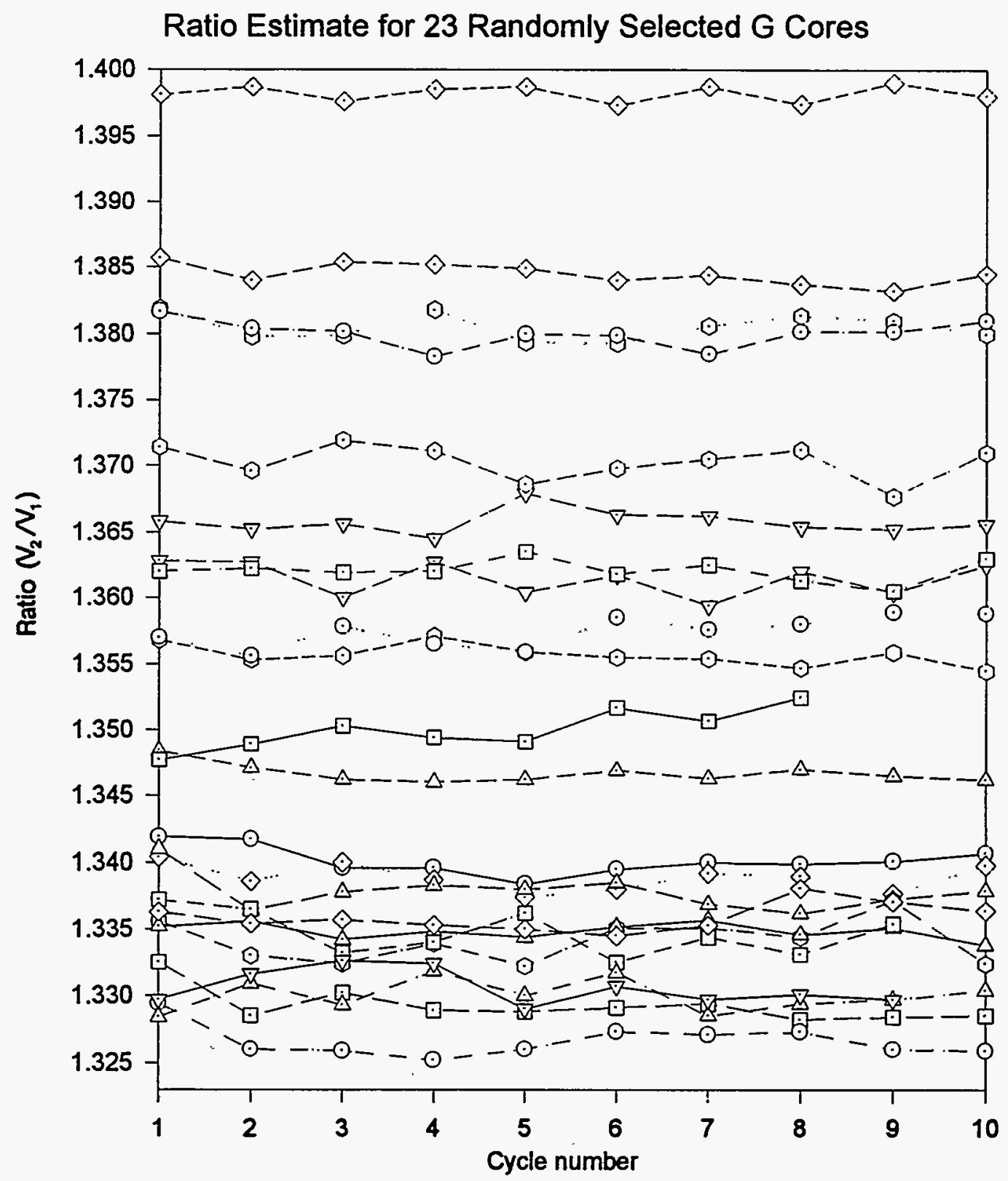

Figure 4.2. Ratio $\left(V_{2} / V_{1}\right)$ estimate as a function of cycle number. The $23 \mathrm{G}$ series cores were randomly selected. The ratio estimate shows no trend through a test and is consistent from cycle to cycle. 


\section{GRAPHIC RESULTS AND DISCUSSION}

\subsection{GRAPHIC RESULTS}

Data from the gas pycnometer testing are reported in Appendix B, in four tables: Table B.3: Y2 Series Data; Table B.4: G Series Data; Table B.5: P Series Data; and Table B.6: Re-Tested Core Data. Each table is accompanied by a key that explains the meaning of the column headings. Table B.2 (Key to Condition Codes) describes column (a) in the G and P series data tables. The code is simply a report of observations made about lithologic characteristics of the samples and is not used to modify any data. All parameters are reported with depth along the borehole to coincide with core logs. Conversion to real depth is approximated by depth times cos $\left(45^{\circ}\right)$.

Trends in the estimated parameters with depth are best recognized graphically, and the data are presented in this format on the following pages. The first parameter to be calculated is grain density $\left(\rho_{g}\right)\left(g / \mathrm{cm}^{3}\right)$, which is the ratio of the oven-dry weight of a core sample to the volume of solids estimated by the pycnometer. Figure 5.1 shows the trend in grain density with depth in the DSB. Both the $P$ series and $G$ series are included. The data for this figure are taken from Tables B.4 and B.5. The volume of solid was changed for one core sample [p33, see Table B.5, column (f)]. The sample was initially determined to contain $289.7 \mathrm{~cm}^{3}$ of solids, which was increased to $302.6 \mathrm{~cm}^{3}$ as a result of the re-test. The original estimate of grain density for this sample was observed as an anomalous data point in Figure 5.1, and the new value more closely agrees with adjacent values.

Bulk volume of the samples has also been measured. Bulk density $\left(\rho_{b}\right)\left(\mathrm{g} / \mathrm{cm}^{3}\right)$ is calculated as the ratio of oven-dry weight to bulk volume. After determination of grain density and bulk density, porosity $\phi\left(\mathrm{cm}^{3} / \mathrm{cm}^{3}\right)$ can be calculated using Equation (1). Figure 5.2 illustrates the trend in porosity and bulk density with depth in the DSB. Both P and G series samples are shown. The data are taken from Tables B.4 and B.5.

Volumetric water content can be calculated from gravimetric water content using Equation (11):

$$
\theta=w\left(\frac{\rho_{b}}{\rho_{w}}\right)
$$

where:

$$
\rho_{w}=\text { water density }\left(\mathrm{g} / \mathrm{cm}^{3}\right) \text {. }
$$

The density of water is assumed to equal $1.0\left(\mathrm{~g} / \mathrm{cm}^{3}\right)$. Figure 5.3 shows volumetric water content with depth in the DSB.

The $\mathrm{Y} 2$ series core was processed in the same way as the $\mathrm{P}$ and $\mathrm{G}$ series core. Grain density for the $\mathrm{Y} 2$ series core is shown in Figure 5.4, and porosity and bulk density for $\mathrm{Y} 2$ series core is illustrated in Figure 5.5.

\subsubsection{Intrinsic Permeability}

An estimate of intrinsic permeability has been made for the core samples. The Kozeny-Carman equation (de Marsily, 1986) is an empirical formulation that relates powers of pore surface area and porosity to permeability. This equation is: 


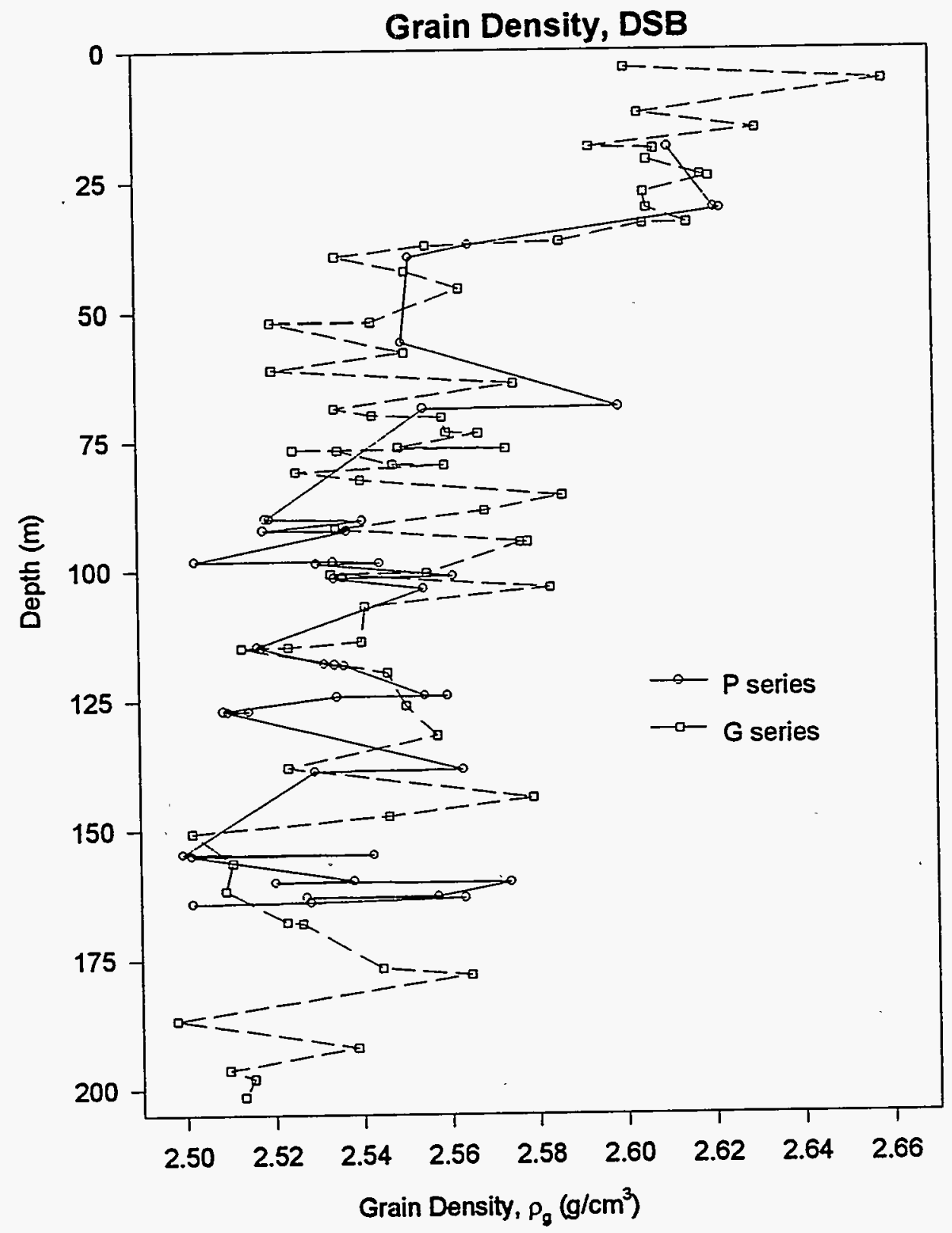

Figure 5.1. Grain density with depth in the DSB. Both $P$ and $G$ series are shown. 


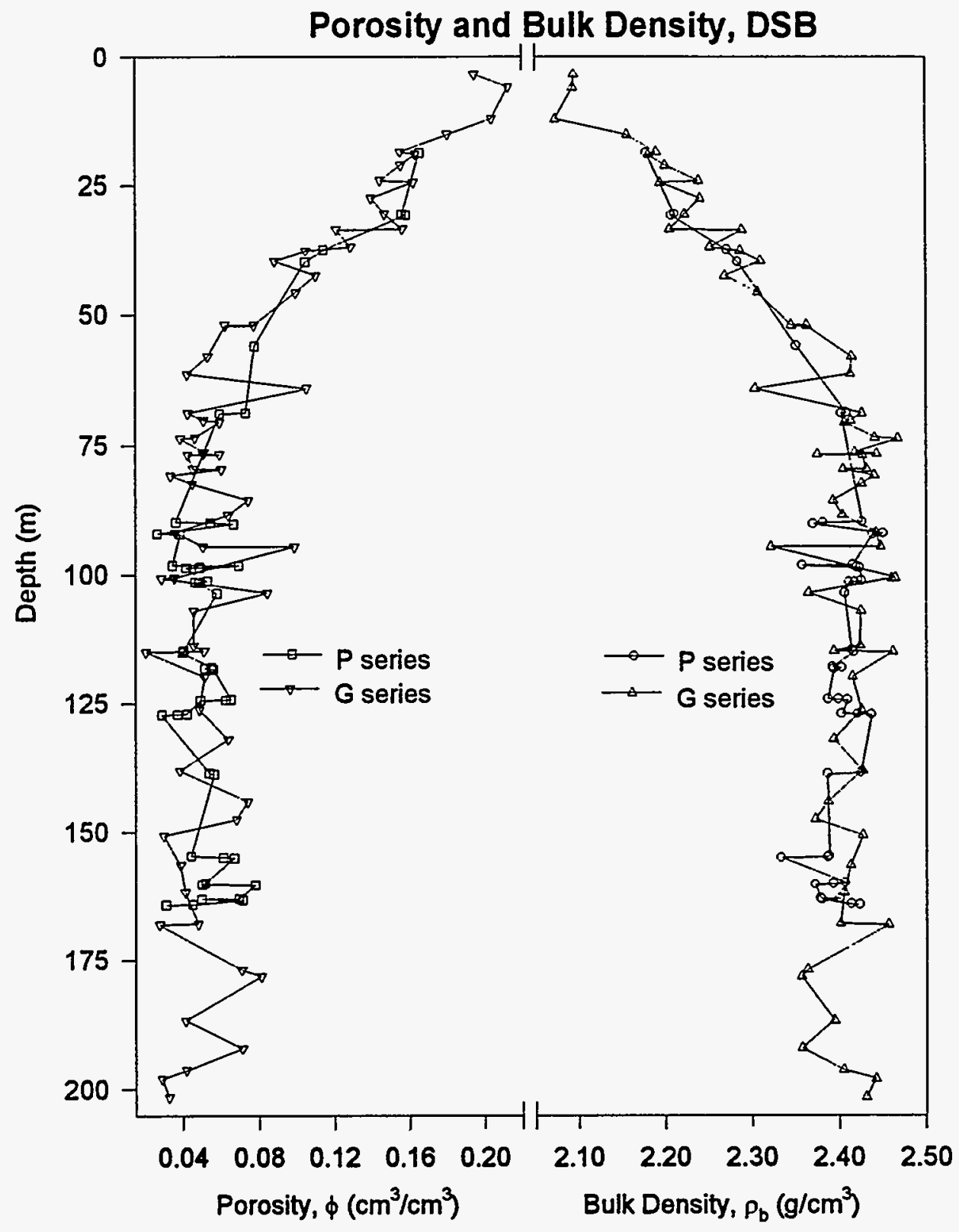

Figure 5.2. Porosity and bulk density with depth in the DSB. Both P and G series samples are shown. 


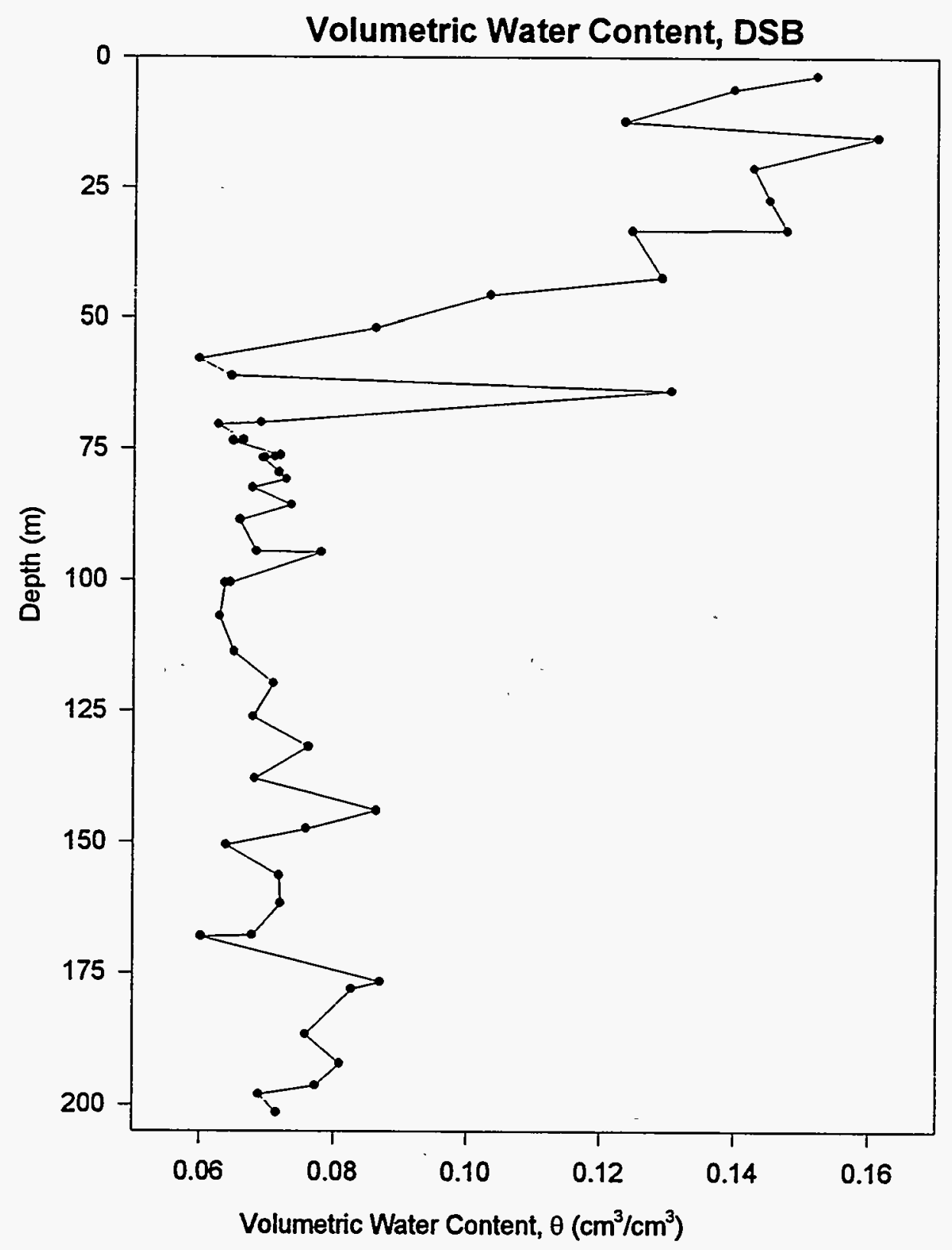

Figure 5.3. Volumetric water content with depth in the DSB. This parameter is calculated from gravimetric water content and bulk density of $\mathbf{G}$ series core. 


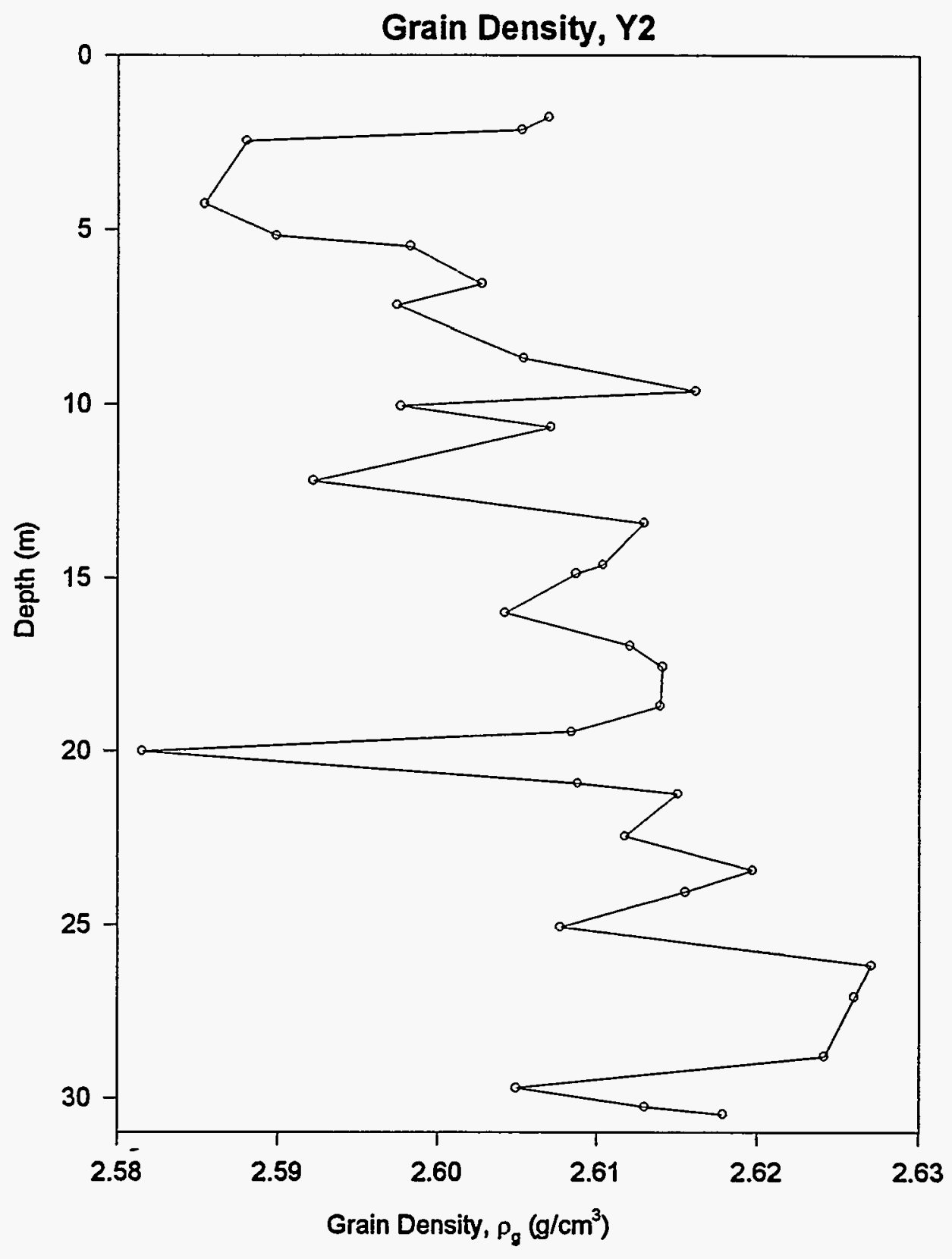

Figure 5.4. Grain density with depth in the Y2 borehole. 


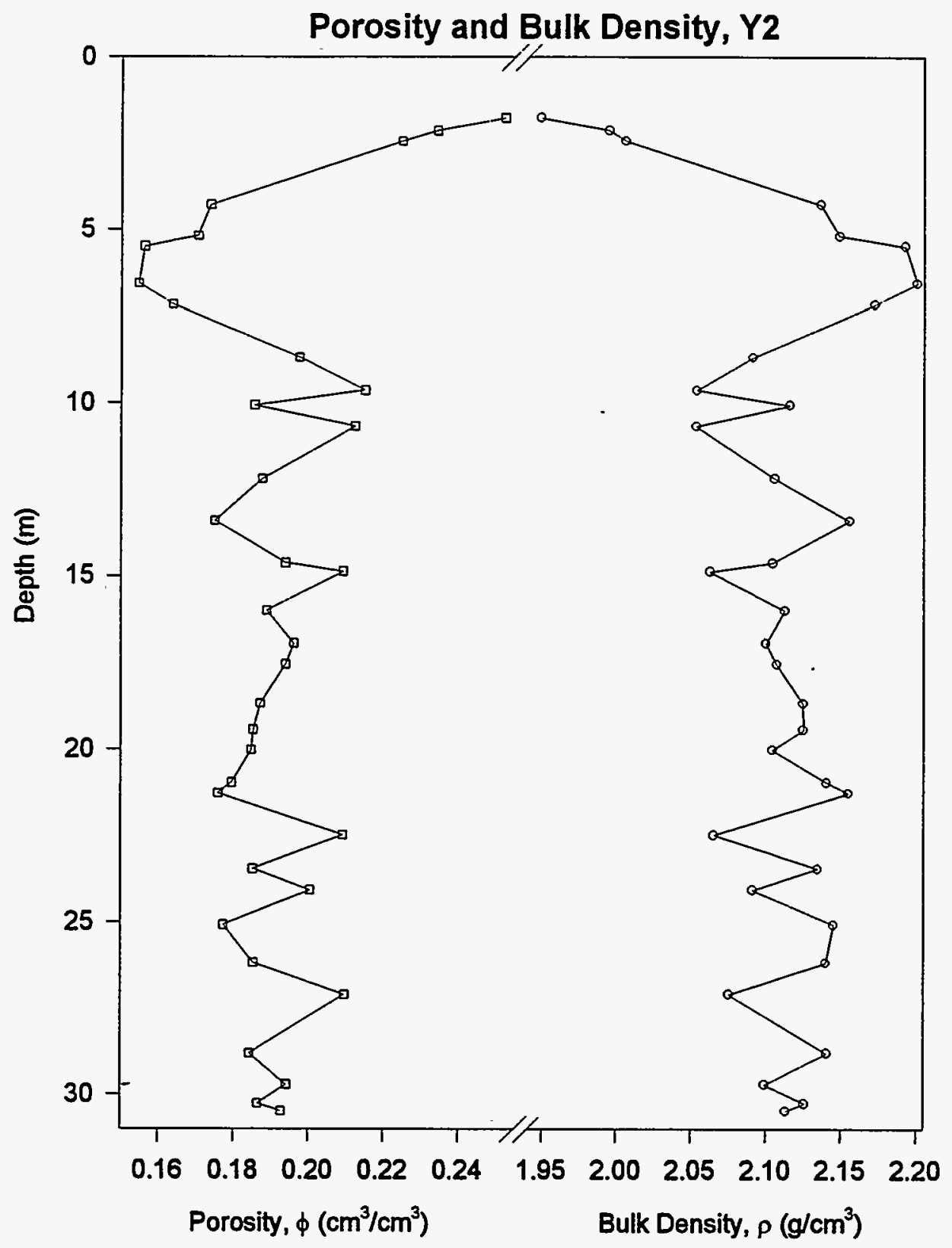

Figure 5.5. Porosity and bulk density with depth in the Y2 borehole. 


$$
k=\frac{\phi^{3}}{5 S^{2}(1-\phi)^{2}}
$$

where:

$$
\begin{aligned}
& \mathrm{S}=\text { pore surface area per unit volume of solid }\left(\mathrm{cm}^{2} / \mathrm{cm}^{3}\right) \text {, and } \\
& \mathrm{k}=\text { permeability }\left(\mathrm{cm}^{2}\right) .
\end{aligned}
$$

The permeability of $G$ and $P$ series core (Tables B.4 and B.5) is reported with the units of $\left(\mathrm{m}^{2}\right.$ ) and is calculated using a mean pore surface area of $3.5 \times 10^{4} \mathrm{~cm}^{2} / \mathrm{g}$ and a grain density of $2.51 \mathrm{~g} / \mathrm{cm}^{3}$. These values are reported as the average gravimetric pore surface area and skeletal (grain) density of the medium size core segments in Rasmussen et al. (1990, Tables 4 and 3, respectively).

The pore surface area is defined as the interfacial area between the wetting fluid and the rock matrix, obtained using the mercury intrusion method. A brief description of this method and its assumptions follows (see Rasmussen et al., 1990). A sample is placed in a chamber that is evacuated and filled with mercury. A commercial device designed to perform the analysis is used (Micromeritics PoreSizer 9320). The volume of mercury intruded into the sample is recorded by monitoring the change of mercury volume in a reservoir. The mercury is intruded in pressure increments up to $175 \mathrm{MPa}$. The applied pressure is used to determine a pore diameter by employing capillary theory. The total work expended for each pressure increment is converted to pore surface area. This is accomplished by assuming a constant contact angle and surface tension of the mercury. The mean value given above is reported with a coefficient of variation of $65 \%$. The pore surface area so measured ranged in value from $1960 \mathrm{~m}^{2} / \mathrm{kg}$ to $16,510 \mathrm{~m}^{2} / \mathrm{kg}$.

Included in the analysis of Rasmussen et al. (1990) was the determination of pore surface area for 12 Y2 core samples. These data are included in Table 5.1 with their sample ID, depth along the borehole, and pore surface area on a gravimetric basis. Pore surface area is converted to a volume basis using the average grain density of $\mathrm{Y} 2$ core determined with the gas pycnometer $(2.61$ $\mathrm{g} / \mathrm{cm}^{3}$ ). An average volumetric pore surface area for $Y 2$ core is $3,321 \mathrm{~cm}^{2} / \mathrm{cm}^{3}$, with a standard deviation of $798 \mathrm{~cm}^{2} / \mathrm{cm}^{3}$, was computed by excluding sample JE (see Table 5.1). This average value and porosity determined by the gas pycnometer was used to calculate the permeability reported in Table B.3. The intrinsic permeability of borehole Y2 has also been determined in-situ by the air permeability method (Guzman, 1994). The arithmetic average of in-situ tests on $50 \mathrm{~cm}$ intervals is compared to the Kozeny-Carman permeability in Figure 5.6.

\subsection{DISCUSSION}

The grain density illustrated in Figure 5.1 for the DSB ranges in value from 2.50 to $2.66 \mathrm{~g} / \mathrm{cm}^{3}$, and there is a trend toward lower grain density with depth. The figure indicates a shift to lower density near the $30 \mathrm{~m}$ depth. The maximum difference in adjacent samples is approximately 0.06 $\mathrm{g} / \mathrm{cm}^{3}$, but averages closer to $0.02 \mathrm{~g} / \mathrm{cm}^{3}$. The variability in grain density for $Y 2$ samples (see Figure 5.4) is much lower. The range is from 2.58 to $2.63 \mathrm{~g} / \mathrm{cm}^{3}$, and there is a slight increase in grain density with depth. The maximum difference in adjacent samples is approximately $0.03 \mathrm{~g} / \mathrm{cm}^{3}$ (at $20 \mathrm{~m}$ ), but averages closer to $0.01 \mathrm{~g} / \mathrm{cm}^{3}$. 
Table 5.1. Pore Surface Area for Y2 Core Reported by Rasmussen et al. (1990).

\begin{tabular}{|c|c|r|r|}
\hline $\begin{array}{c}\text { Sample } \\
\text { ID }\end{array}$ & $\begin{array}{c}\text { Depth } \\
(\mathrm{m})\end{array}$ & $\begin{array}{r}\text { Pore Area } \\
\left(\mathrm{m}^{2} / \mathrm{kg}\right)\end{array}$ & $\begin{array}{r}\text { Pore Area } \\
\left(\mathrm{cm}^{2} / \mathrm{cm}^{3}\right)\end{array}$ \\
\hline \hline JB & 1.8 & 4,051 & 105,731 \\
\hline JC & 3.3 & 3,429 & 89,497 \\
\hline JD & 4.1 & 5,364 & 140,000 \\
\hline JE$^{*}$ & 6.2 & 16,160 & 421,776 \\
\hline JF & 9.3 & 2,291 & 59,765 \\
\hline JG & 12.3 & 3,286 & 85,765 \\
\hline JH & 15.3 & 3,077 & 80,310 \\
\hline JJ & 18.5 & 2,916 & 76,108 \\
\hline JK & 21.3 & 2,819 & 73,576 \\
\hline JM & 24.5 & 3,570 & 93,177 \\
\hline JN & 27.3 & 3,222 & 84,094 \\
\hline JP & 30.3 & 2,500 & 65,250 \\
\hline
\end{tabular}

* excluded from average pore surface area calculation

The porosity illustrated in Figure 5.2 for the DSB ranges from $0.21 \mathrm{~cm}^{3} / \mathrm{cm}^{3}$ near the surface to $0.02 \mathrm{~cm}^{3} / \mathrm{cm}^{3}$ at-depth. The porosity averages around $0.05 \mathrm{~cm}^{3} / \mathrm{cm}^{3}$ in the lower $2 / 3$ of the borehole. It is this low porosity that is used to explain the extended drying times required for the gravimetric analysis. Figure 5.2 also shows bulk density with depth, in the range from 2.07 to 2.47 $\mathrm{g} / \mathrm{cm}^{3}$. Both parameters show remarkable consistency in trend with depth. The porosity and bulk density for Y2 samples again show a smaller range and lower variability from sample to sample. The porosity in Y2 initially decreases with depth away from the surface and averages $0.19 \mathrm{~cm}^{3} / \mathrm{cm}^{3}$ over most of the borehole. Bulk density shows the opposite near-surface trend and averages 2.11 $\mathrm{g} / \mathrm{cm}^{3}$. The Y2 samples were obtained from the same lithologic unit that occurs in the upper 30 $\mathrm{m}$ of the DSB. The parameters obtained over those depths in the DSB show close agreement to those obtained from Y2. The proximity and similar elevation of the two wellheads support this finding.

The volumetric water content illustrated in Figure 5.3 shows a decrease with depth near the surface and a relatively constant (or slightly increasing) value over the lower $2 / 3$ of the borehole. 


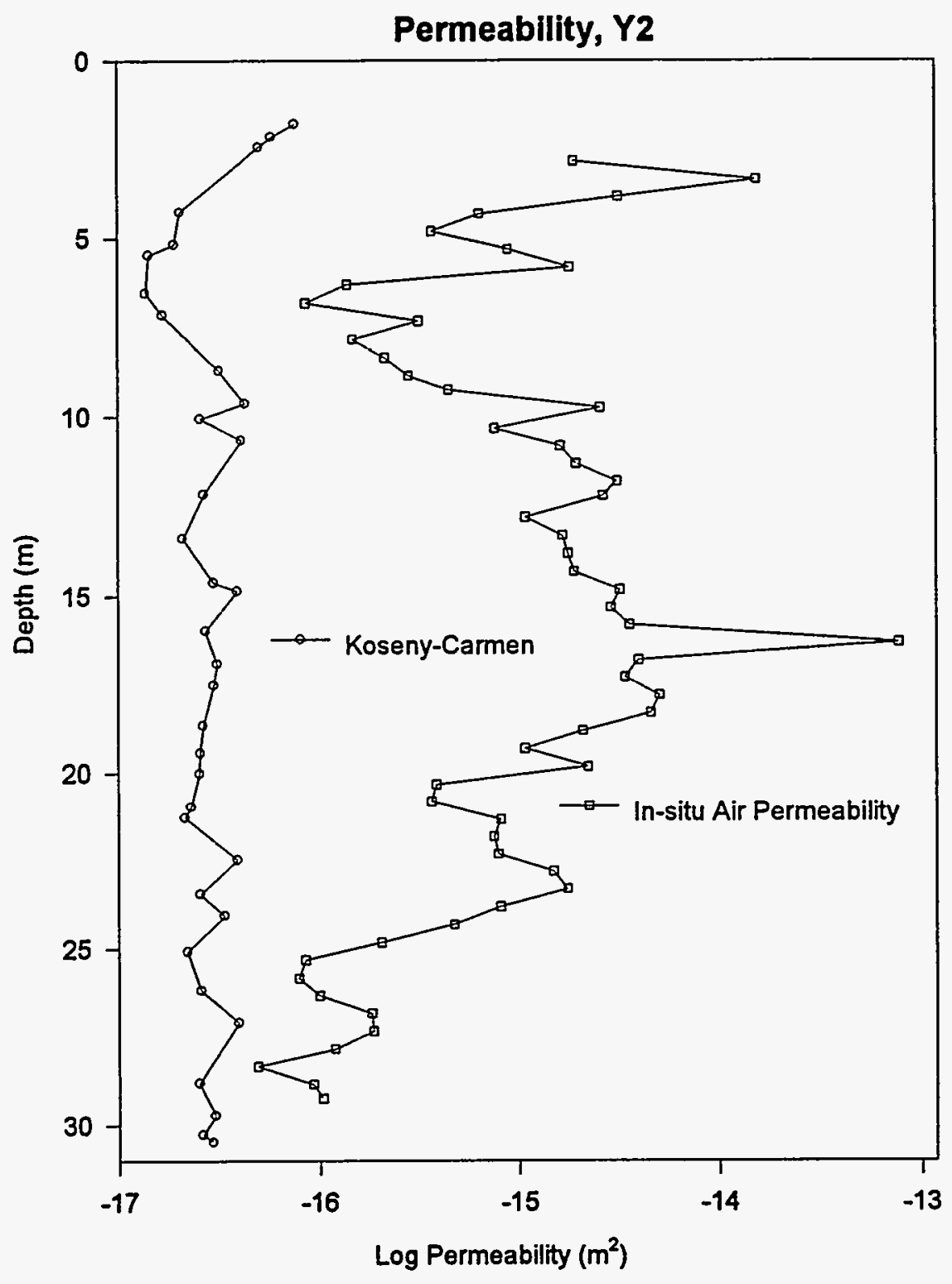

Figure 5.6. Intrinsic permeability with depth in Y2. There appears to be a similar trend between in-situ air permeability estimates (Guzman, 1994), and Kozeny-Carman permeability estimates based on gas pycnometer porosity, in the low permeability range $\left(10^{-17} \mathrm{~m}^{2}\right.$ to $\left.10^{-16} \mathrm{~m}^{2}\right)$. 
As was mentioned previously in the gravimetric analysis, the spike at $65 \mathrm{~m}$ represents a sample obtained immediately below a wet fracture. The fracture aperture (approximately $20 \mathrm{~cm}$ ) was large enough to contain coarse sand and fine gravel in significant quantities; nearly 0.5 liters was retrieved from the core barrel. The sediment was remarkably devoid of clay, and some of the larger rock fragments had the rounded appearance of water-washed pebbles, although some rounding can occur as a result of the drilling. The DSB was drilled in a stream bed that is dry most of the year. Precipitation was recorded at near-record levels over most of central Arizona immediately prior to and during the drilling. The stream flowed with water continuously during this time. The decrease in water content with depth away from the surface could, therefore, be interpreted as a wetting front. The porosity averages $20 \mathrm{~cm}^{3} / \mathrm{cm}^{3}$ over this depth range.

The permeabilities compared in Figure 5.6 for the Y2 borehole show interesting agreement in trend in the $10^{-17}$ to $10^{-16} \mathrm{~m}^{2}$ range. The much larger permeabilities (from approximately $10^{-15}$ to $10^{-13} \mathrm{~m}^{2}$ ) predicted by the in-situ air permeability method are associated with fractured zones (Guzman, 1995). The porosity and pore surface area based Kozeny-Carman permeability is only applicable to matrix permeability and is two orders of magnitude less overall. This implies that the air permeability method is a more accurate and conservative estimate of permeability than that of Kozeny-Carman in fractured tuffs.

A hypothesis was formulated prior to core testing that there would be some noticeable difference in grain density (and therefore bulk density and porosity) between cut samples and uncut samples in the DSB. The assumption was that weathering and secondary mineralization would alter tuff material adjacent to a fracture face. Most of the $G$ series are uncut samples, many of which were retrieved with obvious natural fractures bounding them, while the $P$ series are all cut samples, representing matrix material away from a fracture. There is no apparent difference in these subsets, as is most evident when comparing the $P$ series and the $G$ series in Figure 5.1.

Also reported in the data tables is the coefficient of variation (CV) in solid volume for a test sequence. This parameter is simply the ratio of the standard deviation in solid volume to the average solid volume (multiplied by 100 ) computed over the number of cycles indicated. The maximum $\mathrm{CV}$ in any test sequence was $1.59 \%$, with an average of $0.7 \%$ for all tests.

\subsubsection{Re-Tested Core Samples}

The pycnometer was used to re-test 22 core samples and test three additional $P$ series samples. Most of the re-tested core was selected randomly to cover the length of each borehole. Several samples were selected based on lack of agreement in grain density with adjacent samples. The retested data are reported in Table B.6. The solid volume is also included in Tables B.3, B.4, and B.5 for comparison purposes. The magnitude of the average difference in solid volume between the original test and the re-test of 21 of these samples is $1.6 \mathrm{~cm}^{3}$, with a standard deviation of 1.3 $\mathrm{cm}^{3}$. The re-tested values were not consistently higher or lower than the original data. The error computed for the calibration of the instrument was $2.2 \mathrm{~cm}^{3}$, and the difference between the two tests is consistent with this. Sample p33 could have had an incorrect original estimate as a result of operator error. The close agreement in solid volume implies acceptable instrument precision.

Also reported for the re-tested core data (see Table B.6) is the solid volume predicted by excluding the first cycle of each test series and computing solid volume from the average of the remaining cycles. This is indicated as (N-1) and appears on the second line of data for each sample. This was done because it was observed that the first ratio estimate was greater than the second estimate for many of the tests illustrated in Figure 4.2. In most cases, exclusion of the first ratio estimate results in a slightly greater estimate of solid volume and a slightly lower coefficient of variation for the test. However, there is no physically meaningful difference in the parameters 
estimated using either method, and all cycles of each test were used to calculate grain density, bulk density, porosity, and permeability. It is speculated that the first estimate suffers from the effect of opening the system to insert a new sample. The effect could be the result of water vapor in the laboratory air that enters the system, but is not investigated further. 


\section{CONCLUSIONS}

Gas pycnometry is a simple and accurate technique for measuring the solid volume of porous material. It is especially useful when applied to material that has low matrix permeability and low porosity, as helium is able to enter the smallest accessible pores in a short time period. The pycnometer should be constructed with materials that are poor conductors of heat and do not change shape when operating pressures are applied. The pycnometer should be designed such that the sample chamber can accommodate large samples of variable size and shape. The optimal configuration is one in which the sample bulk volume is almost as large as the sample chamber. This is because the relatively constant random error becomes a smaller percent of the estimate as the solid volume increases. The inside diameter of the sample chamber should be just slightly larger than the outside diameter of the core sample, and the length of the core sample should approach the internal length of the sample chamber. The temperature of the system should be measured and incorporated into the analysis. The reasons are that theory requires it, and it is a simple way to monitor system conditions. In this way, operation of the instrument in a regime not covered in the calibration is easily recognized.

\subsection{FUTURE WORK}

The operation of the instrument could be enhanced with the use of automatic valves and automated data collection. A sample could be inserted into the chamber and an automated sequence initiated that would result in solid volume estimation to specified convergence criteria. This level of automation is used in some of the commercial devices.

A calibration could also be performed with water-saturated helium, and the device could be used to estimate volume of solid and liquid in a partially saturated core sample. This type of calibration would also be required if the device were used to estimate trapped air. The device is ruggedly constructed and could be employed near the borehole during drilling to estimate volumetric water content of freshly retrieved tuff samples. 


\section{REFERENCES}

American Society for Testing and Materials, ASTM C 177(k), Annual Book of ASTM Standards, Vol. 08.01, Plastics (I): C177 - D2343, 1993.

Analog Devices, Solid State Temperature Sensor, AD590 Application Note, Analog Devices, P.O. Box 280, Norwood, Massachusetts 02062 (Omega Catalog, p. F-15.), 1993.

Beckman Instruments, Inc., Model 930 Air Comparison Pycnometer, Data Sheet 7345A, Beckman Instruments, Inc., Scientific Instruments Division, P.O. Box C-19600, Irvine, California 92713, 1981.

Bielders, C.L., L.W. De Backer, and B. Delvaux, Particle Density of Volcanic Soils as Measured with a Gas Pycnometer, Soil Sci. Soc. Am. J., 54, pp. 822-826, 1990.

Blake, G.R. and K.H. Hartage, Particle Density, in Klute, A. (Ed). Methods of Soil Analysis, Part I. Agronomy Monograph No. 9, $2^{\text {nd }}$ ed., Am. Soc. Agr., p. 377, 1986.

Campbell Scientific, Inc., 21XMicrologger Overview, Campbell Scientific, Inc., P.O.Box 551, Logan, Utah 84321, 1990.

Danielson, R.E. and P.L. Sutherland, Porosity, in Klute, A. (Ed.) Methods of Soil Analysis, Part I. Agronomy Monograph No. 9, $2^{\text {nd }}$ Ed., Am. Soc. Agr., p. 443, 1986.

Davidson, G.R., Geochemical and isotopic investigation of the rate and pathway of fluid flow in partially-welded fractured unsaturated tuff, Ph.D. Dissertation, University of Arizona, 208 p, 1995.

DeBacker, L.W., The Measurement of Entrapped Gas in the Study of Unsaturated Flow Phenomena, Water Resources Research, 3:1, pp. 245-249, 1967.

de Marsily, G., Quantitative Hydrogeology, Groundwater Hydrology for Engineers, Academic Press, San Diego, California, p. 62, 1986.

Druck, Inc., PDCR 930, 15 psia, 10V Pressure Transducer, Product Information Sheet, Druck, Inc., 4 Dunham Drive, New Fairfield, Connecticut 06812, 1994.

Gardner, W.R., Water Content, in Klute, A. (Ed). Methods of Soil Analysis, Part I. Agronomy Monograph No. $9,2^{\text {nd }}$ Ed., Am. Soc. Agr., p. 377, 1986.

Guzman, A.G., Air Permeability Tests and Their Interpretation in Partially Saturated Fractured Tuffs, Ph.D. Dissertation (in progress), Dept. of Hydrology and Water Resources, The University of Arizona, Tucson, Arizona, 1995.

Halliday, D. and R. Resnick, Fundamentals of Physics, $2^{\text {nd }}$ Ed., John Wiley \& Sons, Chapter 20, 1981.

Hopmans, J.W. and J.H. Dane, Temperature Dependence of Soil Water Retention Curves, Soil Sci. Soc. Am. J., 50, pp. 562-567, 1986. 
International Plastics Selector, Inc., PVC Material Properties, p. B-846, 1980.

Joyce, R.J., Theory and Selected Applications of the Air Comparison Pycnometer, Conf. Preprint: Inst. Soc. Am., PN 79-LA61, 1961.

Kummer, F.A. and A.W. Cooper, The Dynamic Properties of Soils: IX. Soil Porosity Determinations with the Air Pressure Pycnometer as Compared with the Tension Method, Ag. Eng., Jan., pp. 21-23, 1945.

Leamer, R.W. and B.T. Shaw, A Simple Apparatus for Measuring Non-Capillary Porosity on an Extensive Scale, Amer. Soc. Ag. Jour., 33, pp. 1003-1008, 1941.

LEMO, Inc., Series 03 Underwater Connectors, Product Information, LEMO, Inc., P.O. Box 11488, Santa Rosa, California 95406, 1993.

Matheson Gas Data Book, 6th Ed., Matheson Gas, 711 p., 1980.

Micromeritics Instrument Corporation, MultiVolume 1305 and :ACCUPYC 1330, Product Information Sheet, One Micromeritics Drive, Norcross, Georgia 30093-1877, 1993.

Ohanian, H.C., Physics, Norton \& Co., New York, 1012 p., 1985.

Page, J.B., Advantages of the Pressure Pycnometer for Measuring the Pore Space in Soils, Soil Sci. Soc. Am. Proc., 12, pp. 81-84, 1947.

PRINCO Instruments, Inc., Instruction Booklet: Fortin Type Mercurial Barometer, User Data Schedules, PRINCO Instruments, Inc., 1020 Ind. Hwy., Southampton, Pennsylvania 18966, 1983.

Rasmussen, T.D., D. Evans, P.J. Sheets, and J.H. Blanford, Unsaturated Fractured Rock Characterization Methods and Data Sets at the Apache Leap Tuff Site, NUREG/CR-5596, 125 p., August 1990.

Russell, M.B., A Simplified Air-Pycnometer for Field Use, Soil Sci. Soc. Proc., 14, pp. 73-76, 1949.

Stevens, A.B., A New Device for Determining Porosity by the Gas-Expansion Method, Petrol. Tech., Published by Am. Inst. Min. and Metal. Engrs., Technical Publication No. 1061, 5 p. 1938.

Stonestrom, D.A. and J. Rubin, Water Content Dependence of Trapped Air in Two Soils, Water Resources Research, 25:9, pp. 1947-1958, 1989.

Torstensson, G. and S. Eriksson, A New Method for Determining the Porosity of the Soil, Soil Sci., 42:6, pp. 405-417, 1936.

Visser, W.C., Pore Space Determination as a Field Method, Soil Sci., 44:6, pp 467-479, 1938. 


\section{APPENDIX A: GENERAL INFORMATION}

Table A.1: Datalogger Program

Table A.2: Calibration Sphere Measurements 


\section{Table A.1: Datalogger Operating Program}

This program operates a Campbell Scientific 21X Micrologger and automatically collects data from the pressure and temperature sensors as described in Section 3.2 (Gas Pycnometer Calibration).

Table 1 Programs

01: 0.2 Sec. Execution Interval

01: P6 Full Bridge

$\begin{array}{ll}\text { 01: } 1 & \text { Rep } \\ \text { 02: } 4 & 500 \mathrm{mV} \text { slow Range } \\ \text { 03: } 2 & \text { IN Chan } \\ \text { 04: } 1 & \text { Excite all reps w/EXchan } 1 \\ \text { 05: } 5000 & \text { mV Excitation } \\ 06: 2 & \text { Loc [:P-RES ] } \\ \text { 07: } 10.157 & \text { Mult } \\ \text { 08: }-3.1406 & \text { Offset }\end{array}$

02: P6 Full Bridge

01: $1 \quad$ Rep

02: $4 \quad 500 \mathrm{mV}$ slow Range

03: 3 IN Chan

04: $1 \quad$ Excite all reps w/EXchan 1

05: $5000 \quad m V$ Excitation

06: 3 Loc [:P-SAMP ]

07: 10.188 Mult

08: -4.5628 Offset

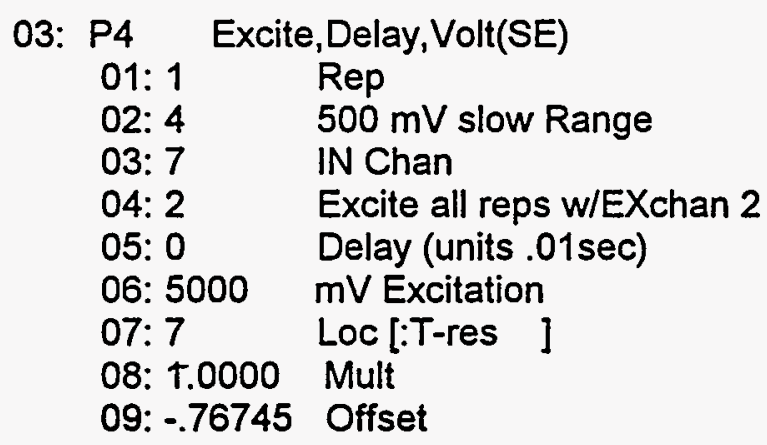


04: P4 Excite,Delay, Volt(SE)

01: 1 Rep

02: $4 \quad 500 \mathrm{mV}$ slow Range

03: 8 IN Chan

04: 2 Excite all reps w/EXchan 2

05: 0 Delay (units .01sec)

06: $5000 \quad m V$ Excitation

07: $8 \quad$ Loc [:T-samp ]

08: 1.0000 Mult

09: 2.4145 Offset

05: P91 If Flag

01: $11 \quad 1$ is set

02: 30 Then Do

06: $P 32 \quad Z=Z+1$

01: 28 Z Loc :

07: P89 If $X \Leftrightarrow \Rightarrow F$

01: $28 \quad X$ LoC

02: $3 \quad>=$

03: $10 \quad F$

04: 10 Set high Flag 0 (output)

08: P77 Real Time

01: 0111 Day,Hour-Minute,Seconds

09: P78 Resolution

01: 1 High Resolution

10: P71 Average

01: 2 Reps

02: 2 LOC P-RES

11: P71 Average

01: 2 Reps

02: 7 Loc T-res

12: P95 End

13: $P 89$ If $X<=>F$

$\begin{array}{ll}\text { 01: } 28 & X \text { Loc } \\ \text { 02: } 3 & >= \\ \text { 03: } 10 & F \\ \text { 04: } 30 & \text { Then Do }\end{array}$

14: P86 Do

01: $21 \quad$ Set low Flag 1 
15: $P 30 \quad Z=F$

01: $0 \quad F$

02: $28 \quad$ Z LoC:

16: P95 End

17: $P \quad$ End Table 1

Input Location Assignments (with comments):

Key: $\quad T=$ Table Number $\quad E=E n t r y$ Number

$L=$ Location Number

T: E: L:

1: 1: 2: Loc [:P-RES ]

1: 2: 3: LOC [:P-SAMP ]

1: 3: 7: Loc [:T-res ]

1: 4: 8: Loc [:T-samp ]

1: 6: 28: Z LOC:

1: 15: 28: Z Loc: 


\section{Table A.2: Calibration Sphere Measurements}

The diameter of each calibration sphere has been measured on five different axes and is tabulated below. The spheres are made from a cast phenolic resin manufactured by the Belgian Aramith Co. They are precision ground to perfect spheres (product information sheet), are assumed to have zero connected porosity, and have a low heat capacity when compared to metallic material.

The diameter measurement is in inches.

\begin{tabular}{|c|c|c|c|c|c|c|c|c|}
\hline $\begin{array}{c}\text { BaLl } \\
\text { ID }\end{array}$ & $M$ & B1 & B2 & C1 & C2 & AVG & Std Dev & $\begin{array}{l}\text { Vol } \\
\text { (cm3) }\end{array}$ \\
\hline $\begin{array}{l}C \\
1 \\
2 \\
3 \\
4 \\
5 \\
6 \\
7 \\
8 \\
9 \\
10\end{array}$ & $\begin{array}{l}1.500 \\
1.499 \\
1.496 \\
1.495 \\
1.498 \\
1.499 \\
1.500 \\
1.503 \\
1.501 \\
1.498 \\
1.500\end{array}$ & $\begin{array}{l}1.498 \\
1.497 \\
1.494 \\
1.493 \\
1.497 \\
1.499 \\
1.498 \\
1.500 \\
1.498 \\
1.497 \\
1.498\end{array}$ & $\begin{array}{l}1.498 \\
1.498 \\
1.494 \\
1.492 \\
1.497 \\
1.497 \\
1.496 \\
1.501 \\
1.497 \\
1.496 \\
1.498\end{array}$ & $\begin{array}{l}1.496 \\
1.497 \\
1.494 \\
1.492 \\
1.497 \\
1.497 \\
1.498 \\
1.500 \\
1.499 \\
1.497 \\
1.498\end{array}$ & $\begin{array}{l}1.497 \\
1.497 \\
1.494 \\
1.492 \\
1.497 \\
1.498 \\
1.498 \\
1.500 \\
1.499 \\
1.497 \\
1.498\end{array}$ & $\begin{array}{l}1.498 \\
1.498 \\
1.494 \\
1.493 \\
1.497 \\
1.498 \\
1.498 \\
1.501 \\
1.499 \\
1.497 \\
1.498\end{array}$ & $\begin{array}{l}0.002 \\
0.001 \\
0.001 \\
0.001 \\
0.001 \\
0.001 \\
0.001 \\
0.001 \\
0.001 \\
0.001 \\
0.001\end{array}$ & $\begin{array}{l}28.820 \\
28.814 \\
28.635 \\
28.532 \\
28.785 \\
28.838 \\
28.838 \\
29.005 \\
28.889 \\
28.783 \\
28.860\end{array}$ \\
\hline $\begin{array}{r}C X \\
1 X \\
2 X \\
3 X \\
4 X \\
5 X \\
6 X \\
7 X \\
8 X \\
9 X \\
10 X\end{array}$ & $\begin{array}{l}1.494 \\
1.503 \\
1.495 \\
1.499 \\
1.500 \\
1.497 \\
1.492 \\
1.497 \\
1.500 \\
1.501 \\
1.499\end{array}$ & $\begin{array}{l}1.492 \\
1.501 \\
1.492 \\
1.498 \\
1.500 \\
1.494 \\
1.490 \\
1.496 \\
1.497 \\
1.500 \\
1.498\end{array}$ & $\begin{array}{l}1.491 \\
1.500 \\
1.492 \\
1.498 \\
1.498 \\
1.495 \\
1.489 \\
1.496 \\
1.498 \\
1.499 \\
1.497\end{array}$ & $\begin{array}{l}1.492 \\
1.500 \\
1.493 \\
1.497 \\
1.499 \\
1.494 \\
1.490 \\
1.497 \\
1.497 \\
1.499 \\
1.497 \\
\text { Averag }\end{array}$ & $\begin{array}{l}1.491 \\
1.500 \\
1.493 \\
1.497 \\
1.498 \\
1.495 \\
1.489 \\
1.496 \\
1.498 \\
1.499 \\
1.498 \\
\text { Values= } \\
\text { Ld. Dev }=\end{array}$ & $\begin{array}{c}1.492 \\
1.501 \\
1.493 \\
1.498 \\
1.499 \\
1.495 \\
1.490 \\
1.496 \\
1.498 \\
1.499 \\
1.498 \\
\max = \\
1.497 \\
0.003\end{array}$ & $\begin{array}{r}0.001 \\
0.001 \\
0.001 \\
0.001 \\
0.001 \\
0.001 \\
0.001 \\
0.001 \\
0.001 \\
0.001 \\
0.001 \\
0.002 \\
0.001 \\
0.0002\end{array}$ & $\begin{array}{r}28.494 \\
28.998 \\
28.547 \\
28.840 \\
28.898 \\
28.663 \\
28.372 \\
28.745 \\
28.843 \\
28.911 \\
28.825 \\
28.769 \\
0.160\end{array}$ \\
\hline
\end{tabular}

Worst case calculation (see section 3.2):

Largest sphere diameter is 1.501 inches,

assume the average is mistakenly measured as 1.504 inches.

$\left(+0.003^{\prime \prime}\right.$ diameter $=\max$ std dev in diameter + micrometer uncertainty $)$

Volume Error $=1 / 6 \cdot \mathrm{pi} *\left(1.504^{3}-1.501^{3}\right)=0.0106 \mathrm{in}^{3}=0.174 \mathrm{~cm}^{3}$ 


\title{
APPENDIX B: DATA TABLES FOR ALRS TUFF
}

\author{
Table B.1: Gravimetric Water Content Data \\ Table B.2: Key To Core Physical Condition Codes \\ Table B.3: Y2 Series Data \\ Table B.4: G Series Data \\ Table B.5: P Series Data \\ Table B.6: Re-Tested Core Data
}


Table B.1: Gravimetric Water Content Data

Samples g1 - g53, ALRS-ASB-1, Jan. \& Feb., 1993

Weights:

WET DRY-1 DRY-2 DRY-3 DRY-4 DRY-5 SAMP DEPTH DEPTH (in field) 24-hrs 48-hrs 72-hrs 16-days 48-days$$
\text { (ft) }
$$

(g)

(g)

(g)

(g) (g)
Gravimetric Water Contents: $w=($ Wet Mass - Dry Mass $) /$ Dry Mass Vol

\begin{tabular}{|c|c|c|c|c|c|c|c|c|c|c|c|c|c|}
\hline$g 1$ & 11.4 & 3.46 & 664.9 & 620.1 & & 619.9 & 619.9 & 620.1 & 0.072 & 0.073 & 0.073 & 0.072 & 0.15 \\
\hline$g 2$ & 19.7 & 5.99 & 634.3 & 594.8 & 594.6 & 594.8 & 594.6 & 594.8 & 0.066 & 0.066 & 0.067 & 0.066 & 0.14 \\
\hline$g 3$ & 39.9 & 12.16 & 727.6 & 686.7 & & 686.5 & 686.7 & 686.8 & 0.060 & 0.060 & 0.060 & 0.059 & 0.12 \\
\hline$g 4$ & 49.9 & 15.19 & 704.6 & 656.0 & & 655.8 & 655.6 & 656.1 & 0.074 & 0.074 & 0.075 & 0.074 & 0.16 \\
\hline 95 & 69.4 & 21.14 & 717.4 & 674.0 & & 673.7 & 673.7 & 673.7 & 0.064 & 0.065 & 0.065 & 0.065 & 0.14 \\
\hline 96 & 89.8 & 27.36 & 1287.4 & 1210.2 & & 1209.6 & 1209.1 & 1209.5 & 0.064 & 0.064 & 0.065 & 0.064 & 0.15 \\
\hline$g 7$ & 109.0 & 33.22 & 857.3 & 803.9 & & 804.0 & 803.5 & 804.0 & 0.066 & 0.066 & 0.067 & 0.066 & 0.15 \\
\hline$g^{8}$ & 109.4 & 33.35 & 743.9 & 705.6 & 705.1 & 705.1 & 705.5 & 705.2 & 0.054 & 0.055 & 0.054 & 0.055 & 0.12 \\
\hline g9 & 139.1 & 42.38 & 643.0 & 609.9 & & 609.0 & 608.4 & 609.0 & 0.054 & 0.056 & 0.057 & 0.056 & 0.13 \\
\hline$g 10$ & 150.0 & 45.70 & 657.7 & 630.3 & & 630.0 & 629.5 & 629.6 & 0.043 & 0.044 & 0.045 & 0.045 & 0.10 \\
\hline$g 11$ & 150.3 & 45.81 & 626.8 & 596.0 & & 596.3 & 596.0 & 595.6 & 0.052 & 0.051 & 0.052 & 0.052 & \\
\hline$g 12$ & 170.6 & 51.98 & 1474.7 & 1424.8 & & 1423.5 & 1422.7 & 1423.4 & 0.035 & 0.036 & 0.037 & 0.036 & 0.09 \\
\hline $\mathrm{g} 13$ & 190.2 & 57.96 & 738.7 & 722.5 & & 721.7 & 720.9 & 721.3 & 0.022 & 0.024 & 0.025 & 0.024 & 0.06 \\
\hline$g 14$ & 201.0 & 61.25 & 745.8 & 729.5 & 728.0 & 727.5 & 726.4 & 726.5 & 0.022 & 0.025 & 0.027 & 0.027 & 0.06 \\
\hline$g 15$ & 210.1 & 64.04 & 775.1 & 734.8 & & 734.1 & 733.6 & 734.0 & 0.055 & 0.056 & 0.057 & 0.056 & 0.13 \\
\hline$g 16$ & 230.0 & 70.10 & 911.8 & 888.8 & & 887.3 & 886.5 & 886.7 & 0.026 & 0.028 & 0.029 & 0.028 & 0.07 \\
\hline$g 17$ & 231.2 & 70.47 & 746.6 & 729.2 & 728.1 & 728.3 & 727.7 & 727.9 & 0.024 & 0.025 & 0.026 & 0.026 & 0.06 \\
\hline$g 18$ & 241.0 & 73.46 & 1303.2 & 1271.9 & & 1270.1 & 1268.8 & 1269.5 & 0.025 & 0.026 & 0.027 & 0.027 & 0.07 \\
\hline g19 & 241.5 & 73.61 & 1353.7 & 1321.9 & & 1320.1 & 1319.1 & 1319.7 & 0.024 & 0.025 & 0.026 & 0.026 & 0.06 \\
\hline $\mathrm{g} 20$ & 250.3 & 76.29 & 717.6 & 698.8 & & 697.5 & 696.9 & 697.2 & 0.027 & 0.029 & 0.030 & 0.029 & 0.07 \\
\hline$g 21$ & 251.3 & 76.60 & 743.7 & 724.4 & & 723.7 & 722.7 & 722.8 & 0.027 & 0.028 & 0.029 & 0.029 & 0.07 \\
\hline g22 & 251.7 & 76.72 & 576.4 & 561.8 & & 560.7 & 560.0 & 560.7 & 0.026 & 0.028 & 0.029 & 0.028 & 0.07 \\
\hline$g 23$ & 252.0 & 76.81 & 1104.4 & 1077.4 & & 1075.8 & 1073.8 & 1074.7 & 0.025 & 0.027 & 0.028 & 0.028 & 0.07 \\
\hline$g 24$ & 261.0 & 79.55 & 1027.2 & 1000.1 & & 998.6 & 997.8 & 998.5 & 0.027 & 0.029 & 0.029 & 0.029 & 0.07 \\
\hline g25 & 261.3 & 79.64 & 518.7 & 504.7 & & 504.5 & 503.7 & 504.2 & 0.028 & 0.028 & 0.030 & 0.029 & 0.07 \\
\hline 926 & 265.3 & 80.86 & 1586.4 & 1546.5 & 1544.2 & 1542.1 & 1540.5 & 1541.2 & 0.026 & 0.029 & 0.030 & 0.029 & 0.07 \\
\hline
\end{tabular}

$\begin{array}{lllll}W-1 & W-3 & W-4 & W-5 & \mathrm{~cm} 3 \\ (\mathrm{~g} / \mathrm{g}) & (\mathrm{g} / \mathrm{g}) & (\mathrm{g} / \mathrm{g}) & (\mathrm{g} / \mathrm{g}) & \mathrm{cm} 3\end{array}$
W-1 W-3 W.C. 
Table B.1: Gravimetric Water Content Data - continued

Samples 91 - g53, ALRS-ASB-1, Jan. \& Feb., 1993

Weights:

Gravimetric Water Contents:

WET DRY-1 DRY-2 DRY-3 DRY-4 DRY-5

SAMP DEPTH DEPTH (in field) 24-hrs 48-hrs 72-hrs 16-days 48-days $w=($ Wet Mass - Dry Mass) / Dry Mass Vol

\begin{tabular}{|c|c|c|c|c|c|c|c|c|c|c|c|c|c|}
\hline $\begin{array}{l}\text { SAMP } \\
\text { ID }\end{array}$ & $\begin{array}{c}\text { DEPTH } \\
\text { (ft) }\end{array}$ & $\begin{array}{l}\text { DEPTH } \\
(\mathbf{m})\end{array}$ & $\begin{array}{l}\text { (in field) } \\
\text { (g) }\end{array}$ & $\begin{array}{c}\text { 24-hrs } \\
\text { (g) }\end{array}$ & $\begin{array}{l}\text { 48-hrs } \\
\text { (g) }\end{array}$ & $\begin{array}{l}\text { 72-hrs } \\
\text { (g) }\end{array}$ & $\begin{array}{c}\text { 16-days } \\
\text { (g) }\end{array}$ & $\begin{array}{l}\text { 48-days } \\
\text { (g) }\end{array}$ & $\begin{array}{l}W-1 \\
(g / g)\end{array}$ & $\begin{array}{l}W-3 \\
(g / g)\end{array}$ & $\begin{array}{l}W-4 \\
(g / g)\end{array}$ & $\begin{array}{l}W-5 \\
(g / g)\end{array}$ & $\frac{\mathrm{cm} 3}{\mathrm{~cm} 3}$ \\
\hline g27 & 270.6 & 82.46 & 722.3 & 705.9 & & 703.4 & 702.7 & 703.2 & 0.023 & 0.027 & 0.028 & 0.027 & 0.07 \\
\hline $\mathrm{g} 28$ & 281.3 & 85.74 & 1282.7 & 1247.9 & & 1245.5 & 1244.5 & 1244.9 & 0.028 & 0.030 & 0.031 & 0.030 & 0.07 \\
\hline g29 & 290.7 & 88.59 & 683.2 & 667.5 & & 665.4 & 665.0 & 665.2 & 0.024 & 0.027 & 0.027 & 0.027 & 0.07 \\
\hline $\mathrm{g} 30$ & 310.6 & 94.66 & 759.4 & 742.1 & 740.1 & 739.4 & 738.8 & 739.0 & 0.023 & 0.027 & 0.028 & 0.028 & 0.07 \\
\hline$g 31$ & 310.8 & 94.73 & 458.5 & 444.9 & & 442.9 & 443.6 & 444.2 & 0.031 & 0.035 & 0.034 & 0.032 & 0.08 \\
\hline $\mathrm{g} 32$ & 329.9 & 100.55 & 1158.5 & 1134.7 & & 1130.0 & 1129.0 & 1129.8 & 0.021 & 0.025 & 0.026 & 0.025 & 0.06 \\
\hline 933 & 330.3 & 100.68 & 1004.4 & 985.5 & & 980.6 & 979.1 & 980.0 & 0.019 & 0.024 & 0.026 & 0.025 & 0.06 \\
\hline g34 & 350.9 & 106.94 & 772.4 & 756.9 & & 753.8 & 752.9 & 753.4 & 0.020 & 0.025 & 0.026 & 0.025 & 0.06 \\
\hline g35 & 373.1 & 113.71 & 785.0 & 769.0 & & 765.6 & 764.5 & 764.8 & 0.021 & 0.025 & 0.027 & 0.026 & 0.07 \\
\hline g36 & 392.9 & 119.74 & 694.4 & 678.3 & 676.1 & 675.1 & 674.6 & 674.9 & 0.024 & 0.029 & 0.029 & 0.029 & 0.07 \\
\hline g37 & 414.0 & 126.17 & 768.2 & 751.8 & & 748.7 & 747.3 & 747.9 & 0.022 & 0.026 & 0.028 & 0.027 & 0.07 \\
\hline $\mathrm{g} 38$ & 432.9 & 131.95 & 956.7 & 932.5 & & 928.3 & 927.2 & 928.2 & 0.026 & 0.031 & 0.032 & 0.031 & 0.08 \\
\hline g39 & 452.9 & 138.03 & 723.4 & 708.3 & & 704.9 & 703.7 & 704.7 & 0.021 & 0.026 & 0.028 & 0.027 & 0.07 \\
\hline $\mathrm{g} 40$ & 472.5 & 144.02 & 836.1 & 810.3 & & 807.8 & 806.9 & 807.3 & 0.032 & 0.035 & 0.036 & 0.036 & 0.09 \\
\hline $\mathrm{g} 41$ & 483.8 & 147.46 & 613.6 & 597.6 & & 595.2 & 594.6 & 595.3 & 0.027 & 0.031 & 0.032 & 0.031 & 0.08 \\
\hline $\mathrm{g} 42$ & 494.1 & 150.59 & 756.2 & 742.8 & 740.7 & 738.8 & 736.8 & 737.5 & 0.018 & 0.024 & 0.026 & 0.025 & 0.06 \\
\hline 643 & 513.1 & 156.38 & 743.8 & 727.7 & & 724.0 & 722.3 & 723.1 & 0.022 & 0.027 & 0.030 & 0.029 & 0.07 \\
\hline$g 44$ & 530.6 & 161.73 & 739.5 & 723.9 & & 720.0 & 718.0 & 719.1 & 0.022 & 0.027 & 0.030 & 0.028 & 0.07 \\
\hline g45 & 550.8 & 167.87 & 615.3 & 603.1 & & 600.1 & 598.4 & 599.6 & 0.020 & 0.025 & 0.028 & 0.026 & 0.07 \\
\hline$g 46$ & 551.5 & 168.08 & 861.5 & 847.7 & & 843.5 & 840.9 & 841.4 & 0.016 & 0.021 & 0.024 & 0.024 & 0.06 \\
\hline $\mathrm{g} 47$ & 580.1 & 176.80 & 540.6 & 524.8 & 523.2 & 522.4 & 521.4 & 522.4 & 0.030 & 0.035 & 0.037 & 0.035 & 0.09 \\
\hline$g 48$ & 584.3 & 178.09 & 613.0 & 595.5 & & 593.1 & 592.2 & 593.5 & 0.029 & 0.034 & 0.035 & 0.033 & 0.08 \\
\hline 949 & 612.5 & 186.67 & 723.3 & 707.4 & & 703.0 & 701.1 & 702.0 & 0.022 & 0.029 & 0.032 & 0.030 & 0.08 \\
\hline $\mathrm{g} 50$ & 630.2 & 192.08 & 536.2 & 521.9 & & 519.6 & 518.4 & 518.9 & 0.027 & 0.032 & 0.034 & 0.033 & 0.08 \\
\hline $\mathrm{g} 51$ & 644.0 & 196.29 & 908.7 & 889.6 & & 883.3 & 880.4 & 881.5 & 0.021 & 0.029 & 0.032 & 0.031 & 0.08 \\
\hline $\mathrm{g} 52$ & 649.6 & 197.98 & 1189.0 & 1167.5 & & 1160.2 & 1156.4 & 1158.1 & 0.018 & 0.025 & 0.028 & 0.027 & 0.07 \\
\hline g53 & 661.1 & 201.50 & 860.9 & 843.3 & 840.6 & 839.0 & 836.3 & 837.2 & 0.021 & 0.026 & 0.029 & 0.028 & 0.07 \\
\hline
\end{tabular}




\section{Table B.2. Key to Condition Codes}

The core physical condition code is used to describe roughness or chips of core missing from cut pieces (see Tables B.4 and B.5). The code is also used to indicate interesting lithologic features such as crystal inclusions or vugs. This information could be used to reduce the bulk volume estimated by direct measurement and the right circular cylinder assumption. It has not been employed to do so, but is included for completeness.

For example, a piece of cut core (see sample g2, Table B.4) is directly measured to have a bulk volume of $286.3 \mathrm{~cm}^{3}$ and has a noticeable vug. It was tested in the bulk volume estimator and found to have a bulk volume of $283.0 \mathrm{~cm}^{3}$. The high bulk volume estimate implies a low bulk density estimate which, in turn, implies a porosity estimate [see Equation (1)]. Sample g61 has a large chip and shows significant difference in the volume estimated by the two methods.

KEY: The volume of a Chip (C) > volume of Vug (Vj), which is > Rough (R).

Other descriptive codes:

$D=$ ditty

- cut = rough cut

ss $=$ slickensides

$\mathrm{Ph}=$ phenocrysts

xtal $=$ crystal

$\mathrm{Hf}=$ healed fracture

$\mathrm{Ft}=$ fracture trace 


\section{Table B.3. Y2 Series Data}

The maximum, minimum, and average series values for each column are listed at the top of the table. The following is a key to column headings.

$a=$ Core ID

$b=$ Depth $Z$ = depth of core sample in feet along the borehole ( $f t)$

$c=$ Depth $Z^{\prime}=$ depth of core sample in meters along the borehole $(m)$

d = Retest Vol Sol = volume of solid from Table B.6: ReTested Core Data (included for comparison purposes only)

$\theta=$ Pyc Vol Sol $=$ average volume of solid calculated using Equation $(8)\left(\mathrm{cm}^{3}\right)$

$f=\operatorname{Std}$ Dev $=$ standard deviation for core test $\left(\mathrm{cm}^{3}\right)$

$g=C V / .01=$ coefficient of variation $(f / e \times 100)$ for core test $(\%)$

$h=\#$ of cycles $=$ the number of cycles pertaining to $(f)$ and $(e)(\#)$

$i=$ Into Pyc Weight $=$ the weight of the oven-dried sample immediately prior to testing in the gas pycnometer (g)

$\mathbf{j}=$ Immer Bulk Vol = bulk volume reported from the immersion method. It is this bulk volume that is used in all calculations. Y2 series core are not cut. $\left(\mathrm{cm}^{3}\right)$

$k=$ Immer Std Dev = standard deviation of 5 or 6 estimates by the immersion method. $\left(\mathrm{cm}^{3}\right)$

$I=$ Grain Dens = column (i) divided by column $(e)\left(\mathrm{g} / \mathrm{cm}^{3}\right)$

$m=$ Dry Bulk Dens = column (i) divided by column (j) $\left(\mathrm{g} / \mathrm{cm}^{3}\right)$

$\mathrm{n}=$ Poros = porosity calculated as $(1-\mathrm{m} / \mathrm{l})\left(\mathrm{cm}^{3} / \mathrm{cm}^{3}\right)$

$0=$ Koz-Carm Perm = intrinsic permeability calculated by using Equation (12) and porosity (n) $\left(m^{2}\right)$ 
Table B.3: Y2-Series Core Summary Data - continued.

34 Y2 series core samples have been tested

\begin{tabular}{|c|c|c|c|c|c|c|c|c|c|c|c|c|c|c|}
\hline $\begin{array}{l}\text { Core } \\
\text { ID }\end{array}$ & $\begin{array}{c}\text { Depth } \\
Z \\
\text { (ft) } \\
\end{array}$ & $\begin{array}{c}\text { Depth } \\
Z^{\prime} \\
(\mathrm{m}) \\
\end{array}$ & $\begin{array}{c}\text { Re- } \\
\text { Test } \\
\text { Volsol } \\
(\mathrm{cm} 3) \\
\end{array}$ & $\begin{array}{l}\text { Pyc } \\
\text { Volsol } \\
(\mathrm{cm} 3)\end{array}$ & $\begin{array}{c}\text { Std } \\
\text { Dev } \\
(\mathrm{cm} 3) \\
\end{array}$ & $\begin{array}{c}\text { CVI.01 } \\
(\%)\end{array}$ & $\begin{array}{l}\text { \# of } \\
\text { Cycle }\end{array}$ & $\begin{array}{c}\text { Into } \\
\text { Pyc } \\
\text { Weight } \\
\text { (g) }\end{array}$ & $\begin{array}{c}\text { Immer } \\
\text { Bulk } \\
\text { Vol } \\
\text { (cm3) } \\
\end{array}$ & $\begin{array}{c}\text { Immer } \\
\text { Std } \\
\text { Dev } \\
(\mathrm{cm} 3) \\
\end{array}$ & $\begin{array}{c}\text { Grain } \\
\text { Dens. } \\
\text { (g) } \\
(\mathrm{cm} 3) \\
\end{array}$ & $\begin{array}{c}\text { Bulk } \\
\text { Dens. } \\
\text { (g) } \\
\text { (cm3) } \\
\end{array}$ & $\begin{array}{l}\text { Poros. } \\
(\mathrm{cm} 3) \\
(\mathrm{cm} 3) \\
\end{array}$ & $\begin{array}{l}\text { Koz- } \\
\text { Carm } \\
\text { Perm. } \\
\text { (m2) } \\
\end{array}$ \\
\hline MIN & 5.8 & 1.8 & & 248.2 & 1.3 & 0.33 & 9.0 & 651.3 & 304.2 & 0.0 & 2.58 & 1.95 & 0.15 & $1.4 \mathrm{E}-17$ \\
\hline $\operatorname{MAX}$ & 100.0 & 30.5 & & 529.9 & 3.5 & 1.11 & 11.0 & 1376.5 & 636.6 & 3.5 & 2.63 & 2.20 & 0.25 & 7.7E-17 \\
\hline VVG & & & & 374.4 & 2.3 & 0.64 & 10.0 & 976.2 & 463.0 & 1.3 & 2.61 & 2.11 & 0.19 & 3.0E-17 \\
\hline a & b & c & d & $\theta$ & $f$ & $g$ & $\mathrm{~h}$ & $i$ & $\mathbf{j}$ & $k$ & $\begin{array}{c}1 \\
\text { (i/e) }\end{array}$ & $\begin{array}{c}m \\
\text { (iji) }\end{array}$ & $\begin{array}{c}n \\
(1-m / 1)\end{array}$ & 0 \\
\hline $1 \mathrm{a}$ & 5.8 & 1.8 & 277.5 & 278.4 & 2.3 & 0.81 & 10 & 725.8 & 372.4 & 2.2 & 2.61 & 1.95 & 0.25 & 7.7E-17 \\
\hline $1 b$ & 7.0 & 2.1 & & 338.7 & 2.0 & 0.58 & 11 & 882.3 & 442.3 & 1.2 & 2.61 & 1.99 & 0.23 & $5.8 \mathrm{E}-17$ \\
\hline $1 c$ & 8.0 & 2.4 & & 332.2 & 2.9 & 0.87 & 10 & 859.7 & 428.6 & 3.5 & 2.59 & 2.01 & 0.22 & $5.0 \mathrm{E}-17$ \\
\hline $2 a$ & 14.0 & 4.3 & & 486.7 & 2.3 & 0.48 & 10 & 1258.3 & 589.0 & 0.9 & 2.59 & 2.14 & 0.17 & 2.0E-17 \\
\hline $2 b$ & 17.0 & 5.2 & & 360.7 & 2.8 & 0.77 & 10 & 934.1 & 434.7 & 1.1 & 2.59 & 2.15 & 0.17 & $1.9 \mathrm{E}-17$ \\
\hline $2 c$ & 18.0 & 5.5 & & 392.2 & 1.3 & 0.33 & 10 & 1019.0 & 464.7 & 0.6 & 2.60 & 2.19 & 0.16 & 1.4E-17 \\
\hline $2 d$ & 21.5 & 6.6 & 361.8 & 359.6 & 2.4 & 0.67 & 11 & 936.0 & 425.4 & 1.4 & 2.60 & 2.20 & 0.15 & 1.4E-17 \\
\hline $3 a$ & 23.5 & 7.2 & & 529.9 & 2.2 & 0.41 & 10 & 1376.5 & 633.6 & 0.7 & 2.60 & 2.17 & 0.16 & 1.7E-17 \\
\hline $3 b$ & 28.5 & 8.7 & & 404.4 & 1.7 & 0.42 & 9 & 1053.6 & 503.8 & 2.5 & 2.61 & 2.09 & 0.20 & 3.2E-17 \\
\hline $4 a$ & 31.6 & 9.6 & & 376.5 & 2.5 & 0.67 & 10 & 985.0 & 479.6 & 0.0 & 2.62 & 2.05 & 0.21 & 4.3E-17 \\
\hline $4 b$ & 33.0 & 10.1 & & 349.1 & 2.0 & 0.58 & 10 & 906.8 & 428.6 & 1.3 & 2.60 & 2.12 & 0.19 & 2.6E-17 \\
\hline $4 c$ & 35.0 & 10.7 & & 422.1 & 1.6 & 0.37 & 10 & 1100.5 & 535.9 & 1.2 & 2.61 & 2.05 & 0.21 & 4.1E-17 \\
\hline $5 a$ & 40.0 & 12.2 & & 333.7 & 1.7 & 0.52 & 10 & 865.1 & 410.8 & 0.6 & 2.59 & 2.11 & 0.19 & 2.7E-17 \\
\hline $5 b$ & 44.0 & 13.4 & & 369.7 & 2.0 & 0.54 & 10 & 966.0 & 448.1 & 1.2 & 2.61 & 2.16 & 0.18 & 2.1E-17 \\
\hline $5 c$ & 48.0 & 14.6 & & 344.1 & 3.1 & 0.91 & 10 & 898.3 & 426.8 & 1.4 & 2.61 & 2.10 & 0.19 & 3.0E-17 \\
\hline
\end{tabular}


Table B.3: Y2-Series Core Summary Data - continued.

\begin{tabular}{|c|c|c|c|c|c|c|c|c|c|c|c|c|c|c|}
\hline $\begin{array}{l}\text { Core } \\
\text { ID }\end{array}$ & $\begin{array}{c}\text { Depth } \\
Z \\
\text { (ft) }\end{array}$ & $\begin{array}{c}\text { Depth } \\
Z^{\prime} \\
(m) \\
\end{array}$ & $\begin{array}{c}\text { Re- } \\
\text { Test } \\
\text { Volsol } \\
\text { (cm3) }\end{array}$ & $\begin{array}{c}\text { Pyc } \\
\text { VolSol } \\
\text { (cm3) }\end{array}$ & $\begin{array}{c}\text { Std } \\
\text { Dov } \\
(\mathrm{cm} 3)\end{array}$ & $\begin{array}{c}\text { CVI.01 } \\
(\%)\end{array}$ & $\begin{array}{c}\# \text { of } \\
\text { Cycle }\end{array}$ & $\begin{array}{l}\text { Into } \\
\text { Pyc } \\
\text { Weight } \\
\text { (g) }\end{array}$ & $\begin{array}{c}\text { Immer } \\
\text { Bulk } \\
\text { Vol } \\
\text { (cm3) }\end{array}$ & $\begin{array}{c}\text { Immer } \\
\text { Std } \\
\text { Dev } \\
\text { (cm3) }\end{array}$ & $\begin{array}{c}\text { Grain } \\
\text { Dens. } \\
\text { (g) } \\
\text { (cm3) }\end{array}$ & $\begin{array}{c}\text { Dry } \\
\text { Bulk } \\
\text { Dens. } \\
\text { (g) } \\
\text { (cm3) }\end{array}$ & $\begin{array}{l}\text { Poros. } \\
\text { (cm3) } \\
\text { (cm3) }\end{array}$ & $\begin{array}{l}\text { Koz- } \\
\text { Carm } \\
\text { Perm. } \\
\text { (m2) }\end{array}$ \\
\hline$a$ & $b$ & c & $d$ & $\theta$ & $f$ & 9 & $\mathrm{~h}$ & $i$ & $j$ & $k$ & $\begin{array}{c}1 \\
(\mathrm{i} / \theta)\end{array}$ & $\begin{array}{c}m \\
\text { (i/j) }\end{array}$ & $\begin{array}{c}n \\
(1-m / /)\end{array}$ & 0 \\
\hline $6 a$ & 48.8 & 14.9 & & 338.4 & 2.5 & 0.75 & 10 & 882.9 & 428.0 & 1.2 & 2.61 & 2.06 & 0.21 & 3.9E-17 \\
\hline $6 b$ & 52.5 & 16.0 & & 516.4 & 3.1 & 0.60 & 10 & 1344.8 & 636.6 & 1.2 & 2.60 & 2.11 & 0.19 & 2.7E-17 \\
\hline $6 c$ & 55.6 & 16.9 & & 473.6 & 3.5 & 0.74 & 10 & 1237.0 & 589.0 & 0.9 & 2.61 & 2.10 & 0.20 & 3.1E-17 \\
\hline $7 a$ & 57.6 & 17.6 & & 355.1 & 2.4 & 0.68 & 11 & 928.4 & 440.5 & 1.4 & 2.61 & 2.11 & 0.19 & 3.0E-17 \\
\hline $7 b$ & 61.3 & 18.7 & & 333.9 & 1.6 & 0.49 & 10 & 872.9 & 410.8 & 1.4 & 2.61 & 2.12 & 0.19 & 2.6E-17 \\
\hline $7 c$ & 63.8 & 19.4 & & 389.0 & 2.9 & 0.74 & 10 & 1014.6 & 477.4 & 1.3 & 2.61 & 2.13 & 0.19 & $2.6 \mathrm{E}-17$ \\
\hline $8 a$ & 65.7 & 20.0 & 260.5 & 259.3 & 2.9 & 1.11 & 10 & 669.3 & 318.0 & 1.4 & 2.58 & 2.10 & 0.18 & $2.5 E-17$ \\
\hline $8 b$ & 68.8 & 21.0 & & 400.0 & 3.4 & 0.85 & 10 & 1043.5 & 487.5 & 0.7 & 2.61 & 2.14 & 0.18 & 2.3E-17 \\
\hline $8 c$ & 69.8 & 21.3 & & 290.0 & 1.4 & 0.48 & 9 & 758.3 & 351.9 & 2.9 & 2.62 & 2.16 & 0.18 & $2.1 \mathrm{E}-17$ \\
\hline $9 a$ & 73.8 & 22.5 & & 345.9 & 2.0 & 0.58 & 10 & 903.3 & 437.3 & 1.6 & 2.61 & 2.07 & 0.21 & 3.9E-17 \\
\hline $9 b$ & 77.0 & 23.5 & & 440.7 & 2.3 & 0.52 & 10 & 1154.6 & 540.9 & 1.8 & 2.62 & 2.13 & 0.19 & 2.5E-17 \\
\hline $9 c$ & 79.0 & 24.1 & & 405.4 & 2.6 & 0.65 & 10 & 1060.4 & 507.0 & 1.1 & 2.62 & 2.09 & 0.20 & 3.4E-17 \\
\hline $10 a$ & 82.3 & 25.1 & & 344.2 & 2.7 & 0.77 & 10 & 897.5 & 418.4 & 0.0 & 2.61 & 2.15 & 0.18 & 2.2E-17 \\
\hline $10 \mathrm{~b}$ & 85.9 & 26.2 & 450.2 & 448.7 & 2.2 & 0.48 & 10 & 1178.8 & 550.8 & 0.6 & 2.63 & 2.14 & 0.19 & 2.6E-17 \\
\hline $10 \mathrm{c}$ & 88.9 & 27.1 & 327.7 & 328.1 & 1.8 & 0.55 & 10 & 861.7 & 415.2 & 2.3 & 2.63 & 2.08 & 0.21 & 3.9E-17 \\
\hline $11 a$ & 94.5 & 28.8 & & 248.2 & 2.3 & 0.94 & 10 & 651.3 & 304.2 & 0.6 & 2.62 & 2.14 & 0.18 & 2.5E-17 \\
\hline $11 b$ & 97.5 & 29.7 & & 361.6 & 2.2 & 0.61 & 10 & 942.0 & 448.7 & 1.4 & 2.60 & 2.10 & 0.19 & $3.0 E-17$ \\
\hline $12 a$ & 99.3 & 30.3 & & 330.4 & 2.1 & 0.62 & 10 & 863.4 & 406.1 & 0.7 & 2.61 & 2.13 & 0.19 & 2.6E-17 \\
\hline $12 b$ & 100.0 & 30.5 & & 443.0 & 2.7 & 0.60 & 10 & 1159.8 & 548.8 & 0.7 & 2.62 & 2.11 & 0.19 & $2.9 E-17$ \\
\hline
\end{tabular}




\section{Table B.4. G Series Data}

The maximum, minimum, and average series values, for each column, are listed at the top of the table. The following is a key to column headings:

$a=$ Cond $=$ physical condition of core. See Table B.2.

$b=$ Core ID

$c=$ Depth $Z=$ depth of core sample in feet along the borehole. $(\mathrm{ft})$

$d=$ Depth $Z^{\prime}=$ depth of core sample in meters along the borehole. $(\mathrm{m})$

$e=R e-T e s t$ VolSol $=$ volume of solid from Table B.6: Re-Tested Core Data. Included for comparison purposes only.

$f=$ Pyc VolSol $=$ average volume of solid calculated using Eqn. (8). $\left(\mathrm{cm}^{3}\right)$

$g=$ Std Dev = standard deviation for core test. $\left(\mathrm{cm}^{3}\right)$

$h=C V / .01=$ coefficient of variation $(g / f \times 100)$ for core test. $(\%)$

$i=\quad \#$ of Cycles $=$ the number of cycles pertaining to $(g)$ and $(f)$. $\#)$

$j=\quad$ Into Pyc Weight $=$ the weight of the oven dry sample immediately prior to testing in the gas pycnometer. (g)

$k=$ Dia $=$ core sample diameter measurement, for cut samples. (in)

$1=$ Len. = length of core samples, for cut samples. (in)

$\mathrm{m}=$ Cut Bulk Vol = bulk volume calculated from (l) and (k). Included for comparison purposes only. The immersion bulk volume was used in all calculations. $\left(\mathrm{cm}^{3}\right)$

$\mathrm{n}=$ Immer Bulk Vol = bulk volume reported from the immersion method. It is this bulk volume that is used in all calculations. $\left(\mathrm{cm}^{3}\right)$

$0=$ Immer Std Dev = standard deviation of 5 or 6 estimates by the immersion method. $\left(\mathrm{cm}^{3}\right)$

$p=$ Grain Dens. = column (j) divided by column $(f) \cdot\left(\mathrm{g} / \mathrm{cm}^{3}\right)$

$q=$ Dry Bulk Dens. = column (j) divided by column $(\mathrm{n}) .\left(\mathrm{g} / \mathrm{cm}^{3}\right)$

$r=$ Poros. $=$ porosity calculated as $(1-q / p) \cdot\left(\mathrm{cm}^{3} / \mathrm{cm}^{3}\right)$

$s=$ Kos-Carm Perm. = intrinsic permeability calculated by using Eqn. (12) and porosity (q). $\left(m^{2}\right)$ 
Table B.4: G-Series Core Summary - continued.

$68 \mathrm{G}$ series core samples have been tested.

Re- Into Cut Cut Bulk Immer Grain Bulk KozCond. Core Depth Depth Test Pyc Std \# of Pyc Then Bulk Vol Std Dens. Dens. Poros. Carm

\begin{tabular}{|c|c|c|c|c|c|c|c|c|c|c|c|c|c|c|c|c|c|c|}
\hline & ID & $\begin{array}{c}Z \\
(f t)\end{array}$ & $\begin{array}{c}Z^{\prime} \\
(m)\end{array}$ & $\begin{array}{l}\text { Volsol } \\
(\mathrm{cm} 3)\end{array}$ & $\begin{array}{l}\text { VolSol } \\
(\mathrm{cm} 3)\end{array}$ & $\begin{array}{c}\text { Dev } \\
(\mathrm{cm} 3)\end{array}$ & $\begin{array}{c}\text { CVI.01 } \\
(\%)\end{array}$ & Cycle & $\begin{array}{c}\text { Weight } \\
\text { (g) }\end{array}$ & $\begin{array}{l}\text { Dia } \\
\text { (in) }\end{array}$ & $\begin{array}{l}\text { Len. } \\
\text { (in) }\end{array}$ & $\begin{array}{c}\text { Vol } \\
(\mathrm{cm} 3)\end{array}$ & $\begin{array}{l}\text { Est. } \\
\text { (cm3) }\end{array}$ & $\begin{array}{c}\text { Dev } \\
(\mathrm{cm} 3)\end{array}$ & $\frac{(\mathrm{g})}{(\mathrm{cm} 3)}$ & $\frac{(\mathrm{g})}{(\mathrm{cm} 3)}$ & $\frac{(\mathrm{cm} 3)}{(\mathrm{cm} 3)}$ & $\begin{array}{c}\text { Perm. } \\
(\mathrm{m} 2)\end{array}$ \\
\hline & MIN & 11 & 3 & & 151.3 & 1.0 & 0.28 & 6 & 384.8 & 2.47 & 3.43 & 273.9 & 164.0 & 0.0 & 2.50 & 2.07 & 0.02 & 2.3E-20 \\
\hline & $\operatorname{MAX}$ & 661 & 202 & & 608.9 & 3.7 & 1.30 & 12 & 1544.1 & 2.51 & 4.98 & 401.2 & 689.3 & 7.4 & 2.66 & 2.47 & 0.21 & 4.1E-17 \\
\hline & AVG & & & & 306.8 & 2.1 & 0.71 & 10 & 784.4 & 2.50 & 3.80 & 304.9 & 334.0 & 1.4 & 2.56 & 2.36 & 0.08 & 4.4E-18 \\
\hline$a$ & b & c & d & $\theta$ & $f$ & $\mathbf{g}$ & $h$ & $i$ & j & $k$ & 1 & $m$ & $n$ & 0 & $\begin{array}{c}p \\
(j / f)\end{array}$ & $\begin{array}{c}q \\
(j / n)\end{array}$ & $\frac{r}{(1-q / p)}$ & $s$ \\
\hline $\mathrm{V}$ & g1 & 11.4 & 3.5 & & 237.7 & 1.6 & 0.66 & 10 & 618.3 & & & & 295.1 & 1.1 & 2.60 & 2.10 & 0.19 & 3.0E-17 \\
\hline V & g2 & 19.7 & 6.0 & 226.0 & 222.8 & 2.9 & 1.30 & 11 & 592.5 & 2.49 & 3.60 & 286.3 & 283.0 & 0.5 & 2.66 & 2.09 & 0.21 & $4.1 E-17$ \\
\hline & g3 & 39.9 & 12.2 & 256.2 & 262.7 & 2.6 & 1.00 & 10 & 684.2 & & & & 330.0 & 0.7 & 2.60 & 2.07 & 0.20 & $3.5 \mathrm{E}-17$ \\
\hline & $\mathrm{g} 4$ & 49.9 & 15.2 & & 248.5 & 1.4 & 0.56 & 10 & 653.8 & & & & 303.1 & 3.1 & 2.63 & 2.16 & 0.18 & 2.3E-17 \\
\hline & 963 & 61.0 & 18.6 & & 252.1 & 1.3 & 0.50 & 10 & 653.9 & & & & 298.5 & 0.6 & 2.59 & 2.19 & 0.16 & $1.4 \mathrm{E}-17$ \\
\hline & $g 64$ & 62.5 & 19.1 & & 230.7 & 2.8 & 1.22 & 11 & 601.6 & & & & 275.7 & 1.4 & 2.61 & 2.18 & 0.16 & $1.6 E-17$ \\
\hline حcut & g5 & 69.4 & 21.1 & & 258.0 & 2.3 & 0.91 & 10 & 672.4 & 2.47 & 3.91 & 308.2 & 305.5 & 1.2 & 2.61 & 2.20 & 0.16 & $1.4 \mathrm{E}-17$ \\
\hline $\mathrm{V}, \mathrm{Ph}$ & 958 & 78.8 & 24.0 & & 589.7 & 3.3 & 0.55 & 10 & 1544.1 & & & & 689.3 & 1.4 & 2.62 & 2.24 & 0.14 & $1.1 \mathrm{E}-17$ \\
\hline $\mathrm{V}, \mathrm{Ph}$ & g59 & 79.9 & 24.4 & & 416.2 & 2.7 & 0.66 & 11 & 1090.7 & & & & 496.8 & 1.9 & 2.62 & 2.20 & 0.16 & $1.6 \mathrm{E}-17$ \\
\hline$v$ & g6 & 89.8 & 27.4 & & 463.4 & 3.3 & 0.70 & 8 & 1207.6 & & & & 538.8 & 2.0 & 2.61 & 2.24 & 0.14 & $9.8 E-18$ \\
\hline & $g 60$ & 99.5 & 30.3 & & 223.8 & 2.9 & 1.30 & 10 & 583.2 & & & & 262.3 & 0.9 & 2.61 & 2.22 & 0.15 & $1.2 \mathrm{E}-17$ \\
\hline & 97 & 109.0 & 33.2 & & 306.4 & 1.5 & 0.49 & 10 & 801.4 & & & & 363.2 & 1.4 & 2.62 & 2.21 & 0.16 & 1.4E-17 \\
\hline$D$ & g8 & 109.4 & 33.3 & & 270.5 & 2.3 & 0.86 & 10 & 704.7 & 2.49 & 3.94 & 313.6 & 307.8 & 1.4 & 2.61 & 2.29 & 0.12 & $6.1 \mathrm{E}-18$ \\
\hline & $g 55$ & 120.5 & 36.7 & & 253.6 & 2.5 & 1.00 & 10 & 656.0 & 2.49 & 3.71 & 296.4 & 291.2 & 1.1 & 2.59 & 2.25 & 0.13 & $7.5 \mathrm{E}-18$ \\
\hline & $\mathrm{g} 56$ & 122.9 & 37.5 & & 283.6 & 2.6 & 0.92 & 10 & 724.8 & 2.49 & 3.99 & 317.7 & 316.9 & 1.2 & 2.56 & 2.29 & 0.11 & $3.8 \mathrm{E}-18$ \\
\hline & $\mathrm{g} 54$ & 129.5 & 39.5 & & 306.9 & 2.0 & 0.65 & 10 & 778.0 & & & & 336.7 & 0.0 & 2.54 & 2.31 & 0.09 & $2.2 \mathrm{E}-18$ \\
\hline xtal & g9 & 139.1 & 42.4 & & 238.0 & 2.2 & 0.92 & 10 & 607.3 & & & & 267.6 & 3.0 & 2.55 & 2.27 & 0.11 & $4.5 E-18$ \\
\hline & 910 & 150.0 & 45.7 & & 245.1 & 2.2 & 0.88 & 12 & 628.2 & 2.49 & 3.43 & 273.9 & 272.2 & 1.7 & 2.56 & 2.31 & 0.10 & $3.2 \mathrm{E}-18$ \\
\hline & $g 11$ & 150.3 & 45.8 & 230.2 & 232.2 & 2.1 & 0.91 & 10 & 594.1 & & & & & & 2.56 & & & \\
\hline & $g 12 b$ & 170.6 & 52.0 & & 151.3 & 1.7 & 1.12 & 10 & 384.8 & & & & 164.0 & 2.7 & 2.54 & 2.35 & 0.08 & $1.4 \mathrm{E}-18$ \\
\hline & g12a & 170.6 & 52.0 & & 411.1 & 2.7 & 0.65 & 10 & 1036.3 & & & & 438.4 & 0.6 & 2.52 & 2.36 & 0.06 & $7.2 E-19$ \\
\hline
\end{tabular}


Table B.4: G-Series Core Summary - continued.

Ro- Into Cut Cut Bulk Immer Grain Bulk, KozCond. Core Depth Depth Test Pyc Std \# of Pyc Then Bulk Vol Std Dens. Dens. Poros. Carm

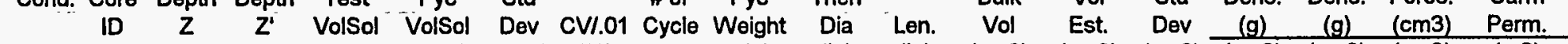

\begin{tabular}{|c|c|c|c|c|c|c|c|c|c|c|c|c|c|c|c|c|c|c|}
\hline & & (tt) & (m) & $(\mathrm{cm} 3)$ & (cm3) & $(\mathrm{cm} 3)$ & (\%) & & (g) & (in) & (in) & $(\mathrm{cm} 3)$ & $(\mathrm{cm} 3)$ & $(\mathrm{cm} 3)$ & $(\mathrm{cm} 3)$ & $(\mathrm{cm} 3)$ & $(\mathrm{cm} 3)$ & (m2) \\
\hline a & b & c & d. & $\theta$ & $f$ & $\mathrm{~g}$ & $h^{\prime}$ & i & $\mathrm{j}$ & $\mathrm{k}$ & 1 & $m$ & $n$ & 0 & $\begin{array}{c}p \\
\text { (ifi) }\end{array}$ & $\begin{array}{c}q \\
-(j / n)\end{array}$ & $\begin{array}{c}r \\
(1-q / p)\end{array}$ & $s$ \\
\hline & g65 & 181.5 & 55.3 & 302.4 & 302.1 & 2.1 & 0.71 & 10 & 762.9 & & & & & & 2.53 & & & \\
\hline & g13 & 190.2 & 58.0 & & 282.3 & 1.2 & 0.41 & 10 & 720.2 & & & & 298.2 & 2.4 & 2.55 & 2.42 & 0.05 & 4.4E-19 \\
\hline & g14 & 201.0 & 61.2 & & 287.8 & 1.5 & 0.52 & 9 & 725.4 & 2.49 & 3.75 & 300.4 & 300.5 & 1.1 & 2.52 & 2.41 & 0.04 & $2.2 \mathrm{E}-19$ \\
\hline & g15 & 210.1 & 64.0 & & 284.0 & 2.4 & 0.84 & 10 & 731.5 & & & & 317.4 & 1.1 & 2.58 & 2.30 & 0.11 & $3.9 \mathrm{E}-18$ \\
\hline & $g 62$ & 225.5 & 68.7 & & 365.9 & 2.2 & 0.61 & 10 & 927.5 & & & & 382.2 & 1.1 & 2.53 & 2.43 & 0.04 & $2.2 \mathrm{E}-19$ \\
\hline & g16 & 230.0 & 70.1 & & 348.1 & 2.0 & 0.57 & 11 & 885.3 & & & & 366.7 & 1.8 & 2.54 & 2.41 & 0.05 & $3.9 \mathrm{E}-19$ \\
\hline & g17 & 231.2 & 70.5 & & 284.0 & 1.8 & 0.65 & 10 & 726.9 & & & & 302.0 & 0.6 & 2.56 & 2.41 & 0.06 & $6.3 \mathrm{E}-19$ \\
\hline & g18 & 241.0 & 73.5 & & 495.0 & 2.0 & 0.39 & 10 & 1267.3 & & & & 519.0 & 0.9 & 2.56 & 2.44 & 0.05 & $2.9 \mathrm{E}-19$ \\
\hline & g19 & 241.5 & 73.6 & 515.4 & 513.2 & 1.7 & 0.33 & 10 & 1317.7 & & & & 533.9 & 1.1 & 2.57 & 2.47 & 0.04 & 1.7E-19 \\
\hline & $\mathrm{g} 20$ & 250.3 & 76.3 & & 273.1 & 2.2 & 0.79 & 10 & 696.2 & & & & 287.8 & 0.7 & 2.55 & 2.42 & 0.05 & $3.9 \mathrm{E}-19$ \\
\hline & g21 & 251.3 & 76.6 & & 278.7 & 1.9 & 0.67 & 6 & 717.3 & & & & 293.5 & 1.5 & 2.57 & 2.44 & 0.05 & $3.8 \mathrm{E}-19$ \\
\hline & g22 & 251.7 & 76.7 & & 219.6 & 1.6 & 0.72 & 11 & 554.6 & & & & 233.4 & 0.6 & 2.53 & 2.38 & 0.06 & $6.2 E-19$ \\
\hline & $\mathrm{g} 23$ & 252.0 & 76.8 & & 423.2 & 2.0 & 0.48 & 10 & 1072.9 & & & & 442.0 & 1.1 & 2.54 & 2.43 & 0.04 & 2.2E-19 \\
\hline V & g24 & 261.0 & 79.6 & & 391.3 & 1.1 & 0.28 & 10 & 997.0 & & & & 409.9 & 1.7 & 2.55 & 2.43 & 0.05 & $2.7 \mathrm{E}-19$ \\
\hline & g25 & 261.3 & 79.6 & & 196.6 & 1.3 & 0.68 & 10 & 503.3 & & & & 209.2 & 1.2 & 2.56 & 2.41 & 0.06 & $6.5 \mathrm{E}-19$ \\
\hline & 926 & 265.3 & 80.9 & & 608.9 & 2.5 & 0.41 & 9 & 1538.1 & & & & 630.1 & 2.7 & 2.53 & 2.44 & 0.03 & $1.1 \mathrm{E}-19$ \\
\hline & g27 & 270.6 & 82.5 & & 276.4 & 1.8 & 0.66 & 10 & 702.3 & 2.50 & 3.63 & 291.4 & 289.4 & 0.7 & 2.54 & 2.43 & 0.04 & $2.6 \mathrm{E}-19$ \\
\hline $\mathrm{HF}$ & 928 & 281.3 & 85.7 & & 480.6 & 2.0 & 0.41 & 10 & 1243.1 & & & & 519.3 & 1.1 & 2.59 & 2.39 & 0.07 & $1.3 E-18$ \\
\hline & g29 & 290.7 & 88.6 & & 258.6 & 2.7 & 1.03 & 8 & 664.4 & 2.50 & 3.43 & 276.7 & 276.3 & 2.7 & 2.57 & 2.40 & 0.06 & 7.9E-19 \\
\hline C & g61 & 301.7 & 92.0 & & 294.5 & 2.2 & 0.75 & 10 & 746.4 & 2.50 & 3.87 & 312.3 & 305.5 & 0.7 & 2.53 & 2.44 & 0.04 & 1.3E-19 \\
\hline & g30 & 310.6 & 94.7 & & 286.2 & 2.8 & 0.99 & 9 & 738.0 & 2.51 & 3.81 & 307.5 & 301.4 & 2.0 & 2.58 & 2.45 & 0.05 & $3.8 \mathrm{E}-19$ \\
\hline $\mathrm{HF}$ & $g 31$ & 310.8 & 94.7 & 172.3 & 172.0 & 1.0 & 0.61 & 10 & 443.2 & & & & 190.8 & 7.4 & 2.58 & 2.32 & 0.10 & $3.1 \mathrm{E}-18$ \\
\hline & g32 & 329.9 & 100.6 & 442.3 & 441.2 & 2.8 & 0.64 & 8 & 1127.4 & & & & 457.4 & 1.2 & 2.56 & 2.46 & 0.04 & 1.3E-19 \\
\hline
\end{tabular}


Table B.4: G-Series Core Summary - continued.

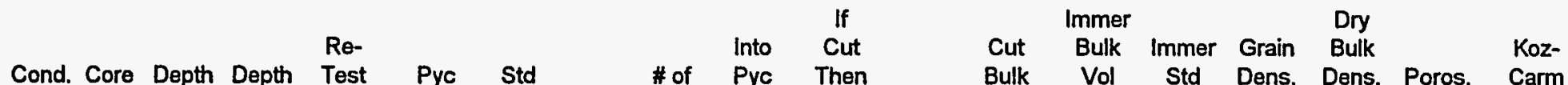

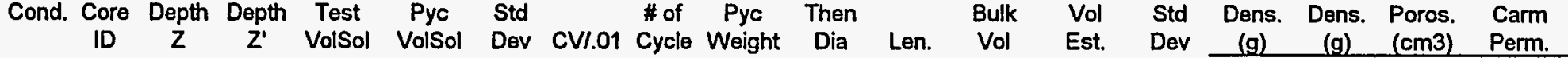

\begin{tabular}{|c|c|c|c|c|c|c|c|c|c|c|c|c|c|c|c|c|c|c|}
\hline & & (ft) & (m) & $(\mathrm{cm} 3)$ & (cm3) & $(\mathrm{cm} 3)$ & (\%) & & (g) & (in) & (in) & (cm3) & (cm3) & (cm3) & $\frac{\mathrm{cm} 3)}{(\mathrm{cm})}$ & (cm3) & (cm3) & (m2) \\
\hline a & b & c & $d$ & $\theta$ & $f$ & $g$ & $h$ & $\mathbf{i}$ & $\mathbf{j}$ & $k$ & 1 & $m$ & $n$ & 0 & $\underset{p}{p}$ & $\begin{array}{c}q \\
(j / n)\end{array}$ & $\begin{array}{c}r \\
(1-q / p)\end{array}$ & $\mathrm{s}$ \\
\hline & g33 & 330.3 & 100.7 & 384.4 & 386.2 & 2.6 & 0.68 & 11 & 978.6 & 2.50 & 4.98 & 401.2 & 397.7 & 1.4 & 2.53 & 2.46 & 0.03 & $6.4 \mathrm{E}-20$ \\
\hline & g57 & 339.5 & 103.5 & & 210.3 & 1.3 & 0.62 & 10 & 543.2 & & & & 229.6 & 2.7 & 2.58 & 2.37 & 0.08 & $1.8 \mathrm{E}-18$ \\
\hline & g34 & 350.9 & 106.9 & & 296.0 & 2.2 & 0.73 & 10 & 752.3 & 2.51 & 3.87 & 312.2 & 310.1 & 1.1 & 2.54 & 2.43 & 0.05 & $2.7 \mathrm{E}-19$ \\
\hline V & g35 & 373.1 & 113.7 & & 300.7 & 2.1 & 0.68 & 10 & 764.0 & 2.50 & 3.95 & 316.7 & 315.1 & 0.6 & 2.54 & 2.42 & 0.05 & $2.7 \mathrm{E}-19$ \\
\hline & $g 67$ & 376.5 & 114.8 & & 281.0 & 2.3 & 0.82 & 10 & 709.2 & 2.50 & 3.71 & 297.1 & 296.1 & 0.6 & 2.52 & 2.39 & 0.05 & $3.8 \mathrm{E}-19$ \\
\hline & g66 & 377.0 & 114.9 & 283.5 & 282.1 & 2.7 & 0.97 & 10 & 709.0 & 2.49 & 3.63 & 290.2 & 288.0 & 0.7 & 2.51 & 2.46 & 0.02 & $2.3 \mathrm{E}-20$ \\
\hline$R$ & g36 & 392.9 & 119.7 & & 264.7 & 1.2 & 0.47 & 10 & 673.9 & 2.50 & 3.51 & 281.6 & 278.9 & 0.7 & 2.55 & 2.42 & 0.05 & $3.8 \mathrm{E}-19$ \\
\hline & 937 & 414.0 & 126.2 & & 292.5 & 3.7 & 1.27 & 9 & 746.1 & 2.50 & 3.86 & 309.3 & 307.5 & 1.8 & 2.55 & 2.43 & 0.05 & $3.3 \mathrm{E}-19$ \\
\hline SS & g38 & 432.9 & 131.9 & & 361.9 & 1.8 & 0.49 & 10 & 925.5 & & & & 386.6 & 2.3 & 2.56 & 2.39 & 0.06 & $7.6 \mathrm{E}-19$ \\
\hline & g39 & 452.9 & 138.0 & & 278.7 & 1.7 & 0.62 & 10 & 703.2 & & & & 289.7 & 0.6 & 2.52 & 2.43 & 0.04 & $1.5 \mathrm{E}-19$ \\
\hline & 940 & 472.5 & 144.0 & & 312.3 & 1.5 & 0.48 & 10 & 805.4 & & & & 337.3 & 0.7 & 2.58 & 2.39 & 0.07 & $1.2 \mathrm{E}-18$ \\
\hline & $g 41$ & 483.8 & 147.5 & & 232.5 & 1.0 & 0.42 & 10 & 592.0 & & & & 249.5 & 1.4 & 2.55 & 2.37 & 0.07 & $9.3 E-19$ \\
\hline & 942 & 494.1 & 150.6 & 296.0 & 294.1 & 2.2 & 0.74 & 10 & 735.8 & 2.50 & 3.79 & 304.0 & 303.1 & 0.9 & 2.50 & 2.43 & 0.03 & $7.2 \mathrm{E}-20$ \\
\hline $\mathrm{V}$ & 943 & 513.1 & 156.4 & & 287.2 & 2.8 & 0.98 & 10 & 721.1 & 2.50 & 3.74 & 300.4 & 298.8 & 0.9 & 2.51 & 2.41 & 0.04 & $1.6 \mathrm{E}-19$ \\
\hline $\mathrm{V}$ & g44 & 530.6 & 161.7 & & 285.9 & 1.0 & 0.36 & 10 & 717.4 & & & & 298.2 & 0.7 & 2.51 & 2.41 & 0.04 & 1.9E-19 \\
\hline & 945 & 550.8 & 167.9 & & 237.0 & 1.4 & 0.59 & 10 & 597.8 & & & & 248.9 & 4.0 & 2.52 & 2.40 & 0.05 & $3.1 \mathrm{E}-19$ \\
\hline & $\mathrm{g} 46$ & 551.5 & 168.1 & 332.0 & 332.2 & 2.5 & 0.74 & 10 & 839.3 & & & & 341.7 & 1.5 & 2.53 & 2.46 & 0.03 & $5.7 \mathrm{E}-20$ \\
\hline $\mathrm{HF}$ & 947 & 580.1 & 176.8 & & 204.7 & 1.7 & 0.85 & 10 & 520.8 & & & & 220.3 & 0.6 & 2.54 & 2.36 & 0.07 & $1.1 \mathrm{E}-18$ \\
\hline $\mathrm{HF}$ & 948 & 584.3 & 178.1 & & 230.3 & 1.6 & 0.69 & 10 & 590.7 & & & & 250.6 & 1.3 & 2.56 & 2.36 & 0.08 & $1.6 \mathrm{E}-18$ \\
\hline & $g 49$ & 612.5 & 186.7 & & 280.6 & 2.3 & 0.83 & 10 & 700.8 & & & & 292.6 & 1.1 & 2.50 & 2.39 & 0.04 & $2.0 \mathrm{E}-19$ \\
\hline HF & g50 & 630.2 & 192.1 & & 203.8 & 1.7 & 0.82 & 10 & 517.4 & & & & 219.4 & 2.0 & 2.54 & 2.36 & 0.07 & $1.1 E-18$ \\
\hline & g51 & 644.0 & 196.3 & & 350.7 & 3.5 & 0.99 & 6 & 880.0 & & & & 365.9 & 0.0 & 2.51 & 2.41 & 0.04 & $2.0 E-19$ \\
\hline & g52 & 649.6 & 198.0 & & 459.5 & 1.3 & 0.29 & 10 & 1155.7 & & & & 473.2 & 0.7 & 2.52 & 2.44 & 0.03 & $6.6 E-20$ \\
\hline & g53 & 661.1 & 201.5 & & 332.0 & 1.8 & 0.54 & 10 & 834.2 & & & & 343.1 & 0.7 & 2.51 & 2.43 & 0.03 & $9.4 \mathrm{E}-20$ \\
\hline
\end{tabular}




\section{Table B.5. P Series Data}

The maximum, minimum, and average series values, for each column, are listed at the top of the table. All P series samples are cut. The following is a key to column headings:

$a=$ Cond $=$ physical condition of core. See Table B.2.

$b=$ Core ID

$c=$ Depth $Z=$ depth of core sample in feet along the borehole. (ft)

$d=$ Depth $Z=$ depth of core sample in meters along the borehole. $(\mathrm{m})$

$e=R e-T e s t$ VolSol $=$ volume of solid for samples p8 p9 p33, and p43, from Table B.6: Re-Tested Core Data. Used for those samples only. $\left(\mathrm{cm}^{3}\right)$

$f=\quad$ Pyc Volsol $=$ average volume of solid calculated using Eqn. (8), except for p33. $\left(\mathrm{cm}^{3}\right)$

$g=$ Std Dev = standard deviation for core test. $\left(\mathrm{cm}^{3}\right)$

$h=C V / .01=$ coefficient of variation $(g / f \times 100)$ for core test $(g / e \times 100$ for samples p9, p8, and p43). (\%)

$\mathrm{i}=\quad \#$ of Cycle $=$ the number of cycles pertaining to $(g)$ and $(f)$. (\#)

$j=\quad$ Into Pyc Weight = the weight of the oven dry sample immediately prior to testing in the gas pycnometer. (g)

$k=$ Re-Test Weight $=$ weight of dry sample from Table B.6. Only used for samples $p 8, p 9, p 33$, and p43. (g)

$I=\quad$ Dia $=$ core sample diameter measurement. (in)

$m=$ Len. $=$ length of core samples. (in)

$\mathrm{n}=$ Bulk Vol Est = bulk volume calculated from $(\mathrm{m})$ and $(\mathrm{l}) .\left(\mathrm{cm}^{3}\right)$

$0=$ Grain Dens. $=$ column $(j)$ divided by column $(f) \cdot\left(\mathrm{g} / \mathrm{cm}^{3}\right)$

$p=$ Dry Bulk Dens. = column $(j)$ divided by column $(n) .\left(g / \mathrm{cm}^{3}\right)$

$q=$ Poros. $=$ porosity calculated as $(1-p / 0) \cdot\left(\mathrm{cm}^{3} / \mathrm{cm}^{3}\right)$

$r=$ Kos-Carm Perm. = intrinsic permeability calculated by using Eqn. (12) and porosity (q). ( $\left.m^{2}\right)$ 
Table B.5: P-Series Core Summary - continued.

$45 P$ series core samples have boen tested, 3 of which

were tested for the first time in the re-test.

Core Depth Depth Re Pyc Std

Pyc Tost Vol Dens. Dens. Poros Carm

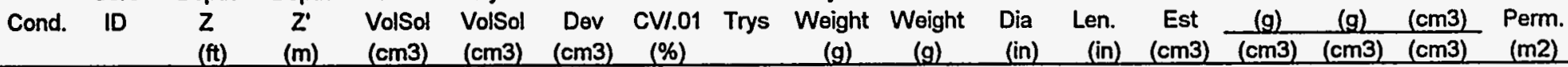

\begin{tabular}{|c|c|c|c|c|c|c|c|c|c|c|c|c|c|c|c|c|c|}
\hline & & & & & & & & & & & & & & & & & \\
\hline & MIN & 61.7 & 18.8 & & 0.0 & 1.10 & 0.38 & 8 & 0.0 & & 2.39 & 2.02 & 161.2 & 2.50 & 2.18 & 0.03 & $5.2 \mathrm{E}-20$ \\
\hline & MAX & 538.9 & 164.2 & & 305.4 & 4.35 & 1.59 & 12 & 766.6 & & 2.51 & 3.97 & 320.1 & 2.62 & 2.45 & 0.17 & 1.7E-17 \\
\hline & AVG & & & & 244.6 & 2.13 & 0.83 & 10 & 620.8 & & 2.48 & 3.54 & 280.7 & 2.54 & 2.38 & 0.06 & 1.7E-18 \\
\hline a & b & c & d & $\theta$ & $f$ & $\mathbf{g}$ & $h$ & $i$ & $j$ & k & 1 & $m$ & $n$ & $\begin{array}{c}0 \\
(j / f)\end{array}$ & $\begin{array}{c}p \\
(j / n)\end{array}$ & $\begin{array}{c}q \\
(1-p / o)\end{array}$ & $r$ \\
\hline $\mathrm{V}, \mathrm{C}$ & p11 & 61.7 & 18.8 & 209.2 & 207.7 & 1.66 & 0.80 & 10 & 542.3 & 542.1 & 2.48 & 3.14 & 248.8 & 2.61 & 2.18 & 0.17 & 1.7E-17 \\
\hline & p6 & 99.9 & 30.4 & & 236.6 & 1.51 & 0.64 & 9 & 620.2 & & 2.49 & 3.52 & 280.4 & 2.62 & 2.21 & 0.16 & $1.4 \mathrm{E}-17$ \\
\hline & p5 & 100.3 & 30.6 & & 202.8 & 1.88 & 0.93 & 10 & 532.0 & & 2.50 & 3.00 & 240.9 & 2.62 & 2.21 & 0.16 & $1.5 E-17$ \\
\hline $\mathbf{R}$ & p3 & 122.5 & 37.3 & & 269.5 & 1.78 & 0.66 & 10 & 691.6 & & 2,49 & 3.82 & 304.3 & 2.57 & 2.27 & 0.11 & $5.0 E-18$ \\
\hline $\mathrm{V}, \mathrm{C}$ & p1 & 130.2 & 39.7 & 272.6 & 274.0 & 2.52 & 0.92 & 8 & 699.2 & 699.1 & 2.49 & 3.82 & 306.0 & 2.55 & 2.28 & 0.10 & 3.8E-18 \\
\hline $\mathrm{C}$ & p12 & 183.5 & 55.9 & & 246.5 & 1.71 & 0.69 & 10 & 628.6 & & 2.50 & 3.31 & 267.3 & 2.55 & 2.35 & 0.08 & $1.5 E-18$ \\
\hline & $\mathrm{pg}$ & 225.6 & 68.7 & 195.0 & 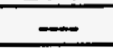 & 1.10 & 0.56 & 9 & - & 506.9 & 2.49 & 2.63 & 210.4 & 2.60 & 2.41 & 0.07 & $1.2 \mathrm{E}-18$ \\
\hline $\mathbf{R}$ & p10 & 225.9 & 68.8 & & 297.8 & 2.95 & 0.99 & 10 & 760.8 & & 2.50 & 3.94 & 316.5 & 2.56 & 2.40 & 0.06 & $6.2 \mathrm{E}-19$ \\
\hline & $\mathrm{p} 30$ & 295.3 & 90.0 & & 280.7 & 1.64 & 0.58 & 10 & 707.0 & & 2.50 & 3.61 & 291.2 & 2.52 & 2.43 & 0.04 & $1.4 \mathrm{E}-19$ \\
\hline & p31 & 295.6 & 90.1 & & 302.6 & 1.49 & 0.49 & 10 & 762.6 & & 2.51 & 3.94 & 320.1 & 2.52 & 2.38 & 0.05 & $4.8 E-19$ \\
\hline & p32 & 296.5 & 90.4 & & 259.0 & 2.80 & 1.08 & 10 & 658.2 & & 2.50 & 3.45 & 277.6 & 2.54 & 2.37 & 0.07 & 9.0E-19 \\
\hline & $\mathrm{p} 8$ & 302.7 & 92.2 & 203.3 & - & 1.63 & 0.80 & 8 & - & 512.0 & 2.50 & 2.59 & 208.8 & 2.52 & 2.45 & 0.03 & $5.2 E-20$ \\
\hline & p7 & 303.0 & 92.3 & & 287.9 & 1.69 & 0.59 & 9 & 730.6 & & 2.50 & 3.71 & 299.5 & 2.54 & 2.44 & 0.04 & 1.6E-19 \\
\hline & p19 & 322.2 & 98.2 & 260.8 & 260.9 & 1.74 & 0.67 & 10 & 653.0 & 653.3 & 2.50 & 3.35 & 270.2 & 2.50 & 2.42 & 0.03 & $1.2 \mathrm{E}-19$ \\
\hline 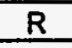 & $p 20$ & 322.5 & 98.3 & & 242.9 & 2.32 & 0.95 & 12 & 615.7 & & 2.50 & 3.24 & 261.0 & 2.53 & 2.36 & 0.07 & $1.0 \mathrm{E}-18$ \\
\hline & p17 & 323.5 & 98.6 & & 301.2 & 2.38 & 0.79 & 10 & 766.5 & & 2.50 & 3.93 & 316.6 & 2.54 & 2.42 & 0.05 & $3.4 \mathrm{E}-19$ \\
\hline & p18 & 323.8 & 98.7 & & 292.4 & 3.98 & 1.36 & 10 & 740.0 & & 2.50 & 3.78 & 305.2 & 2.53 & 2.42 & 0.04 & 2.1E-19 \\
\hline & p33 & 332.1 & 101.2 & 302.6 & $289.7^{\star}$ & 1.76 & 0.61 & 10 & $775.2^{*}$ & 775.1 & 2.50 & 3.97 & 319.4 & 2.56 & 2.43 & 0.05 & 4.3E-19 \\
\hline & p34 & 332.7 & 101.4 & & 299.5 & 3.35 & 1.12 & 12 & 759.8 & & 2.50 & 3.89 & 314.2 & 2.54 & 2.42 & 0.05 & $2.9 \mathrm{E}-19$ \\
\hline & p35 & 333.0 & 101.5 & & 289.7 & 1.76 & 0.61 & 10 & 734.2 & & 2.50 & 3.78 & 304.4 & 2.53 & 2.41 & 0.05 & $3.3 \mathrm{E}-19$ \\
\hline xtal & $\mathrm{p} 4$ & 339.8 & 103.6 & & 293.6 & 2.77 & 0.94 & 10 & 750.1 & & 2.51 & 3.85 & 311.6 & 2.55 & 2.41 & 0.06 & 5.7E-19 \\
\hline & p14 & 376.2 & 114.7 & & 304.2 & 1.72 & 0.57 & 9 & 765.6 & & 2.50 & 3.94 & 317.0 & 2.52 & 2.42 & 0.04 & $1.9 \mathrm{E}-19$ \\
\hline & p15 & 377.4 & 115.0 & & 268.3 & 4.28 & 1.59 & 12 & 675.6 & & 2.50 & 3.49 & 279.5 & 2.52 & 2.42 & 0.04 & $1.8 \mathrm{E}-19$ \\
\hline & p36 & 387.0 & 117.9 & & 295.6 & 1.45 & 0.49 & 10 & 748.5 & & 2.50 & 3.89 & 312.7 & 2.53 & 2.39 & 0.05 & $4.9 \mathrm{E}-19$ \\
\hline C & $\mathrm{p} 37$ & 387.6 & 118.1 & & 276.3 & 4.35 & 1.57 & 10 & 700.3 & & 2.50 & 3.64 & 291.3 & 2.53 & 2.40 & 0.05 & 4.0E-19 \\
\hline$R$ & p38 & 388.2 & 118.3 & & 284.4 & 1.59 & 0.56 & 10 & 721.4 & & 2.50 & 3.76 & 301.2 & 2.54 & 2.39 & 0.06 & $5.2 \mathrm{E}-19$ \\
\hline
\end{tabular}


Table B.5: P-Series Core Summary - continued.

\begin{tabular}{|c|c|c|c|c|c|c|c|c|c|c|c|c|c|c|c|c|c|}
\hline Cond. & $\begin{array}{l}\text { Core } \\
\text { ID }\end{array}$ & $\begin{array}{c}\text { Depth } \\
Z \\
\text { (ft) }\end{array}$ & $\begin{array}{c}\text { Depth } \\
Z^{\prime} \\
(\mathrm{m})\end{array}$ & $\begin{array}{c}\mathrm{Re-} \\
\text { Test } \\
\text { VolSol } \\
\text { (cm3) }\end{array}$ & $\begin{array}{l}\text { Pyc } \\
\text { Volsol } \\
\text { (cm3) }\end{array}$ & $\begin{array}{c}\text { Std } \\
\text { Dev } \\
(\mathrm{cm} 3)\end{array}$ & $\begin{array}{c}\text { CVI.01 } \\
(\%)\end{array}$ & $\begin{array}{l}\text { \# of } \\
\text { Trys }\end{array}$ & $\begin{array}{c}\text { Into } \\
\text { Pyc } \\
\text { Weight } \\
\text { (g) }\end{array}$ & $\begin{array}{c}\text { Re- } \\
\text { Test } \\
\text { Weight } \\
\text { (g) }\end{array}$ & $\begin{array}{l}\text { Dia } \\
\text { (in) }\end{array}$ & $\begin{array}{r}\text { Len. } \\
\text { (in) }\end{array}$ & $\begin{array}{c}\text { Bulk } \\
\text { Vol } \\
\text { Est } \\
(\mathrm{cm} 3) \\
\end{array}$ & $\begin{array}{c}\text { Grain } \\
\text { Dens. } \\
\text { (g) } \\
(\mathrm{cm} 3) \\
\end{array}$ & $\begin{array}{c}\text { Dry } \\
\text { Bulk } \\
\text { Dens. } \\
\text { (g) } \\
\text { (cm3) }\end{array}$ & $\begin{array}{l}\text { Poros. } \\
(\mathrm{cm} 3) \\
(\mathrm{cm} 3)\end{array}$ & $\begin{array}{l}\text { Koz- } \\
\text { Carm } \\
\text { Perm. } \\
\text { (m2) }\end{array}$ \\
\hline a & b & $\mathrm{c}$ & $d$ & $\theta$ & $f$ & $\mathrm{~g}$ & $\mathrm{~h}$ & i & j & $k$ & 1 & $m$ & $n$ & $\begin{array}{c}0 \\
(j / f) \\
\end{array}$ & $\begin{array}{c}p \\
(\mathrm{j} / \mathrm{n})\end{array}$ & $\begin{array}{c}q \\
(1-p / 0)\end{array}$ & $r$ \\
\hline & $\mathrm{p} 21$ & 407.4 & 124.2 & & 260.5 & 2.88 & 1.11 & 9 & 665.4 & & 2.50 & 3.48 & 278.6 & 2.55 & 2.39 & 0.07 & $8.4 \mathrm{E}-19$ \\
\hline & $\mathrm{p} 22$ & 407.7 & 124.3 & & 274.8 & 2.51 & 0.91 & 10 & 703.5 & & 2.49 & 3.66 & 293.2 & 2.56 & 2.40 & 0.06 & $7.4 \mathrm{E}-19$ \\
\hline & p23 & 408.0 & 124.3 & & 261.4 & 1.75 & 0.67 & 11 & 662.5 & & 2.50 & 3.43 & 274.8 & 2.53 & 2.41 & 0.05 & $3.5 \mathrm{E}-19$ \\
\hline$V, D$ & p39 & 416.8 & 127.0 & & 304.7 & 1.46 & 0.48 & 10 & 764.4 & & 2.50 & 3.96 & 318.0 & 2.51 & 2.40 & 0.04 & 2.1E-19 \\
\hline & $\mathrm{p} 40$ & 417.1 & 127.1 & & 297.4 & 1.31 & 0.44 & 10 & 748.0 & & 2.50 & 3.84 & 308.9 & 2.51 & 2.42 & 0.04 & $1.4 \mathrm{E}-19$ \\
\hline & $\mathrm{p} 41$ & 417.4 & 127.2 & 303.1 & 305.4 & 1.16 & 0.38 & 10 & 766.6 & 767.1 & 2.50 & 3.93 & 314.5 & 2.51 & 2.44 & 0.03 & $6.7 E-20$ \\
\hline & $\mathrm{p} 43$ & 454.4 & 138.5 & 152.5 & $\cdots$ & 2.38 & 1.56 & 8 & - & 390.9 & 2.49 & 2.02 & 161.2 & 2.56 & 2.43 & 0.05 & $4.6 \mathrm{E}-19$ \\
\hline $\mathrm{V}$ & $\mathrm{p} 42$ & 455.3 & 138.8 & & 277.0 & 1.14 & 0.41 & 10 & 700.6 & & 2.51 & 3.63 & 293.5 & 2.53 & 2.39 & 0.06 & $5.3 \mathrm{E}-19$ \\
\hline & $\mathrm{p} 25$ & 507.3 & 154.6 & & 301.3 & 1.88 & 0.63 & 10 & 753.0 & & 2.50 & 3.91 & 315.2 & 2.50 & 2.39 & 0.04 & $2.5 \mathrm{E}-19$ \\
\hline$R, D$ & p26 & 508.2 & 154.9 & & 250.0 & 2.48 & 0.99 & 10 & 635.8 & & 2.49 & 3.33 & 266.3 & 2.54 & 2.39 & 0.06 & $6.8 \mathrm{E}-19$ \\
\hline C & p24 & 508.6 & 155.0 & & 277.4 & 2.09 & 0.75 & 10 & 693.9 & & 2.50 & 3.70 & 297.3 & 2.50 & 2.33 & 0.07 & $9.1 \mathrm{E}-19$ \\
\hline & p29 & 524.7 & 159.9 & & 240.8 & 2.66 & 1.11 & 11 & 611.1 & & 2.40 & 3.43 & 253.8 & 2.54 & 2.41 & 0.05 & 4.0E-19 \\
\hline$R, D$ & P28 & 525.5 & 160.2 & & 194.5 & 2.66 & 1.37 & 10 & 490.3 & & 2.39 & 2.79 & 204.8 & 2.52 & 2.39 & 0.05 & $3.7 \mathrm{E}-19$ \\
\hline C & $\mathrm{p} 27$ & 525.9 & 160.3 & & 229.0 & 2.66 & 1.16 & 10 & 589.5 & & 2.39 & 3.38 & 248.4 & 2.57 & 2.37 & 0.08 & $1.5 \mathrm{E}-18$ \\
\hline $\mathrm{V}$ & p47 & 534.7 & 163.0 & 216.2 & 214.8 & 2.09 & 0.97 & 9 & 549.4 & 550.2 & 2.39 & 3.14 & 230.9 & 2.56 & 2.38 & 0.07 & 1.0E-18 \\
\hline C & p48 & 534.9 & 163.0 & & 260.3 & 1.86 & 0.72 & 11 & 658.0 & & 2.40 & 3.69 & 274.0 & 2.53 & 2.40 & 0.05 & $3.6 \mathrm{E}-19$ \\
\hline & p49 & 535.7 & 163.3 & & 242.3 & 1.99 & 0.82 & 10 & 621.1 & & 2.40 & 3.52 & 260.9 & 2.56 & 2.38 & 0.07 & $1.1 \mathrm{E}-18$ \\
\hline & p46 & 538.3 & 164.1 & & 272.0 & 1.59 & 0.59 & 11 & 687.6 & & 2.40 & 3.84 & 284.8 & 2.53 & 2.41 & 0.04 & 2.6E-19 \\
\hline & p44 & 538.9 & 164.2 & & 268.2 & 1.46 & 0.54 & 10 & 671.0 & & 2.40 & 3.74 & 276.8 & 2.50 & 2.42 & 0.03 & $8.4 \mathrm{E}-20$ \\
\hline
\end{tabular}




\section{Table B.6. Re-Tested Core Data}

Each core sample has two rows of data. The maximum, minimum, and average values, for each column, are listed at the top of the table. The following is a key to column headings:

$a=$ Core ID

$b=$ First \& Second Ratio = ratio estimate for the first and second cycle of the pycnometer for this core test. In most cases the second is slightly lower.

$c=A V G . N \& N-1$ Ratio = average ratio estimate for all cycles $(\mathrm{N})$, and average ratio estimate excluding the first cycle $(\mathrm{N}-1)$. The two averages are usually identical.

$d=$ First \& Second VolSol = volume of solid calculated using Eqn. (8), for the first and second ratio estimate. $\left(\mathrm{cm}^{3}\right)$

$\theta=$ AVG. N\&N-1 VolSol = volume of solid calculated using Eqn. (8), for all $(\mathrm{N})$ cycles, and $\mathrm{N}-1$ cycles. This is used to compute all parameters. $\left(\mathrm{cm}^{3}\right)$

$f=\quad N \& N-1$ Std. Dev. $=$ standard deviation for all $(\mathrm{N})$ cycles, and $\mathrm{N}-1$ cycles. $\left(\mathrm{cm}^{3}\right)$

$g=N \& N-1 C V / .01=$ the coefficient of variation ( $\mathrm{f} / \mathrm{e} \times 100) .(\%)$

$h=$ The difference in coefficients of variation calculated each way. (\%)

$i=\quad \#$ of Cycles $=$ the number of all cycles pertaining to $(f)$ and $(e) .(\#)$

$j=\quad$ Into Pyc Weight $=$ the weight of the oven dry sample immediately prior to testing in the gas pycnometer. (g)

$k=$ If Cut Then Dia: $=$ diameter measurement for cut samples. (in)

$I=$ Len: $=$ length of cut core samples. (in)

$\mathrm{m}=$ Bulk Vol Est. = bulk volume calculated either by (1) Immersion in the bulk volume estimator, or (2) Diameter and length of cut core samples. Where there are two estimates the immersion bulk volume is always used for calculations. $\left(\mathrm{cm}^{3}\right)$

$\mathrm{n}=$ Std. Dev. $=$ standard deviation of 5 or 6 estimates by the immersion method. $\left(\mathrm{cm}^{3}\right)$

$0=. C V / .01=$ coefficient of variation $(\mathrm{n} / \mathrm{m} \times 100)$, as a percent. $(\%)$

$p=$ Grain Dens. = column $(j)$ divided by column $(e 1$ and $e 2) \cdot\left(\mathrm{g} / \mathrm{cm}^{3}\right)$

$q=$ Dry Bulk Dens. = column (j) divided by column (m, immersion). $\left(\mathrm{g} / \mathrm{cm}^{3}\right)$

$r=$ Poros. $=$ porosity calculated as $(1-q /(p 1$ or $p 2)) .\left(\mathrm{cm}^{3} / \mathrm{cm}^{3}\right)$

$s=$ Kos-Carm Perm. $=$ intrinsic permeability calculated using Eqn. (14) and the two 
Table B.6: Re-Tested Core Data

25 core samples were processed for the re-test.

First \& AVG. First \& AVG. N\&N-1 Into Cut Bulk Grain Bulk Core Secon N\&N-1 Secon N\&N-1 Std. N\&N-1 \# of Pyc Then Vol Std. Dens. Dens. Poros. Carm ID Ratio Ratio VolSol VolSol Dev. CVI.01 Diff Cycle Weight Dia: Len: Est. Dev. CVI.0 (g) (g) (cm3) Perm.

\begin{tabular}{|c|c|c|c|c|c|c|c|c|c|c|c|c|c|c|c|c|c|c|}
\hline & & & $(\mathrm{cm} 3)$ & $(\mathrm{cm} 3)$ & $(\mathrm{cm} 3)$ & $(\%)$ & $(\%)$ & & (g) & (in) & (in) & $(\mathrm{cm} 3)$ & $(\mathrm{cm} 3)$ & $(\%)$ & $(\mathrm{cm} 3)$ & $(\mathrm{cm} 3)$ & $(\mathrm{cm} 3)$ & $(\mathrm{m} 2)$ \\
\hline MIN & 1.207 & 1.207 & 149.3 & 152.5 & 0.63 & 0.17 & -0.05 & 6 & 390.9 & 2.40 & 2.02 & 161.2 & -1.67 & -0.63 & 2.49 & 2.02 & 0.02 & $1.9 E-20$ \\
\hline $\operatorname{MAX}$ & 1.411 & 1.409 & 516.3 & 515.9 & 2.91 & 1.56 & 0.83 & 10 & 1318.5 & 2.50 & 4.98 & 551.4 & 11.76 & 3.28 & 2.67 & 2.46 & 0.23 & $5.5 E-17$ \\
\hline AVG & 1.334 & 1.333 & 287.8 & 289.6 & 1.76 & 0.66 & 0.18 & 8 & 742.4 & 2.49 & 3.43 & 321.9 & 0.66 & 0.19 & 2.56 & 2.31 & 0.10 & $1.2 \mathrm{E}-17$ \\
\hline$a$ & b & c & $d$ & $\theta$ & $f$ & $\mathrm{~g}$ & $h$ & $i$ & $j$ & $k$ & 1 & $m$ & $n$ & 0 & $\begin{array}{c}p \\
(j / e)\end{array}$ & $\begin{array}{c}q \\
(\mathrm{j} / \mathrm{m})\end{array}$ & $\begin{array}{c}r \\
(1-q / p)\end{array}$ & $s$ \\
\hline \multirow[t]{2}{*}{ g3 } & 1.353 & 1.351 & 254.0 & 256.2 & 2.35 & 0.92 & -0.00 & 10 & 684.6 & & & 333.2 & -0.95 & -0.29 & 2.67 & 2.05 & 0.23 & $5.5 \mathrm{E}-17$ \\
\hline & 1.353 & 1.351 & 253.6 & 256.4 & 2.36 & 0.92 & & 9 & & & & & & & 2.67 & & 0.23 & $5.5 E-17$ \\
\hline \multirow[t]{2}{*}{$p 9$} & 1.385 & 1.385 & 195.1 & 195.0 & 1.10 & 0.56 & -0.03 & 9 & 506.9 & & & & & & 2.60 & & 0.07 & $1.2 \mathrm{E}-18$ \\
\hline & 1.384 & 1.385 & 196.8 & 195.0 & 1.16 & 0.60 & & 8 & & 2.49 & 2.63 & 210.4 & & & 2.60 & 2.41 & 0.07 & $1.2 E-18$ \\
\hline \multirow[t]{2}{*}{ p33 } & 1.329 & 1.326 & 296.2 & 302.6 & 2.80 & 0.92 & 0.45 & 8 & 775.1 & & & & & & 2.56 & & 0.05 & $4.5 E-19$ \\
\hline & 1.326 & 1.325 & 301.7 & 303.6 & 1.44 & 0.47 & & 7 & & 2.50 & 3.97 & 319.8 & & & 2.55 & 2.42 & 0.05 & $3.8 E-19$ \\
\hline \multirow[t]{2}{*}{ p43 } & 1.411 & 1.409 & 149.3 & 152.5 & 2.38 & 1.56 & 0.13 & 8 & 390.9 & & & & & & 2.56 & & 0.05 & $4.6 E-19$ \\
\hline & 1.408 & 1.409 & 154.2 & 152.9 & 2.18 & 1.43 & & 7 & & 2.49 & 2.02 & 161.2 & & & 2.56 & 2.43 & 0.05 & $3.9 E-19$ \\
\hline \multirow[t]{2}{*}{ p1 } & 1.344 & 1.342 & 270.1 & 272.6 & 1.89 & 0.70 & 0.05 & 8 & 699.1 & & & & & & 2.56 & & 0.11 & $4.4 E-18$ \\
\hline & 1.343 & 1.342 & 270.6 & 272.9 & 1.77 & 0.65 & & 7 & & 2.50 & 3.82 & 306.2 & & & 2.56 & 2.28 & 0.11 & 4.3E-18 \\
\hline \multirow[t]{2}{*}{$10 c$} & 1.315 & 1.312 & 322.3 & 327.7 & 2.61 & 0.80 & 0.27 & 8 & 862.2 & & & 416.9 & -0.74 & -0.18 & 2.63 & 2.07 & 0.21 & $4.2 E-17$ \\
\hline & 1.312 & 1.311 & 327.3 & 328.5 & 1.72 & 0.52 & & 7 & & & & & & & 2.62 & & 0.21 & 4.1E-17 \\
\hline \multirow[t]{2}{*}{$10 b$} & 1.246 & 1.244 & 445.4 & 450.2 & 2.20 & 0.49 & 0.19 & 8 & 1179.1 & & & 551.4 & 1.16 & 0.21 & 2.62 & 2.14 & 0.18 & $2.4 E-17$ \\
\hline & 1.244 & 1.243 & 449.5 & 450.9 & 1.34 & 0.30 & & 7 & & & & & & & 2.62 & & 0.18 & $2.4 E-17$ \\
\hline \multirow[t]{2}{*}{911} & 1.365 & 1.366 & 231.8 & 230.2 & 2.27 & 0.99 & -0.03 & 8 & 593.9 & & & 263.8 & -1.67 & -0.63 & 2.58 & 2.25 & 0.13 & $7.2 \mathrm{E}-18$ \\
\hline & 1.365 & 1.366 & 231.7 & 229.9 & 2.33 & 1.01 & & 7 & & & & & & & 2.58 & & 0.13 & 7.3E-18 \\
\hline \multirow[t]{2}{*}{$1 \mathrm{a}$} & 1.342 & 1.340 & 273.7 & 277.5 & 2.91 & 1.05 & 0.08 & 8 & 725.5 & & & 358.6 & 11.76 & 3.28 & 2.61 & 2.02 & 0.23 & $5.1 E-17$ \\
\hline & 1.338 & 1.339 & 280.5 & 278.1 & 2.69 & 0.97 & & 7 & & & & & & & 2.61 & & 0.22 & $5.0 \mathrm{E}-17$ \\
\hline \multirow[t]{2}{*}{ p41 } & 1.327 & 1.325 & 300.8 & 303.1 & 1.10 & 0.36 & 0.12 & 8 & 767.1 & & & & & & 2.53 & & 0.04 & $1.2 \mathrm{E}-19$ \\
\hline & 1.325 & 1.325 & 304.2 & 303.4 & 0.73 & 0.24 & & 7 & & 2.50 & 3.92 & 314.1 & & & 2.53 & 2.44 & 0.03 & 1.1E-19 \\
\hline \multirow[t]{2}{*}{$\mathrm{p} 47$} & 1.376 & 1.374 & 212.7 & 216.2 & 1.67 & 0.77 & 0.28 & 8 & 550.2 & & & & & & 2.54 & & 0.07 & $9.5 E-19$ \\
\hline & 1.374 & 1.373 & 214.7 & 216.7 & 1.08 & 0.50 & & 7 & & 2.40 & 3.14 & 232.0 & & & 2.54 & 2.37 & 0.07 & $8.6 E-19$ \\
\hline \multirow[t]{2}{*}{$\mathrm{p8}$} & 1.381 & 1.381 & 202.9 & 203.3 & 1.63 & 0.80 & -0.05 & 8 & 512.0 & & & & & & 2.52 & & 0.03 & $5.3 E-20$ \\
\hline & 1.381 & 1.381 & 202.9 & 203.3 & 1.73 & 0.85 & & 7 & & 2.50 & 2.59 & 208.8 & & & 2.52 & 2.45 & 0.03 & 5.1E-20 \\
\hline
\end{tabular}


Table B.6: Re-Tested Core Data - continued

First \& AVG. First \& AVG. N\&N-1 Core Secon N\&N-1 Secon N\&N-1 Std. N\&N-1

$$
\begin{array}{lllll} 
& \text { If } & \text { Dry } \\
\text { Into Cut } & \text { Bulk } & \text { Grain Bulk }
\end{array}
$$
\# of Pyc Then Vol Std. Dens. Dens. Poros. Carm ID Ratio Rato Volsol VolSol Dov. CVI.01 Diff Cycle Weight Dia: Len: Est. Dev. CVI.0 (g) (g) (cm3) Perm.

\begin{tabular}{|c|c|c|c|c|c|c|c|c|c|c|c|c|c|c|c|c|c|c|}
\hline & & & (CM3) & (CM3) & (CM3) & $(\%)$ & $(\%)$ & & (g) & (in) & (in) & (cm3) & $(\mathrm{cm} 3)$ & $(\%)$ & (cm3) & $(\mathrm{cm} 3)$ & $(\mathrm{cm} 3)$ & $(\mathrm{m} 2)$ \\
\hline $\mathbf{a}$ & $b$ & c & $d$ & $\theta$ & $f$ & g & $h$ & i & j & $k$ & 1 & $m$ & $n$ & 0 & $\begin{array}{c}p \\
(j / e)\end{array}$ & $\begin{array}{c}q \\
(j / m)\end{array}$ & $\begin{array}{c}r \\
(1-q / p)\end{array}$ & $\mathbf{s}$ \\
\hline \multirow[t]{2}{*}{ g32 } & $1 . \overline{248}$ & 1.248 & 441.6 & 442.3 & 1.92 & 0.43 & -0.03 & 8 & 1128.4 & & & 461.2 & 0.88 & 0.19 & 2.55 & 2.45 & 0.04 & $2.0 \mathrm{E}-19$ \\
\hline & 1.250 & 1.248 & 439.0 & 442.4 & 2.03 & 0.46 & & 7 & & & & & & & 2.55 & & 0.04 & 2.0E-19 \\
\hline \multirow[t]{2}{*}{933} & 1.282 & 1.280 & 380.2 & 384.4 & 1.81 & 0.47 & 0.20 & 9 & 979.0 & & & 403.2 & -0.95 & -0.24 & 2.55 & 2.43 & 0.05 & $4.2 E-19$ \\
\hline & 1.280 & 1.280 & 384.0 & 385.0 & 1.06 & 0.27 & & 8 & & 2.50 & 4.98 & 401.6 & & & 2.54 & & 0.05 & $3.8 E-19$ \\
\hline \multirow[t]{2}{*}{ g46 } & 1.313 & 1.309 & 326.0 & 332.0 & 2.50 & 0.75 & 0.44 & 8 & 840.4 & & & 344.9 & -0.95 & 0.00 & 2.53 & 2.44 & 0.04 & $2.1 E-19$ \\
\hline & 1.309 & 1.309 & 332.5 & 332.9 & 1.04 & 0.31 & & 7 & & & & & & & 2.52 & & 0.03 & 1.7E-19 \\
\hline \multirow[t]{2}{*}{92} & 1.372 & 1.368 & 219.8 & 226.0 & 2.53 & 1.12 & 0.68 & 8 & 592.7 & & & 283.0 & -0.58 & -0.20 & 2.62 & 2.09 & 0.20 & $4.8 \mathrm{E}-17$ \\
\hline & 1.369 & 1.368 & 225.0 & 226.9 & 0.99 & 0.44 & & 7 & & 2.49 & 3.58 & 285.5 & & & 2.61 & & 0.20 & $4.6 \mathrm{E}-17$ \\
\hline \multirow[t]{2}{*}{$\overline{931}$} & 1.401 & 1.398 & 166.3 & 172.3 & 2.52 & 1.46 & 0.83 & 8 & 443.6 & & & 186.8 & -0.58 & -0.31 & 2.57 & 2.38 & 0.08 & $2.0 E-18$ \\
\hline & 1.398 & 1.398 & 172.1 & 173.2 & 1.10 & 0.64 & & 7 & & & & & & & 2.56 & & 0.07 & $1.7 E-18$ \\
\hline \multirow[t]{2}{*}{$2 d$} & 1.295 & 1.293 & 357.7 & 361.8 & 1.57 & 0.43 & 0.26 & 9 & 936.1 & & & 424.2 & -0.07 & -0.02 & 2.59 & 2.21 & 0.15 & $1.6 \mathrm{E}-17$ \\
\hline & 1.292 & 1.292 & 362.7 & 362.3 & 0.63 & 0.17 & & 8 & & & & & & & 2.58 & & 0.15 & 1.6E-17 \\
\hline \multirow[t]{2}{*}{$\overline{\mathrm{g19}}$} & 1.210 & 1.207 & 510.3 & 515.4 & 2.57 & 0.50 & 0.10 & 10 & 1318.5 & & & 541.2 & -1.08 & -0.20 & 2.56 & 2.44 & 0.05 & $4.5 E-19$ \\
\hline & 1.207 & 1.207 & 516.3 & 515.9 & 2.03 & 0.39 & & 9 & & & & & & & 2.56 & & 0.05 & 4.2E-19 \\
\hline \multirow[t]{2}{*}{$8 a$} & 1.352 & 1.349 & 254.6 & 260.5 & 2.34 & 0.90 & 0.46 & 9 & 669.4 & & & 313.1 & 5.62 & 1.79 & 2.57 & 2.14 & 0.17 & $2.6 \mathrm{E}-17$ \\
\hline & 1.349 & 1.349 & 260.4 & 261.2 & 1.14 & 0.44 & & 8 & & & & & & & 2.56 & & 0.17 & 2.5E-17 \\
\hline \multirow[t]{2}{*}{ p19 } & 1.350 & 1.349 & 258.7 & 260.8 & 1.50 & 0.58 & 0.05 & 8 & 653.3 & & & & & & 2.50 & & 0.03 & $1.3 E-19$ \\
\hline & 1.348 & 1.349 & 262.4 & 261.1 & 1.36 & 0.52 & & 7 & & 2.50 & 3.35 & 269.5 & & & 2.50 & 2.42 & 0.03 & $1.2 \mathrm{E}-19$ \\
\hline \multirow[t]{2}{*}{ g66 } & 1.337 & 1.336 & 282.0 & 283.5 & 1.82 & 0.64 & -0.01 & 8 & 710.0 & & & 288.6 & 0.59 & 0.21 & 2.50 & 2.46 & 0.02 & $2.2 E-20$ \\
\hline & 1.337 & 1.336 & 282.8 & 283.7 & 1.85 & 0.65 & & 7 & & 2.50 & 3.63 & 290.4 & & & 2.50 & & 0.02 & $1.9 \mathrm{E}-20$ \\
\hline \multirow[t]{2}{*}{942} & 1.331 & 1.329 & 292.9 & 296.0 & 1.45 & 0.49 & 0.17 & 8 & 736.6 & & & 302.3 & -0.95 & -0.32 & 2.49 & 2.44 & 0.02 & $3.6 E-20$ \\
\hline & 1.329 & 1.329 & 296.7 & 296.4 & 0.94 & 0.32 & & 7 & & 2.50 & 3.78 & 302.7 & & & 2.49 & & 0.02 & $2.9 E-20$ \\
\hline \multirow[t]{2}{*}{ p11 } & 1.377 & 1.378 & 209.6 & 209.2 & 1.03 & 0.49 & -0.02 & 9 & 542.1 & & & & & & 2.59 & & 0.16 & $2.1 E-17$ \\
\hline & 1.378 & 1.378 & 209.0 & 209.1 & 1.08 & 0.51 & & 8 & & 2.49 & 3.13 & 248.4 & & & 2.59 & 2.18 & 0.16 & $2.1 \mathrm{E}-17$ \\
\hline \multirow[t]{2}{*}{$\overline{g 65}$} & 1.325 & 1.326 & 303.6 & 302.4 & 1.76 & 0.58 & -0.02 & 7 & 763.3 & & & 312.8 & -0.95 & -0.30 & 2.52 & 2.44 & 0.03 & $1.5 E-19$ \\
\hline & 1.325 & 1.326 & 303.0 & 302.2 & 1.82 & 0.60 & & 6 & & & & & & & 2.53 & & 0.03 & $1.6 \mathrm{E}-19$ \\
\hline
\end{tabular}




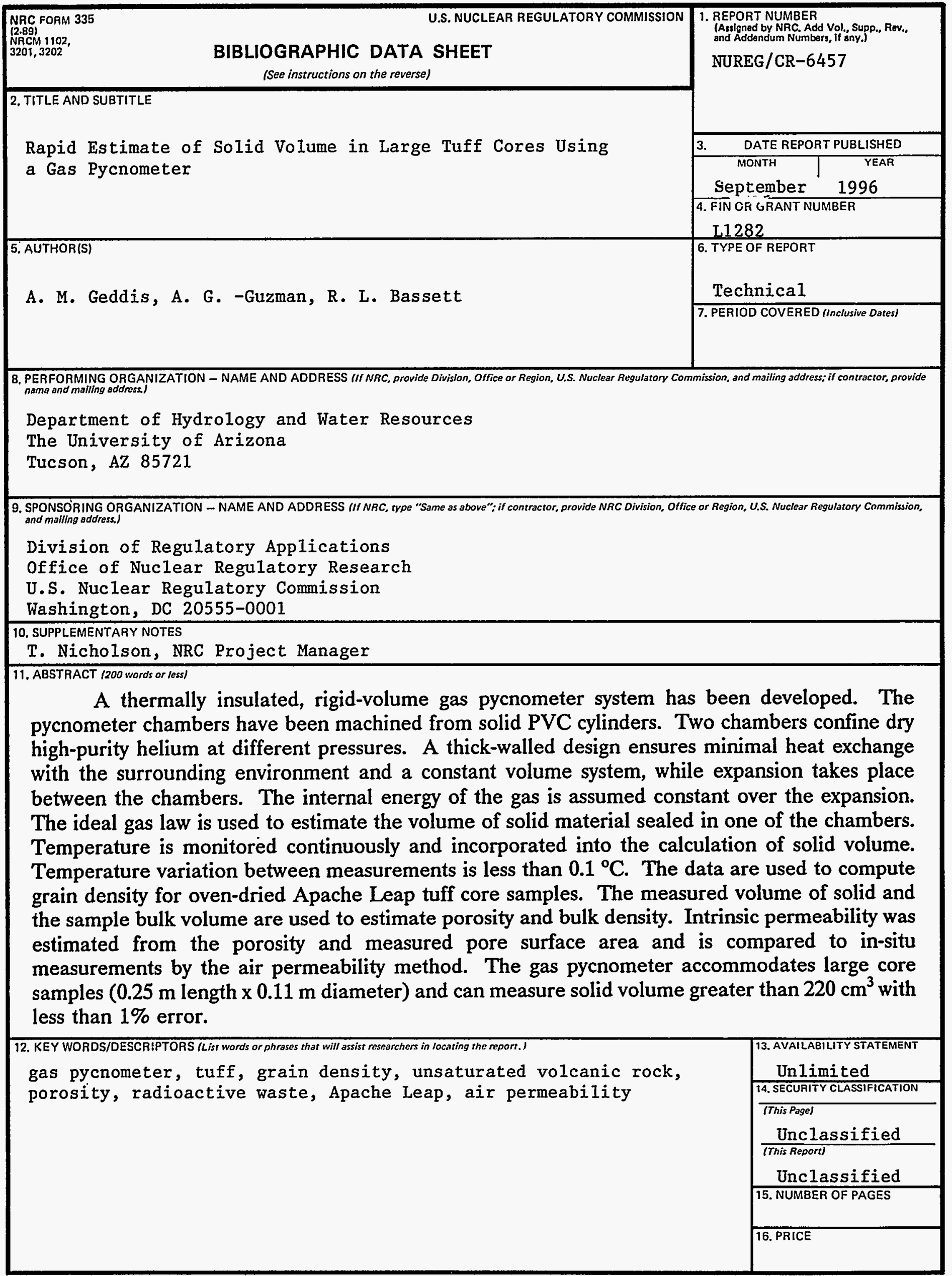

